Aus der Abteilung Innere Medizin II

Gastroenterologie, Hepatologie, Infektiologie und Endokrinologie der Albert-Ludwigs-Universität, Freiburg im Breisgau Ärztlicher Direktor: Prof. Dr. Drs. h.c. H. E. Blum

\title{
Differenzielle transkriptionelle Regulation der humanen Telomerase in einem zellulären Karzinogenese-Modell am Beispiel des Plattenepithelkarzinoms des Ösophagus
}

\author{
INAUGURAL-DISSERTATION
}

zur

Erlangung des Medizinischen Doktorgrades der Medizinischen Fakultät der Albert-Ludwigs-Universität Freiburg im Breisgau

vorgelegt 2004 von Michael Quante geboren in Münster 
Dekan der Medizinischen Fakultät: Prof. Dr. med. C. Peters

1. Gutachter: Prof. Dr. med. Drs. h.c. H.E. Blum

2. Gutachter: PD Dr. med. U. Martens

Promotionsjahr: 2005 
Meinen Eltern und Anne 


\section{Inhalt}

1 Einleitung 1

1.1 Aufbau und Funktion der Telomere 1

1.2 Struktur und Mechanismus der Telomerase 3

1.3 Regulation der Telomerase 5

1.4 Ätiologie des Plattenepithelkarzinoms des Ösophagus 10

\begin{tabular}{ll}
1.5 & Bedeutung der Telomerase für die Tumorgenese \\
\hline
\end{tabular}

$\begin{array}{ll}1.6 \text { Zielsetzung } & 15\end{array}$

2 Material und Methoden 17

$\begin{array}{lll}2.1 & \text { Zelltypen } & 17\end{array}$

2.2 Methoden zur Arbeit mit eukaryonten Zellen 18

$\begin{array}{lll}2.3 & \text { Herstellung der Deletionskonstrukte } & 18\end{array}$

2.4 Transiente Transfektionen 23

2.5 EMSA (Electro Mobility Shift Assay) 24

2.6 MSP (Methylierungs Spezifische PCR) 27

2.7 RT-PCR (Reverse Transkriptase Polymerase Chain Reaction) 29

2.8 Real Time PCR 30

2.9 TRAP-Assay (Telomeric Repeat Amplification Protocol) 31

2.10 TRF (Telomere Restriction Fragments) 32

2.11 Western Blot Analyse 33

2.12 Lösungen und Reagenzien 35

3 Ergebnisse $\quad 41$

3.1 Generierung definierter ösophagealer Keratinozyten 41

3.2 Charakterisierung der Telomerbiologie 46

3.2.1 Telomeraseexpression 46

$\begin{array}{ll}3.2 .2 \text { Telomeraseaktivität } & 48\end{array}$

3.2.3 Telomerlänge 49

3.3 hTERT-Promotor Analysen $\quad 51$

3.4 Transiente Transfektion der hTERT-Deletionskonstrukte 53

3.4.1 Vergleich der hTERT-Promotoraktivität 53

3.4.2 Transiente Transfektion von EPC 54

3.4.3 Transiente Transfektion von EPC- $\Delta$ p53 55 
3.4.4 Transiente Transfektion von EPC-hTERT 56

3.4.5 Transiente Transfektion von EPC-D1 57

3.4.6 Transiente Transfektion von TE-12 58

3.5 Methylierung des hTERT-Promotors 59

3.6 Expression verschiedener Transkriptionsfaktoren 60

3.7 Untersuchung der DNA-Protein-Bindung mittels EMSA 61

3.7.1 Transkriptionsfaktor-Bindungsstellen im hTERT-Promotor 61

3.7.2 Transkriptionsfaktoren in EPC 62

3.7.3 Transkriptionsfaktoren in EPC- $\Delta$ p53 62

3.7.4 Transkriptionsfaktoren in EPC-hTERT 63

3.7.5 Transkriptionsfaktoren in EPC-D1 64

3.7.6 Transkriptionsfaktoren in TE-12 65

3.7.7 Weitere nicht spezifische Transkriptionsfaktoren 66

4 Diskussion $\quad 69$

4.1 Telomerase Regulation und maligne Transformation 69

$\begin{array}{lll}4.2 & \text { Charakterisierung der einzelnen Zelltypen } & 71\end{array}$

$\begin{array}{lll}4.3 & \text { Herstellung der hTERT-Promotor-Konstrukte } & 73\end{array}$

4.4 Differenzielle transkriptionelle Regulation der Telomerase 75

4.5 Telomerase Regulation durch Promotormethylierung 79

$\begin{array}{lll}4.6 & \text { Schlussfolgerungen } & 80\end{array}$

$\begin{array}{lll}4.7 & \text { Perspektiven } & 82\end{array}$

$\begin{array}{llr}5 & \text { Zusammenfassung } & 83\end{array}$

$\begin{array}{llr}6 & \text { Literaturverzeichnis } & 84\end{array}$

$\begin{array}{lll}7 & \text { Abkürzungen } & 91\end{array}$

8 Danksagung $\quad 93$

9 Veröffentlichungen $\quad 94$

10 Lebenslauf $\quad 96$ 


\section{Einleitung}

\subsection{Aufbau und Funktion der Telomere}

Alle Eukaryonten besitzen lineare Chromosomen, deren Enden eine besondere Struktur aufweisen, die als Telomere bezeichnet werden (Greider 1998). Sie wurden erstmals 1938 von Müller beschrieben, der auch den Begriff der ,Telomere‘ prägte. Unabhängig hiervon beschrieb McClintock 1941 diese spezielle Struktur der endständigen DNA der Chromosomen. Die Telomere setzen sich aus DNA und verschiedenen Strukturproteinen (,telomere binding proteins ${ }^{6}$ ), die an diese binden, zusammen und bilden einen Telomer-Chromatin Komplex. Die DNA-Komponente besteht aus einer charakteristischen Basensequenz, die sich vielfach wiederholt, jedoch für kein transkribierbares Gen kodiert. Je nach Gewebeart besteht sie beim Menschen und anderen Säugetieren aus bis zu 200.000 Basenpaaren spezifischer TTAGGG Wiederholungen. Die Strukturproteine der Telomere unterscheiden sich von den Proteinen, die an der internen DNA eines Chromosoms gebunden sind. Es gibt Hinweise darauf, dass diese Proteine entscheidenden Einfluss auf die Regulation der Telomerlänge haben (Armbruster et al. 2003; Fujimoto et al. 2003). Dem TelomerChromatin Komplex werden eine Reihe wichtiger Funktionen in der Zelle zugeschrieben, zum Beispiel den Chromosomen Schutz und Stabilität gegenüber Degradation, Translokation, Non-disjunction oder Fusion von Chromosomen zu verleihen (Abbildung 1.1) (Harley et al. 1990; Blackburn 1991; Hahn 2003). Der Telomer-Chromatin-Komplex gewährleistet die spezifische Position der Chromosomen im Zellkern, da er während der Zellteilung als Anheftungsstelle an der Kernmatrix dient (Blasco et al. 2003; Hahn 2003). Weiterhin wirken die Telomere bei der Paarung homologer Chromosomen in der Meiose und bei der Bewegung der Chromosomen während der Teilung mit (Morin 1997). Als wichtigste Funktion jedoch ermöglichen die Telomere die vollständige Replikation der linearen DNA-Enden (Greider 1996). Die DNA-Polymerase ist jedoch nicht in der Lage, die DNA vom $3^{\text {‘ }}$ zum $5^{\text {‘ }}$ Ende zu synthetisieren, so dass die DNA-Verdopplung des einen Stranges diskontinuierlich in so genannten Okazaki-Fragmenten erfolgen muss (Okazaki 2002). Hierfür benötigt die DNA-Polymerase einen 8-12 Basenpaare umfassenden RNA-Primer als Startpunkt, um die Synthese in 5'-3' Richtung zu starten. Im Anschluss an die Replikation werden diese Primer wieder entfernt. Die verbliebenen Lücken werden von einer weiteren 
Polymerase aufgefüllt. Eine Komplementierung des DNA-Stranges am äußersten $3^{6}$ Ende der chromosomalen DNA ist jedoch aufgrund eines fehlenden Ansatzpunktes für das Replikationsenzym nicht möglich (Ogawa et al. 1980; Levy et al. 1992). Diese Tatsache wird als Endreplikationsproblem bezeichnet. Daraus resultiert, dass bei jeder Zellteilung 50 bis 200 Basenpaare verloren gehen. Dank der Telomere ist hiervon nicht die eigentliche Erbinformation betroffen (Okazaki 2003) (Abbildung 1.2).

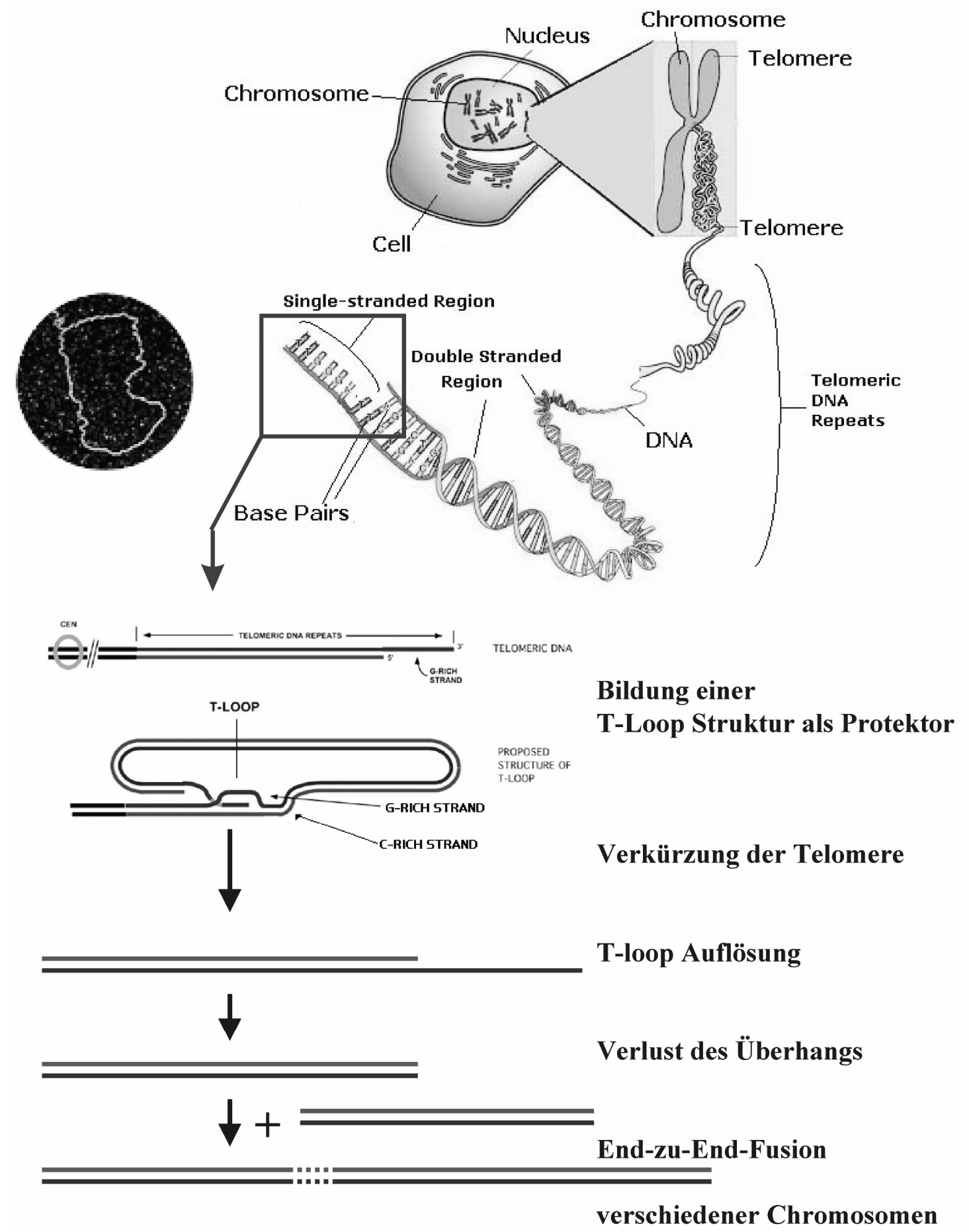

Abbildung 1.1: Struktur der Telomere. Bei Verlust der Telomerlänge bilden sich Fusionen aus verschiedenen Telomeren unterschiedlicher Chromosomen (www.chemsoc.org) 


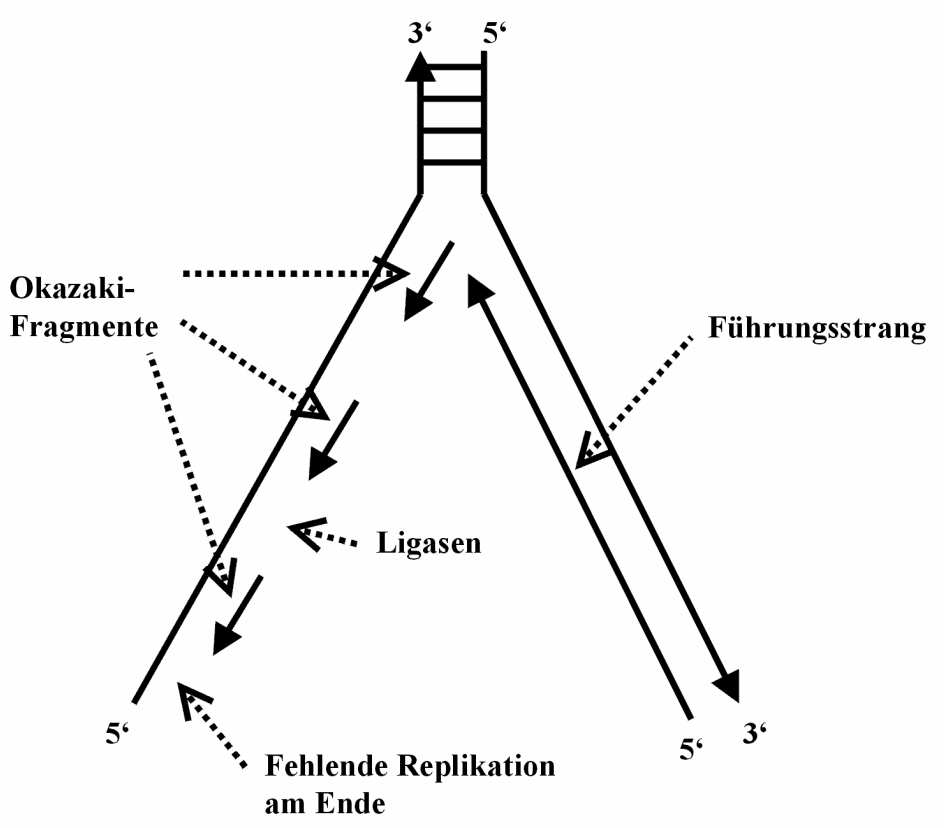

Abbildung 1.2: Das Endreplikationsproblem. Bildung von Okazaki Fragmenten in 3' - 5' Richtung.

In Abhängigkeit von Zelltyp, Spezies und genetischer Ausstattung einer Zelle wird nach 60 bis 80 Teilungen eine kritische Länge der Telomere erreicht, die bei 1500 bis 4000 Basenpaaren liegt und mit einem Funktionsverlust einhergeht (Weinberg 1998). Bei zu kurzen Telomeren kommt es zum Stillstand des Zellzyklus (Seneszenz) und anschließend zum Tod der Zelle (Sherr et al. 2000). Die Telomere haben also die Aufgabe einer sogenannten ,mitotischen Uhr', welche die Anzahl der Zellteilungen registriert und, bei Unterschreiten einer Mindestlänge, den Zellzyklus anhält; es folgen keine weiteren Replikationen (Harley 1991). Prinzipiell kann man also davon ausgehen, dass sich humane Zellen unendlich teilen können, solange sie in der Lage sind, ihre Telomere zu stabilisieren und diese auf einer lebensfähigen Länge zu erhalten (Hayflick 1997). Expression von Telomerase, einem Enzym, das in den meisten post-embryonalen Zellen zumindest Zellzyklus abhängig supprimiert ist (Masutomi et al. 2003), erlaubt es Zellen, ihre Telomere zu verlängern (Hahn et al. 2001). Man geht davon aus,daß unter anderem Tumorzellen ihre Unsterblichkeit hierdurch erlangen.

\subsection{Struktur und Mechanismus der Telomerase}

Die Telomerase ist ein Ribonukleoproteinkomplex bestehend aus RNA und mindestens zwei Proteinuntereinheiten mit einem Molekulargewicht zwischen 200 kDa und 500 kDa (Shippen-Lentz et al. 1990; Romero et al. 1991). Da der Telomerase für die DNA- 
Synthese ein „RNA-Template“ als Matrize dient, zählt man sie zu den Reversen Transkriptasen, mit der ungewöhnlichen Ausnahme, dass die benötigte RNA bereits im Enzym integriert ist. Es bestehen nicht nur funktionelle, sondern auch strukturelle Ähnlichkeiten zu anderen Reversen Transkriptasen, wie zum Beispiel sequenzielle Übereinstimmungen in den aktiven Zentren dieser Enzyme (Nakamura et al. 1998). Der Nachweis des RNA-Anteils der Telomerase erfolgte 1987 über Experimente von Greider und Blackburn, die in einem Telomerase-haltigen Zellextrakt nach Inkubation mit RNase keine Telomeraseaktivität mehr nachweisen konnten (Greider et al. 1987). Man weiß heute, dass die RNA nicht nur im Komplex der Telomerase integriert ist, sondern dass sie entscheidend für die Determinierung der Telomersequenz ist. So führten Mutationen in der RNA der Telomerase zu veränderten Sequenzen der Telomere (Greider et al. 1996).

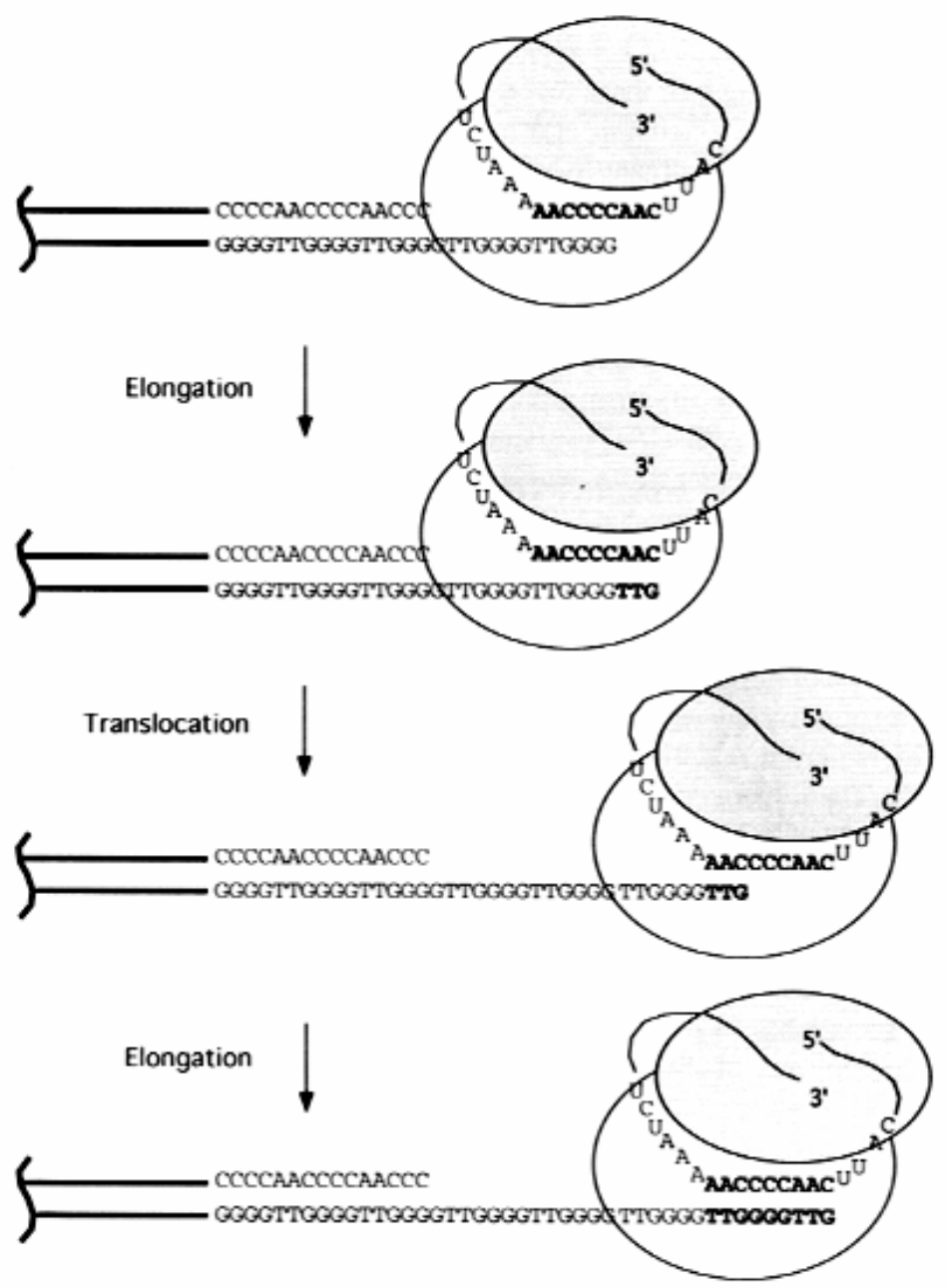

Abbildung 1.3: Verlängerung der Telomere durch die Telomerase, bestehend aus RNA-Untereinheit und Protein Komplex mit hTERT (Harley 2002) 
Der katalytisch wichtigste Teil des Komplexes besteht aus der sogenannten humanen Telomerase Reverse Transkriptase (hTERT) (Meyerson et al. 1997; Nakamura et al. 1997), die für die eigentliche Enzymaktivität verantwortlich ist und zur Verlängerung der Telomere führt. Die Arbeitsgruppe von Lendvay konnte an mutierten Hefezellen, deren Telomere sich aufgrund einer fehlerhaften Telomerase verkürzten, Mutationen in vier verschiedenen Genen nachweisen, die sie als EST (ever shorter telomeres) Gene bezeichneten (Lendvay et al. 1996). Das legte die Vermutung nahe, dass es sich bei dem Protein dieser Gene tatsächlich um die katalytische Untereinheit der Telomerase handelt (Lingner et al. 1997). Einige Monate später fand Meyerson aufgrund der signifikanten Ähnlichkeit zu EST2 das Homolog im menschlichen Genom auf Chromosom 5 und bezeichnete es als hEST2 (jetzt hTERT genannt) (Meyerson et al. 1997).

Wie Abbildung 1.3 zeigt geht man davon aus, dass zwei unabhängige Regionen der Telomerase mit einem Primer interagieren; zum einen die Region, welche die RNA und das katalytische Zentrum enthält und sich an das 3'-Ende des Primers setzt, um diesen zu verlängern, zum anderen die Region, die an das $5^{6}$-Ende bindet und den Weg für den neu entstandenen Strang stabilisiert. Auf diese Weise bleibt das Enzym auch nach vollzogener Synthese eines „Templates“ am Strang haften, auch wenn dieser sich weiterbewegt, um ein neues „Template anzuhängen“ (Greider 1991). Für die Synthese eines DNA-Stranges benötigt das Enzym Nukleosidtriphosphate und einen DNAPrimer, an den die Sequenzen in $5^{6}-3^{6}$-Richtung angefügt werden.

\subsection{Regulation der Telomerase}

Die Aktivierung der humanen Telomerase scheint hauptsächlich transkriptionell gesteuert zu werden, da eine hohe Korrelation zwischen hTERT-mRNA-Expression und Telomeraseaktivität (Takakura et al. 1998), aber auch transkriptioneller Aktivität in Reporter Gen Studien besteht. Es sind zwar auch andere Mechanismen, wie die posttranskriptionelle Regulation durch verschiedene Splicing Varianten (Ulaner et al. 2001; Cerezo et al. 2002) oder post-translationale Modifikationen (Liu et al. 2001; Aisner et al. 2002) beschrieben worden, aber die transkriptionelle Kontrolle des hTERT Gens scheint der limitierende Schritt in der Aktivierung der humanen Telomerase zu sein (Poole et al. 2001). Nach der Sequenzierung und Charakterisierung des hTERTPromotors im Jahr 1999 konnten ausführliche Untersuchungen zur transkriptionellen Regulation durchgeführt werden. Der hTERT-Promotor ist ein sehr GC-reicher, TATABox loser Promotor (Cong et al. 1999; Horikawa et al. 1999; Takakura et al. 1999), mit 
einem 200 bp bis 250 bp langen, proximal gelegenen Kernpromotor, der für die basale transkriptionelle Aktivität von hTERT verantwortlich zu sein scheint. Promotoranalysen konnten diesen Kernpromotor funktionell bestätigen und zahlreiche Transkriptionsfaktor-Bindungsstellen charakterisieren. Die gleichzeitige Veröffentlichung der Sequenzierungs-Ergebnisse verschiedener Arbeitsgruppen hat leider zu einiger Verwirrung bei der Festlegung der Transkriptions-Startstelle des hTERT Gens geführt. So wird immer noch von einer Startstelle bei $-77 \mathrm{bp}$, einer bei $58 \mathrm{bp}$ und einer bei -22 bp strangaufwärts der ATG Translations-Startstelle ausgegangen. Für unsere Promotorstudien haben wir die Transkriptions-Startstelle, wie sie von Roderick Beijersbergen (Netherlands Cancer Center, Amsterdam) bei -58 bp strangaufwärts der ATG Translations Startstelle beschrieben wurde, übernommen (Counter et al. 1998) (Abbildung 1.4).

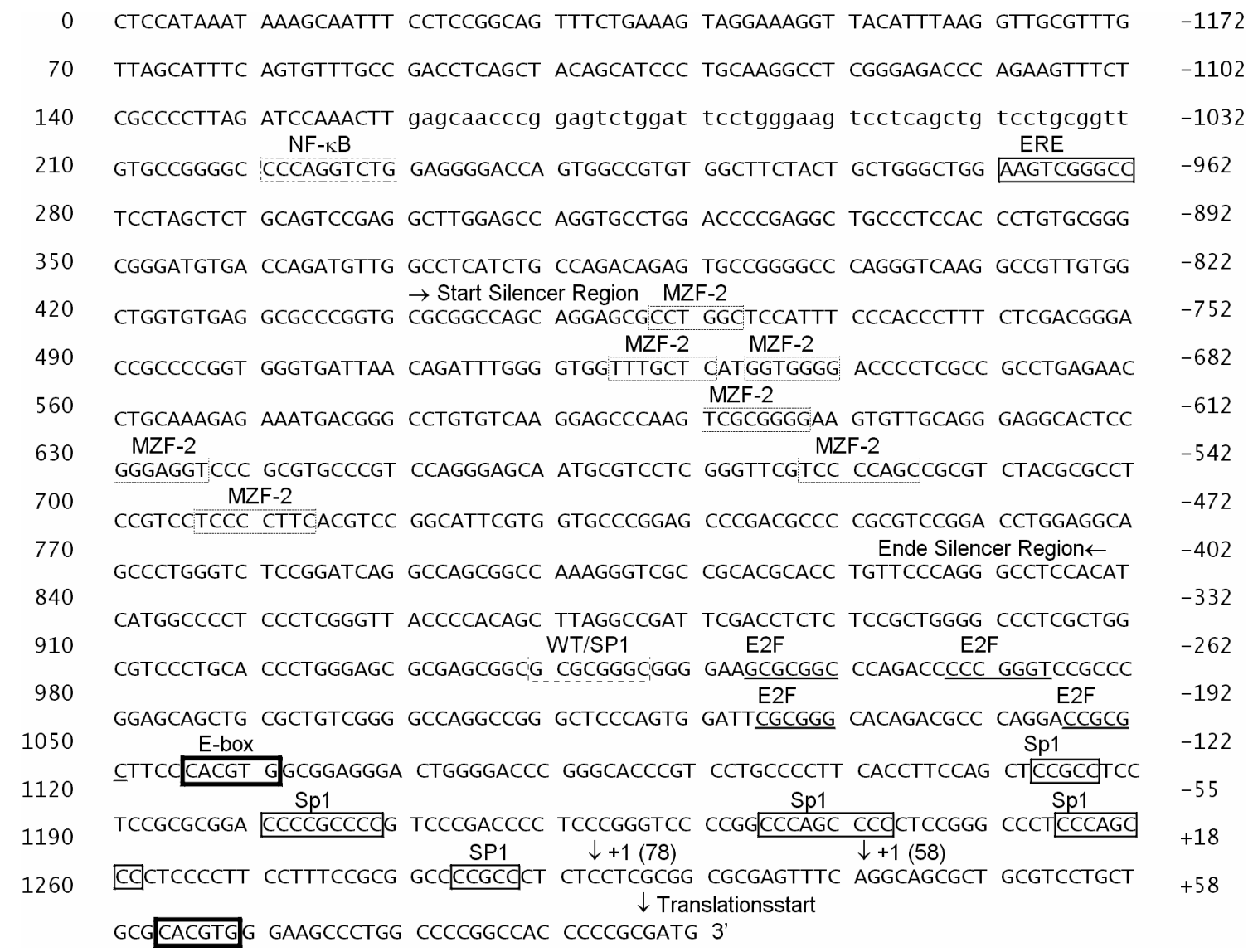

Abbildung 1.4: Nukleotidsequenz des verwendeten hTERT-Promotors. Eingezeichnet sind die Bindungsstellen der einzelnen Transkriptionsfaktoren, die für dieses Projekt von Bedeutung waren. Zusätzlich sind zwei mögliche Transkriptions-Startstellen bei -58 bp und bei -78 bp strangaufwärts der Translations-Startstelle ATG eingezeichnet. Die Nummerierung der Basenpaare startet auf der linken Seite bei 5' und auf der rechten Seite bei 3'. 
Bisherige Untersuchungen zur Regulation der humanen Telomerase wurden hauptsächlich an Tumorzellen durchgeführt (Abbildung 1.5). Es wurden in den letzten Jahren zahlreiche Transkriptionsfaktoren beschrieben, welche auf die eine oder andere Weise zur Aktivierung oder Repression der Telomerase führen. Obwohl die genaue Lokalisation der einzelnen Bindungsstellen auf dem Promotor immer wieder diskutiert wurden, spricht ein Vorliegen verschiedener Repressoren und Aktivatoren für ein komplex reguliertes System.

A

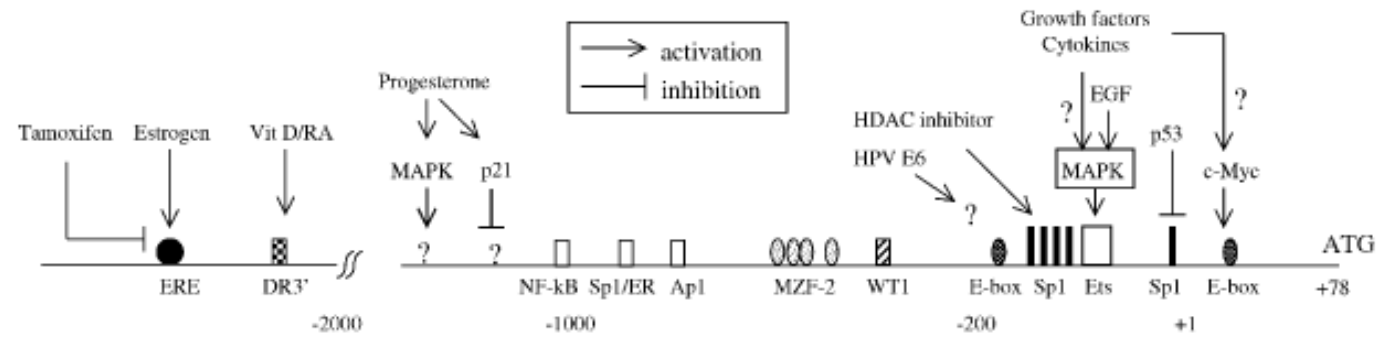

B

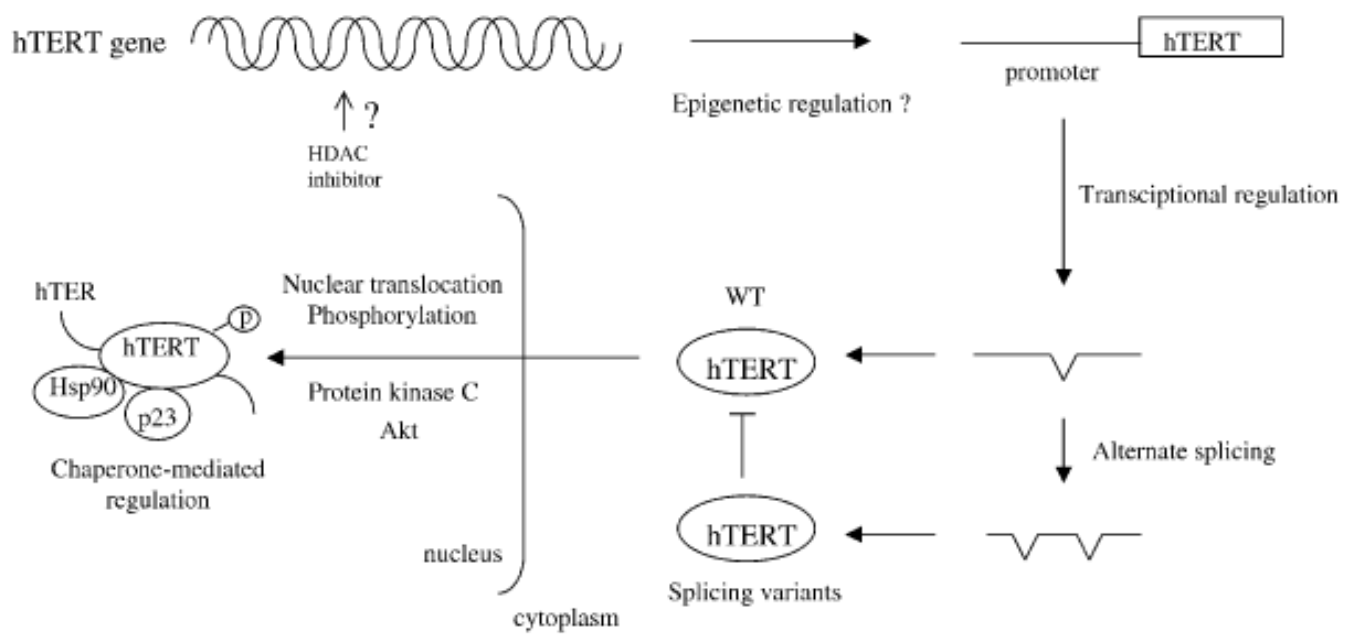

Abbildung 1.5: A: Aktivierende und inhibierende Transkriptionsfaktoren am hTERT-Promotor;

B: Schema der Regulation der humanen Telomerase (Kyo et al. 2002)

Noch bevor der hTERT-Promotor charakterisiert wurde, konnte Wang et al. 1998 zeigen, dass durch retrovirale Überexpression des c-myc Onkogens in Telomerasenegativen Zellen Telomerase induziert werden kann (Wang et al. 1998). Mit der Sequenzierung des hTERT-Promotors wurde dann die Bindungsstelle von c-myc als typische E-box mit der Konsensus Sequenz 5'-CACGTG-3' identifiziert (Wu et al. 1999; Kyo et al. 2000). Das c-myc Onkoprotein bildet dabei einen Komplex mit dem Max Protein und bindet als Heterodimer an die Promotorregion der E-box oder ähnlichen Bindungsstellen (Wu et al. 1999). Von 29 möglichen Bindungsstellen für das 
Myc/Max Heterodimer sind bis dato 18 experimentell bestätigt worden, zwei davon sind als E-box im Kernpromotor lokalisiert (Greenberg et al. 1999; Wu et al. 1999). Das Mad Protein gilt als Antagonist von c-myc und ein Switch von Myc/Max zu Mad/Max resultiert in einer Verminderung der hTERT-Promotoraktivität (Gunes et al. 2000; Oh et al. 2000; Xu et al. 2001; Kyo et al. 2002).

Ein weiterer wichtiger Transkriptionsfaktor, der an die GC-reiche Sequenz des hTERTPromotors bindet, ist Sp1, ein ubiquitär exprimierter Zink-Finger Transkriptionsfaktor. Mutationsanalysen an Bindungsstellen für $\mathrm{Sp} 1$ zeigten eine reduzierte hTERTPromotoraktivität in Tumorzellen. Die Überexpression von Sp1 dagegen ging mit einer erhöhten Telomeraseaktivität einher. Es lassen sich im hTERT-Promotor zahlreiche mögliche Bindungsstellen für Sp1 lokalisieren. Das ubiquitär exprimierte Sp1 kann die hTERT-Transkription in Kooperation mit c-myc aktivieren und scheint an der basalen Aktivität des hTERT-Promotors mitzuwirken (Kyo et al. 2000). Zusätzlich kann Sp1 einen Komplex mit dem Tumorsuppressorgen p53 bilden und in dieser Form die Transkription des hTERT-Promotors inhibieren. Obwohl die Wiedereinführung von p53 in verschiedenen Tumoren $\mathrm{zu}$ einer Reduktion der Telomeraseaktivität durch eben diesen Sp1/p53 Komplex führt (Kanaya et al. 2000; Xu et al. 2000), ist zum jetzigen Zeitpunkt noch nicht geklärt, ob die p53 Inaktivierung eine direkte Rolle bei der Aktivierung der Telomerase spielt (Horikawa et al. 2003).

Proteine der E2F-Familie sind normalerweise in die Transaktivierung von Genen involviert, die den Zellzyklus regulieren. So führt die Phosphorylierung des Tumorsuppressorgens $\mathrm{pRb}$ zur Freisetzung des Transkriptionsfaktors E2F und damit zur Progression des Zellzyklus in die S-Phase. E2F-1 gilt auch als Tumorsuppressorgen, da in E2F-1 defizienten Mäusen nach kurzer Zeit verschiedenste Tumore entstehen (Yamasaki et al. 1998). In Bezug auf die Telomerase wurde beschrieben, dass E2F-1, E2F-2, und E2F-3, nicht aber E2F-4 und E2F-5, die hTERT-Promotoraktivität in humanen Tumorzellen reprimieren, jedoch alle fünf die Promotoraktivität in primären humanen Zellen aktivieren können (Won et al. 2002).

Als Repressor der hTERT-Promotoraktivität wurde das Wilms-Tumor-1 Protein identifiziert. Ein rekombinantes WT-1 Protein bindet an die Konsensus Bindungsstelle im hTERT-Promotor und reprimiert dessen Aktivität in embryonalen Nierenzellen (Oh et al. 1999). Als ein Transkriptionsfaktor, der Telomerase nur in Niere, Milz und Gonaden reprimiert, kann WT-1 aber nicht der einzige Repressor des hTERT-Promotors sein. Die Suche nach anderen Repressoren führte zu dem Zink-Finger-Protein-2 (MZF- 
2), das strangaufwärts des Kernpromotors an mehreren Bindungsstellen innerhalb einer funktionellen Silencer Region, an den hTERT-Promotor bindet (Horikawa et al. 1999; Takakura et al. 1999). Weitere Transkriptionsfaktoren, wie NF- $\mathrm{BB}, \mathrm{AP} 1$, ERE (estrogen responsive element) in strangaufwärts gelegenen Regionen des hTERT-Promotors, spielen möglicherweise bei der Regulation der Telomerase ebenso eine Rolle (Kyo et al. 2002).

Ein anderer Regulationsmechanismus, der bei der Aktivierung oder Inaktivierung der humanen Telomerase im Prozess der malignen Transformation wichtig sein könnte, ist die Methylierung des hTERT-Promotors. Die Methylierung von CpG-Inseln innerhalb eines Promotors ist mit der Unterdrückung der Genexpression des entsprechenden Gens assoziiert. So wurde der hTERT-Promotor von einigen Arbeitsgruppen auf eine Regulation der Telomerase durch Methylierung untersucht. Bis heute gibt es aber nur wenige Daten, die für eine direkte Regulation des hTERT-Promotors durch Methylierung sprechen. Es konnte gezeigt werden, dass immortale Zelltypen, die ihre Telomere durch ALT (alternative lengthening of telomeres), eine von der Telomerase unabhängigen Alternative Telomere zu verlängern, erhalten und Telomerase negativ sind, einen methylierten hTERT-Promotor aufweisen. Eine Demethylierung dieses Promotors führte wiederum zu einer Reaktivierung der Telomerase (Dessain et al. 2000). Im Gegensatz dazu konnte gezeigt werden, dass normale primäre humane Zellen einen unmethylierten oder hypomethylierten Promotor aufweisen und die meisten Tumorzellen einen stark methylierten Promotor besitzen (Devereux et al. 1999; Dessain et al. 2000). Diese Daten lassen den Schluss zu, dass die Methylierung potenziell eine Rolle bei der Regulation der humanen Telomerase spielen könnte. Es muss dennoch andere Mechanismen geben, die eventuell zusammen mit der Methylierung, den Promotor in normalen Zellen reprimieren (Horikawa et al. 2003) und die es Tumorzellen erlauben, die Telomerase trotz massiver Methylierung des hTERTPromotors zu exprimieren.

Eine weitere Möglichkeit der Regulation der humanen Telomerase ist das posttranskriptionelle alternative „Splicing“. Bisher wurden sechs verschiedene Splicing Stellen, zwei Deletionsstellen und vier Insertionsstellen, im Telomerase Gen gefunden (Ulaner et al. 1998; Ulaner et al. 2000; Ulaner et al. 2001; Cerezo et al. 2002). Eine Deletionsstelle $(\alpha)$ und alle vier Insertionsstellen sind verantwortlich für eine Beendigung der Translation. Eine andere Deletionsstelle $(\beta)$ ist $39 \mathrm{bp}$ lang und liegt 
innerhalb des Reverse Transkriptase Motivs. Führt man jeweils eine oder beide Splicing Varianten in Telomerase-negative Zellen ein, so ist es nicht möglich, Telomeraseaktivität zu induzieren. Varianten ohne die $\beta$-Deletionsstelle können sogar als dominant negative Inhibitoren wirken. Weiterhin haben klinische Studien gezeigt, das verschiedene Tumore Splicing Varianten der Telomerase exprimieren und keine Telomeraseaktivität besitzen. Dieser Mechanismus ist somit zumindest an der negativen Regulation der Telomerase beteiligt.

\section{4 Ätiologie des Plattenepithelkarzinoms des Ösophagus}

Plattenepithelkarzinome des Ösophagus stellen weltweit häufige Tumorerkrankungen mit sehr schlechter Prognose dar. Die Inzidenz des Plattenepithelkarzinoms des Ösophagus zeigt starke geographische Unterschiede; in den meisten Ländern, so auch in Deutschland, liegt sie bei 2,5-5/100.000 Einwohner in der männlichen und bei 1,52,5/100.000 Einwohner in der weiblichen Bevölkerung (Sons 1987; Messmann 2001). In einigen Regionen der Erde, so zum Beispiel in China, Iran, Indien, Teilen der früheren Sowjetunion sowie einigen Mittelmeerländern, ist die Inzidenz zum Teil 500fach höher (Messmann 2001). Das Zusammenspiel von Umwelteinflüssen und genetischen Faktoren ist für die Entstehung dieser Tumorerkrankung verantwortlich (Sidransky 1995; Rustgi 1997; Lam 2000; Todd et al. 2002). Wichtige Umweltfaktoren sind vor allem Tabak- und Alkoholgenuss, Vitamin- (A,C,E) und Mineralmangel (Zink, Selen) sowie chemische Karzinogene (Shillitoe et al. 1993; Li et al. 2003) wie die Nitrosamine (Bartsch et al. 1984; Stoner et al. 1991). Genetische Veränderungen sind besonders den Onkogenaktivierungen (z.B. durch Punktmutationen, chromosomale Translokationen oder Genamplifizierungen) den Tumorsuppressorgeninaktivierungen (z.B. durch Punktmutationen oder Allelverlust) zuzuordnen (Hanahan et al. 2000; Lam 2000). Die Überexpression des Zellzyklus regulierenden Proteins Cyclin D1 stellt hierbei die häufigste Onkogenaktivierung dar und ist damit häufigste genetische Alteration dieses Tumortyps (Jiang et al. 1993; Bartkova et al. 1995).

Hauptaufgabe des Cyclin D1/cdk4/6-Komplexes ist die Phosphorylierung des Retinoblastom-Tumorsuppressorgen-Produktes $\mathrm{pRb}$. Durch Phosphorylierung wird $\mathrm{pRb}$ in seinen wachstumsinhibierenden und tumorsupprimierenden Funktionen gehemmt (Hinds et al. 1992). Phosphoryliertes $\mathrm{pRb}$ ist nicht mehr in der Lage Transkriptionsfaktoren wie E2F zu binden. Freies E2F führt dazu, dass Gene, die an der 
S-Phasen-Progression des Zellzyklus beteiligt sind, transkriptionell aktiviert werden.

Der Cyclin D1/cdk-Komplex ist in vielen Tumoren, vor allem Plattenepithelkarzinomen, aktiviert und hebt so die zelluläre Kontrollfunktion des Tumorsuppressorgens $\mathrm{pRb}$ auf (Abbildung 1.6).

\section{Cyclin D1 Pathway}

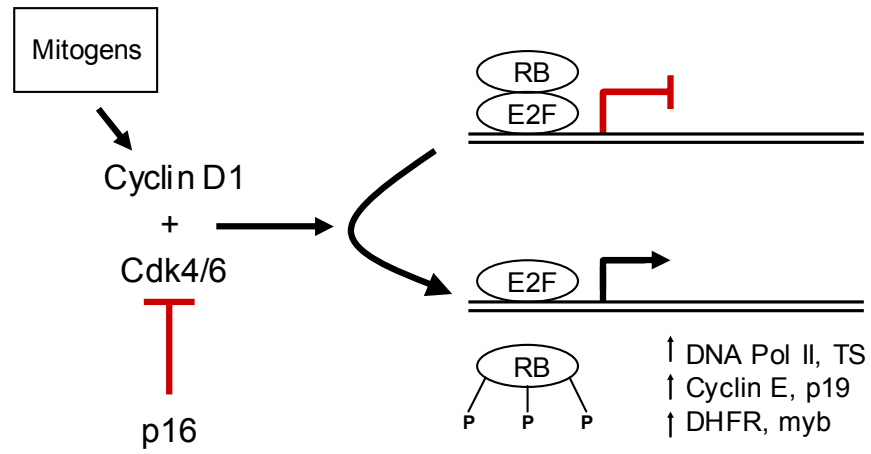

Abbildung 1.6: Schematische Darstellung des Cyclin D1-Signalweges

Spezifische Inhibitoren des Cyclin D1/cdk-Komplexes sind Mitglieder der INK4Familie mit p16 ${ }^{\mathrm{INK} 4 \mathrm{~A}}$ sowie $15^{\mathrm{INK} 4 \mathrm{~b}}, \mathrm{p} 18^{\mathrm{INK} 4 \mathrm{c}}$ und $\mathrm{p} 14^{\mathrm{ARF}}$ (human) bzw. p19 $9^{\mathrm{ARF}}$ (murin). p16 ${ }^{\mathrm{INK} 4 \mathrm{~A}}$ bindet an den Cyclin D1/cdk4/6-Komplex und hemmt dessen Aktivität. Eine Überexpression von p16 führt somit zum G1-Arrest (Enders et al. 1996). Das c-myc Onkogen ist ebenfalls häufig in Plattenepithelkarzinomen des Ösophagus überexprimiert oder amplifiziert (Mandard et al. 2000; Ishizuka et al. 2002). C-myc reguliert unterschiedlichste biologische Funktionen der Zelle, unter anderem die Proliferation und Differenzierung (Dang 1999; Pelengaris et al. 2002).

Neben aktivierten Onkogenen sind Alterationen in Tumorsuppressorgenen häufige Ereignisse in der Karzinogenese des Plattenepithelkarzinoms des Ösophagus. Mechanismen, die zur Inaktivierung von Tumorsuppressorgenen führen sind z.B. Deletionen von Allelen (,Loss of Heterozygosity', LOH) oder Punktmutationen. Unter den Tumorsuppressorgeninaktivierungen sind Mutationen im p53 Tumorsuppressorgen am häufigsten anzutreffen, gefolgt von der Inaktivierung des p16 Tumorsuppressorgens (Hollstein et al. 1990; Hollstein et al. 1991; Huang et al. 1993; Nobori et al. 1994).

Die Mehrzahl der Plattenepithelkarzinome des Ösophagus hat ein p53 Allel auf Chromosom 17p verloren und weist eine Mutation, üblicherweise eine „Missense“ 
Mutation, auf dem zweiten Allel auf (Levine 1997). Typischerweise finden sich Mutationen im p53 Gen auf den hochkonservierten Exons 5-9. Das p53 Gen ist in fast 50\% der menschlichen Tumore mutiert und etwa 15.000 mutierte p53 Allele sind bis heute sequenziert und als inaktive Mutanten in der Literatur beschrieben worden (Harris 1996; Soussi et al. 2000).

p16 ${ }^{\mathrm{INK} 4 \mathrm{a}}$ ist, wie schon erwähnt, ein spezifischer Inhibitor des Cyclin D1/cdk4/6 Komplexes und wird auf demselben genetischen Locus kodiert wie p14 ${ }^{\mathrm{ARF}}$ (Sharpless et al. 1999). Initial wurde es als ein Gen entdeckt, welches in zahlreichen Tumorzelllinien homozygot deletiert war (Serrano et al. 1993). Die p16 Inaktivierung ist ein häufiges Ereignis in vielen Tumoren (Cairns et al. 1995; Reed et al. 1996). Die Inaktivierung von p16 kann durch verschiedene Mechanismen wie Punktmutationen, Mikrodeletionen oder auch Methylierung des p16 Promotors erfolgen. Inaktivierung von p16 führt vermehrt zu katalytisch aktiven Cyclin D1/cdk4/6-Komplexen. Interessanterweise ist $\mathrm{pRb}$, entscheidendes Substrat des aktiven Cyclin D1/cdk4/6-Komplexes und selbst ein in zahlreichen Tumoren inaktiviertes Tumorsuppressorgen, in ösophagealen Plattenepithelkarzinomen nicht alteriert (Kim et al. 1993; Yoo et al. 1994).

Wie ausgeführt sind für den Prozess der malignen Transformation genetische Alterationen wie Onkogenaktivierung und Inaktivierung von Tumorsuppressorgenen und vermutlich andere, notwendig. Ein anderer Kontrollmechanismus, der die Lebensdauer von Zellen mitbestimmt und dem sich Tumorzellen entziehen können, ist die abnehmende Länge der chromosomalen Telomere.

\subsection{Bedeutung der Telomerase für die Tumorgenese}

Um die Bedeutung der Telomerase für die Entstehung und das Wachstum menschlicher Tumore zu verstehen, wurden zahlreiche Untersuchungen an verschiedenen Tumoren durchgeführt. In $85 \%$ der malignen Tumore konnte eine Telomeraseaktivität nachgewiesen werden, in entsprechenden Proben von normalen Geweben war dies nicht der Fall (Dahse et al. 1997). Erstmals konnte die Aktivität des Enzyms Telomerase 1994 in einem menschlichen Ovarialkarzinom nachgewiesen werden (Counter et al., 1994). Mit der Entwicklung sensitiver auf PCR basierender Methoden zum Nachweis der Telomeraseaktivität (TRAP-Assay (telomeric repeat amplification protocol)), fanden Kim et al. Telomeraseaktivität in vielen humanen Geweben und Zelltypen (Kim et al. 1994). Die anfängliche Euphorie über den Nachweis der Telomerase in malignen 
Tumoren, bei gleichzeitigem Fehlen in normalen menschlichen Zellen, wurde etwas gedämpft, als Telomeraseaktivität auch in Keimzellen, Stammzellen des hämatopoetischen Systems und anderen Zellen mit physiologischer Regeneration und hohem Teilungspotential festgestellt wurde (Broccoli et al. 1995; Wright et al. 1996; Shay 1997). Durch die verbesserten Nachweistechniken konnte eine geringfügige Telomeraseaktivität in Basalzellen der Epidermis (Harle-Bachor et al. 1996), in Lebergewebe (Tahara et al. 1995) und während der Proliferationsphase im Endometrium (Tanaka et al. 1998) entdeckt werden. Bis auf die Keimzelllinien, deren Telomerlänge unabhängig vom Lebensalters des Individuums komplett erhalten wird, weisen diese Zellen eine schwächere Telomeraseaktivität als Tumorzellen auf, so dass es trotz Aktivität des Enzyms zu einem langsameren Abbau der Telomere, und nicht zu ihrer vollständigen Erhaltung oder Verlängerung führt (Holt et al. 1997). Die Telomeraseaktivität ist nicht nur Ausdruck von Zellproliferation, sondern sie hängt auch vom Differenzierungsgrad und dem Zellzyklus einer Zelle ab. Kürzlich konnte gezeigt werden, dass die Telomerase in normalen humanen Zellen Zellzyklus-abhängig in der S-Phase herauf-, ansonsten herunterreguliert wird (Masutomi et al. 2003).

Krebszellen unterscheiden sich von den meisten normalen Zellen durch ihre Fähigkeit sich unendlich oft $\mathrm{zu}$ teilen und damit $\mathrm{zu}$ einer unregulierten Tumorprogression $\mathrm{zu}$ führen (Hahn et al. 2002). Da das Teilungspotential einer Zelle normalerweise durch die Verkürzung der Telomere mit jeder Zellteilung begrenzt ist (Hayflick 1965), müssen Krebszellen einen Mechanismus entwickeln, der es ihnen erlaubt, dieses Problem zu umgehen. Nach den heutigen Erkenntnissen ermöglicht die robuste Aktivierung der Telomerase einer Tumorzelle die Telomerverkürzung aufzuhalten, Telomere zu verlängern und damit einen Proliferationsstop zu verhindern.

Telomere können aber auch durch alternative Mechanismen der Telomerverlängerung, sog. ALT-Mechanismen (alternative lengthening of telomeres), erhalten werden (Reddel et al. 2001). So verlängern einige Tumorzellen und immortalisierte Zelltypen ihre Telomere über solche ALT-Mechanismen, die wahrscheinlich auf Rekombinationen basieren (McEachern et al. 1996; Bryan et al. 1997; Henson et al. 2002). ALT wird durch eine fehlende Telomeraseaktivität, sehr heterogene Telomerlängen der einzelnen Chromosomen und das Auftreten von sog. ALT assoziierten PML-Körperchen (APBs) charakterisiert. ALT wurde bis zum jetzigen Zeitpunkt in genetisch veränderten Zellen und Tumorzellen nachgewiesen. Es ist jedoch noch nicht genau geklärt, welche Rolle dieser Mechanismus in der Tumorgenese spielt (Henson et al. 2002). 
In der überwiegenden Mehrzahl humaner Tumore, so auch in ösophagealen Plattenepithelkarzinomen, sind die Telomere jedoch durch unkontrolliert reaktivierte Telomerase stabilisiert und die Tumorzellen immortalisiert (Kim et al. 1994; Mao et al. 1996; Bodnar et al. 1998; Kolquist et al. 1998). Die Progression eines Tumors ist also unter anderem von der Aktivierung der Telomerase abhängig (Stewart et al. 2000).

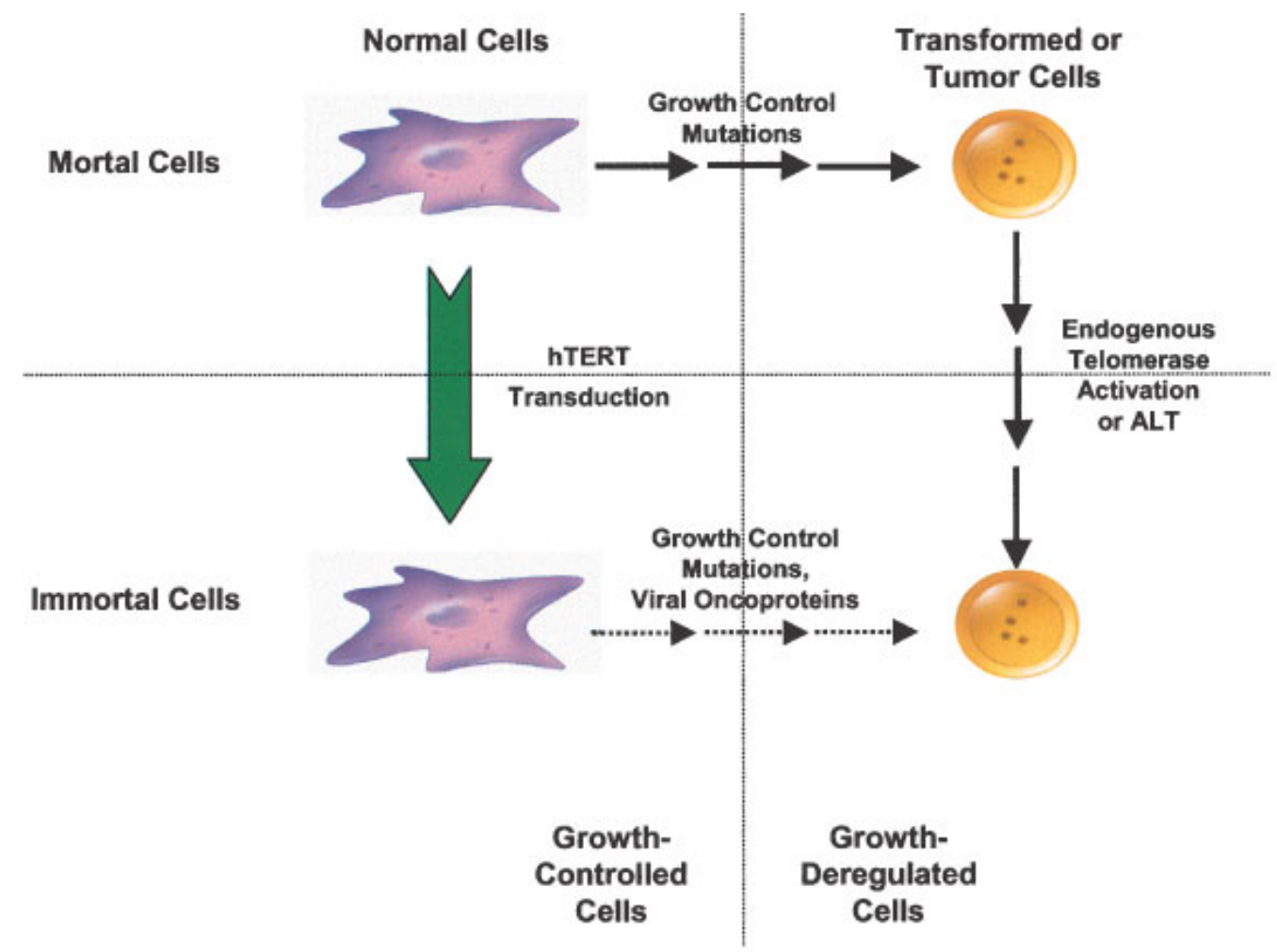

Abbildung 1.7: Modell der Immortalisierung und malignen Transformation in der Zellkultur (Harley 2002)

Die meisten „normal“ alternden Zellen verbleiben in der Phase der Seneszenz bis sie schließlich sterben (Hahn et al. 2001). Eine Zelle kann ohne Telomerase oder einen alternativen Mechanismus der Telomerverlängerung das Mortalitätsstadium nach bisherigen Erkenntnissen nicht überwinden, so dass die Telomere eine kritische Länge erreichen. Nur wenige Zellen, denen es gelingt ihre lebenswichtigen Telomere zu stabilisieren, können in das Stadium der Immortalität eintreten (Counter et al. 1992). Telomerase kann Zellen somit in die Lage versetzen, sich trotz aquirierten genetischen Defekten ungehindert zu teilen und dadurch maligne $\mathrm{zu}$ transformieren. Demzufolge wird die exzessive Proliferation, die im Normalfall durch die Telomerverkürzung gestoppt wird und der Krebsentstehung entgegen wirkt (Rhyu 1995), durch die Aktivierung der Telomerase ermöglicht. 
Um die Rolle der Telomerase bei der Zellproliferation und der Entstehung von Tumoren besser $\mathrm{zu}$ verstehen, sind Kenntnisse über die Telomere sowie über die Struktur, Funktion und ganz besonders Regulation der Telomerase in unterschiedlich immortalisierten Zellen unerlässlich. Generiert man solche Zellen mit den, für das Plattenepithelkarzinom des Ösophagus charakteristischen genetischen Veränderungen, läßt sich ein Model das die verschiedenen Stadien der Immortalisierung und malignen Transformation repräsentiert, etablieren, an dem man die Regulation der Telomerase untersuchen kann (Abbildung 1.7). So kann die ektope Überexpression von hTERT, der katalytischen Untereinheit der humanen Telomerase, die meisten primären humanen Zellen immortalisieren (Bodnar et al. 1998; Yang et al. 1999; Harada et al. 2003). Die Kombination von mehreren genetischen Veränderungen ohne Telomerase Überexpression kann unter bestimmten Voraussetzungen ebenfalls eine Immortalisierung hervorrufen (Opitz et al. 2001; Hahn 2002). Diese geht dann mit einem ALT Mechanismus einher. Die Aktivierung des Schlüsselenzyms Telomerase scheint jedoch in dem Prozess der malignen Transformation von besonderer Bedeutung zu sein, so dass eine eingehende Analyse der Regulation der humanen Telomerase in solchen genetisch definierten Zellen Aufschluss über den für das jeweilige Stadium der Tumorgenese relevanten Regulationsmechanismus geben könnte.

\subsection{Zielsetzung}

Normale humane Zellen haben eine limitierte replikative Lebenszeit bevor sie in Seneszenz gehen. Die Verkürzung der Telomere ist ein wichtiger Faktor in diesem Prozess. Die Mehrzahl humaner Tumorzellen, unter anderem die des Plattenepithelkarzinoms des Ösophagus, erhalten ihre Telomere durch die Aktivierung der Telomerase. Bisher ist relativ wenig über die Regulation der Telomerase sowie über den Einfluss verschiedener genetischer Veränderungen auf die Regulation während des Prozesses der malignen Transformation bekannt. Aus diesem Grund haben wir die transkriptionelle Regulation der Telomerase im Prozess der malignen Transformation von ösophagealen Plattenepithelzellen untersucht.

Normale humane ösophageale Keratinozyten (EPC) wurden aus chirurgischem Material entnommen, in der Zellkultur etabliert und eingehend charakterisiert. In diesen primären humanen Zellen wurde entweder dominant negatives p53 (EPC- $\Delta$ p53), hTERT (EPChTERT) oder Cyclin D1 (EPC-D1), drei wichtige genetische Veränderungen im Prozess der Tumorentstehung des ösophagealen Plattenepithelkarzinoms, retroviral 
überexprimiert. Zusammen mit der ösophagealen Tumorzelllinie TE-12 wurde ein Modell der malignen Transformation von Plattenepithelzellen etabliert. Zuerst sollten Proliferationseigenschaften (Zellkultur), Telomeraseaktivität (TRAP), Telomerlänge (TRF) und Telomerase Genexpression (RT-PCR und QRT-PCR) in den einzelnen Zelltypen EPC, EPC- $\Delta$ p53, EPC-hTERT, EPC-D1 sowie in TE-12 untersucht werden, um die Telomerbiologie dieser Zellen genau zu charakterisieren. Des weiteren musste ein transientes Transfektionssystem für diese Zellen etabliert werden, um die hTERTPromotoraktivität in den unterschiedlichen Zellen untersuchen zu können. Es wurden der komplette (1242bp) hTERT-Promotor und elf Deletionskonstrukte, die mittels PCR hergestellt wurden, verwendet. Diese Deletionskonstrukte wurden transient in oben genannten Zellen transfiziert, und die verschiedenen hTERT-Promotorregionen analysiert. Die Transfektionsergebnisse sollten schließlich nicht nur mit der unterschiedlichen Telomerbiologie der Zellen, sondern auch mit der Bindung von Transkriptionsfaktoren (EMSA), unter Berücksichtigung ihrer Expression (Western Blot), korreliert werden. Zusätzlich sollte der Methylierungs-Status des hTERTPromotors mit den Transfektionsergebnissen verglichen werden.

Als Ziel dieser Arbeit sollten anhand der gewonnen Daten die unterschiedliche transkriptionelle Regulation der humanen Telomerase in den verschiedenen, genetisch definierten Zellen analysiert und ein Modell für die Regulation der Telomerase im Prozess der Entstehung des Plattenepithelkarzinoms des Ösophagus skizziert werden. 


\section{Material und Methoden}

Entsprechend der Zielsetzung wurden die verschiedenen in dieser Arbeit verwendeten Zelltypen auf ihre Telomerlänge, Telomeraseaktivität und hTERT-Transkription untersucht. Zur transienten Transfektion des hTERT-Promotors wurde eine Lipofectamin Methode etabliert. Der Promotor wurde mittels einer PCR-Strategie in elf Deletionskonstrukte unterteilt. Die Deletionskonstrukte wurden dann in das pGL3 Reporter Plasmid subkloniert, transient in die verschiedenen Zellen transfiziert und mit einem Luziferase-Assay ausgewertet. Auf den Transfektionsergebnissen basierend, wurde der hTERT-Promotor auf mögliche Transkriptionsfaktor-Bindungsstellen und DNA-Methylierung überprüft.

Alle Methoden und Vorschriften wurden, soweit nicht anders vorgegeben, dem Laborhandbuch „Molecular Cloning“ von Sambrock et al. (1989) bzw. „Current Protocols in Molecular Biology“" von Ausubel et al. (1995) entnommen.

\subsection{Zelltypen}

Die einzelnen Zelltypen waren in der Arbeitsgruppe etabliert. Dabei handelt es sich um primäre humane ösophageale Keratinozyten (EPC) und deren Derivate. EPC wurden aus chirurgischen Geweben etabliert und eingehend charakterisiert. Danach wurden Cyclin D1, humane Telomerase (hTERT) oder dominant negatives p53 in den Zellen überexprimiert. Für die retrovirale Transduktion von Cyclin D1 (EPC-D1) wurde der retrovirale Vektor pBPSTR-D1, ein Tetracyclin-regulierbares Vektor-System, welches auf dem Vektor pBabe-puro aufgebaut ist und ein Puromycinresistenzgen als Selektions-Marker besitzt (S.A. Reeves; Massachusetts General Hospital, Boston, Massachusetts, USA), verwendet (Hiyama et al. 1997; Opitz et al. 2000; Opitz et al. 2001). Um EPC mit Überexpression einer dominant negativen p53 Variante (V143A) (EPC- $\Delta$ p53) herzustellen, wurde der retrovirale Vektor LXSN verwendet (Thompson et al. 1997). Robert Weinberg (Whitehead Institute, Cambridge, Massachusetts, USA) stellte den Vektor pBABE-hTERT für die Überexpression der humanen Telomerase (EPC-hTERT) in EPC zur Verfügung (Harada et al. 2003). Diese Vektoren wurden transient in die amphotrophe sog. Packaging Zelllinie Phoenix $\alpha$ transfiziert. Der so gewonnene retrovirale Überstand wurde zur Infektion der normalen humanen ösophagealen Keratinozyten (EPC) verwendet. Die Zellen wurden nach Selektion expandiert, gepoolt und weiter analysiert. Die so generierten Zellen wurden EPC- $\Delta$ p53, 
EPC-D1 und EPC-hTERT genannt. Die Infektionseffizienz wurde mittels eines LacZGen enthaltenden Vektors (pBabe-lacZ) kontrolliert. Als Tumorzelllinie wurde die bekannte Zelllinie TE-12 verwendet.

\subsection{Methoden zur Arbeit mit eukaryonten Zellen}

Die Arbeit mit humanen Zellen erfolgte in einem Zellkulturlabor unter sterilen Bedingungen. Die Zellen wurden in wassergesättigter Atmosphäre unter $5 \% \mathrm{CO}_{2}$ bei $37^{\circ} \mathrm{C}$ kultiviert. Medien und Lösungen wurden bei $-20^{\circ} \mathrm{C}$ bzw. $4^{\circ} \mathrm{C}$ aufbewahrt und vor Gebrauch auf $37^{\circ} \mathrm{C}$ vorgewärmt. Die Zellen wurden regelmäßig mit PBS (ohne $\mathrm{Ca}^{2+}$ und $\mathrm{Mg}^{2+}$ ) gewaschen und mit Trypsin von der Gewebekulturplatte gelöst. Die Zellmorphologie wurde unter dem Mikroskop beobachtet, das Medium regelmäßig gewechselt und abhängig von der Wachstumsrate die Zellen subkultiviert. Bei regulären Passagen wurden die Zellen zweimal durch Zugabe von PBS gewaschen und anschließend nach Trypsinierung 1:2 bis 1:100 geteilt. Vor der erneuten Plattierung wurde die Trypsinlösung durch Zentrifugation bei $800 \mathrm{U} / \mathrm{min}$ entfernt. Die Subkultivierung (Passagierung) der Zellen erfolgte stets zu einem Zeitpunkt, an dem die Zellen zu 30\%-40\% konfluent waren. In der Regel lagen zwischen zwei Passagen 3 bis 6 Tage. Bei einigen Passagen wurde ein Teil der Zellen bei $-80^{\circ} \mathrm{C}$ kryopräserviert, dafür wurden die Zellen trypsiniert und anschließend in Zellmedium aufgenommen. Nach dem Abzentrifugieren (5 min, $800 \mathrm{rpm}$ ) und Absaugen des Überstandes wurde das Zellpellet in $500 \mu \mathrm{l}$ Zellmedium resuspendiert. In Kryoröhrchen wurden $500 \mu 1$ Einfriermedium vorgelegt, anschließend die Zellsuspension zügig hinzugegeben und mit Hilfe einer Styropor-Ummantelung langsam auf $-80^{\circ} \mathrm{C}$ abgekühlt. Zum Auftauen eines Tiefkühlaliquots wurde ein Kryoröhrchen, nach der Entnahme aus dem Stickstofftank oder aus $-80^{\circ} \mathrm{C}$ für etwa $1 \mathrm{~min}$ im $37^{\circ} \mathrm{C}$-Wasserbad aufgetaut. Die Zellsuspension wurde dann über $45 \mathrm{sec}$ lang in $6 \mathrm{ml}$ DMEM überführt, gemischt und bei $800 \mathrm{rpm}$ für 5 min zentrifugiert. Der Überstand wurde verworfen und die Zellen in $10 \mathrm{ml}$ Medium resuspendiert, auf eine Zellkulturschale $(10 \mathrm{~cm})$ plattiert und bei $37^{\circ} \mathrm{C}$ inkubiert.

\subsection{Herstellung der Deletionskonstrukte}

Der 1242 bp lange hTERT-Promotor wurde von Roderick Beijersbergen vom Netherlands Cancer Center in Amsterdam kloniert und uns in dem Vektor pGL3-Basic (Promega, Abbildung 2.1) zur Verfügung gestellt. Um die elf verschiedenen 
Deletionskonstrukte zu konstruieren, wurde der 1242 bp lange hTERT-Promotor auf eventuelle, bereits bekannte, Transkriptionsfaktor-Bindungsstellen hin untersucht und in elf unterschiedlich lange Fragmente aufgeteilt (Horikawa et al. 1999; Takakura et al. 1999; Poole et al. 2001; Ducrest et al. 2002; Kyo et al. 2002). Mit dem Computer Programm Vector NTI wurden für die so ausgesuchten Konstrukte PCR-Primer hergestellt (Tabelle 2.1).

Tabelle 2.1

\begin{tabular}{|c|c|c|c|}
\hline Name & Nukleotidsequenz & Enzym & $\begin{array}{c}\% G C \\
\text { Temp } \\
\end{array}$ \\
\hline Antisense (as0Nco1) & 5' TACCATGGCA TCGCGGGGGT GGCCGGGGCC A 3' & Nco I & $68,5^{\circ} \mathrm{C}$ \\
\hline DC -1011 (s231Nhe1) & 5' GCGCTAGCGA GGGGACCAGT GGCCGTGTGG C 3' & Nhe I & $68,5^{\circ} \mathrm{C}$ \\
\hline DC -905 (s337Nhe1) & 5' GCGCTAGCCC ACCCTGTGCG GGCGGGATGT G 3' & Nhe I & $68,5^{\circ} \mathrm{C}$ \\
\hline DC -700 (s542Nhe1) & 5' GCGCTAGCCC CCTCGCCGCC TGAGAACCTG C 3' & Nhe I & $68,5^{\circ} \mathrm{C}$ \\
\hline DC -357 (s885Nhe1) & 5' ATGCTAGCCC TCTCTCCGCT GGGGCCCTCG C $3^{\prime}$ & Nhe I & $67,2^{\circ} \mathrm{C}$ \\
\hline DC -290 (s952Nhe1) & 5' CTGCTAGCAA GCGCGGCCCA GACCCCCGGG T 3' & Nhe I & $68,5^{\circ} \mathrm{C}$ \\
\hline DC -247 (s995Nhe1) & 5' ATGCTAGCGT CGGGGCCAGG CCGGGCTCCC A 3' & Nhe I & $68,5^{\circ} \mathrm{C}$ \\
\hline DC -187 (s1055Nhe1) & 5' GCGCTAGCCC ACGTGGCGGA GGGACTGGGG A 3 ' & Nhe I & $68,5^{\circ} \mathrm{C}$ \\
\hline DC -161 (s1081Nhe1) & 5' GCGCTAGCGG GCACCCGTCC TGCCCCTTCA C 3' & Nhe I & $68,5^{\circ} \mathrm{C}$ \\
\hline DC -101 (s1141Nhe1) & 5' GCGCTAGCTC CCGACCCCTC CCGGGTCC 3' & Nhe I & $68,0^{\circ} \mathrm{C}$ \\
\hline DC -48 (s1194Nhe1) & 5' GCGCTAGCTC CCCTTCCTTT CCGCGGCCCC G 3' & Nhe I & $68,5^{\circ} \mathrm{C}$ \\
\hline DC -16 (s1226Nhe1) & 5' GCGCTAGCCG CGGCGCGAGT TTCAGGCAGC G 3' & Nhe I & $68,5^{\circ} \mathrm{C}$ \\
\hline
\end{tabular}

Mit dem Computer Programm Vector NTI konstruierte PCR-Primer für die verschiedenen Deletionskonstrukte des hTERT-Promotors. Der Antisense Primer war für alle Konstrukte identisch und wurde 5' mit der Restriktionsenzym-Schnittstelle Nco I (fett) ausgestattet. Die Sense Primer wurden immer 5' der ausgesuchten Promotorregion mit einer Restriktionsenzym-Schnittstelle für Nhe I (fett) versehen. In der rechten Spalte sind die Annealing Temperaturen der PCR angegeben.

Der Antisense Primer war für alle Konstrukte identisch und wurde 5' mit der Restriktionsenzym-Schnittstelle Nco I (New England BioLabs) ausgestattet, um die Konstrukte später in das Plasmid pGL3 (Promega) zu ligieren. Die Sense Primer wurden immer 5, der ausgesuchten Promotorregion, jeweils mit einer Restriktionsenzym-Schnittstelle für Nhe I (New England BioLabs) an der 5' Seite, konstruiert. Antisense und Sense Primer wurden zusätzlich zu den RestriktionsenzymSchnittsellen auf der 5' Seite um je zwei Basenpaare verlängert, um eventuelle prozentuale GC-Unterschiede oder Annealing Temperaturunterschiede auszugleichen und später ein optimales Schneiden der Restriktionsenzyme zu gewährleisten. Alle Primer wurden bei der Firma Tib-Molbiol in Berlin nach Sequenzvorgabe synthetisiert. 
Das 1300 bp lange hTERT-Promotor-Konstrukt bestand aus 1242 bp bis zur Transkriptions-Startstelle des hTERT Gens und zusätzliche 58 bp bis zur TranslationsStartstelle (ATG) der humanen Telomere Reverse Transkriptase. Es wurde von Roderick Beijersbergen 5' mit dem Restriktionsenzym Nhe I (GCTAGC) und 3' mit dem Restriktionsenzym Nco I (CCATGG) in den Luziferase Reporter Gen Vektor pGL3-Basic (Promega) (Abbildung 2.1) subkloniert (Meyerson et al. 1997), so dass die hTERT Translations-Startstelle (ATG) bei +58 identisch mit der der Luziferase positioniert war. Dieses Plasmid diente nach Vervielfältigung als „Template“ für die PCR. Diese wurde mit einem Gesamtvolumen von $60 \mu$ mit je $3 \mu$ l Sense und Antisense Primer und $6 \mu \mathrm{l}$ pGL3-hTERT-Plasmid als „Template“ unter Verwendung des Invitrogen Platinum Pfx-DNA-Polymerase (1,5 U) Protokolls durchgeführt (Tabelle 2.2).

Tabelle 2.2

\begin{tabular}{lccl}
\hline PCR-Schritt & Zyklen & Temperatur & Zeit \\
\hline Vorabdenaturierung & 1 & $94^{\circ} \mathrm{C}$ & $45 \mathrm{sec}$ \\
Denaturierung & 30 & $94^{\circ} \mathrm{C}$ & $45 \mathrm{sec}$ \\
Annealing & 30 & $64^{\circ} \mathrm{C}$ & $1 \mathrm{~min}$ \\
Extension & 30 & $72^{\circ} \mathrm{C}$ & $2 \mathrm{~min}$ \\
Extension & 1 & $72^{\circ} \mathrm{C}$ & $10 \mathrm{~min}$ \\
Kühlen & 1 & $4{ }^{\circ} \mathrm{C}$ & $\infty$ \\
\hline $\begin{array}{l}\text { PCR-Programm zur Herstellundg der Deletionskonstrukte des } \\
\text { hTERT-Promotors }\end{array}$ &
\end{tabular}

Zur Auftrennung der DNA-Fragmente unterschiedlicher Größe wurden Ethidiumbromid-haltige 1-2\% Agarosegele verwendet. Die Elektrophorese wurde unter einer Spannung von 3-4 V/cm² durchgeführt. Die gewünschte DNA-Bande wurde unter UV-Licht $(\lambda=312 \mathrm{~nm})$ ausgeschnitten und dann unter Verwendung des Protokolls für das Qiagen Gel Extraction Kit isoliert. 1 Vol. Gel wurde mit 3 Vol. Solubilisierungspuffer QG versetzt und für 10 min inkubiert, bis das Gel vollständig aufgelöst war. Nach Gabe von 1 Vol. Isopropanol wurde die Lösung auf eine Säule aufgetragen und für $1 \mathrm{~min}$ bei $15000 \mathrm{rpm}$ in der Minizentrifuge zentrifugiert. Die nun an die Säule gebundene DNA wurde mit Waschpuffer (PE-Puffer mit Ethanol) gewaschen. Anschließend wurde $50 \mu \mathrm{l}$ EB Puffer (10 mM Tris-HCl, pH 8,5) auf die Membran platziert, ca. 1 min bei Raumtemperatur (RT) inkubiert und schließlich die DNA in einem letzten Zentrifugationsschritt eluiert. 
Die elf so isolierten PCR Amplifikate wurden nach Lehrach und Frischauf (1982) mit den Restriktionsendonukleasen Nco I und Nhe I $\left(3 \mathrm{~h}\right.$ bei $\left.37^{\circ} \mathrm{C}\right)$ an den endständigen Schnittstellen geschnitten. Die hergestellten Deletionskonstrukte (Abbildung 2.1) wurden wiederum auf ein Agarosegel aufgetragen und mittels Qiagen Gel Extraction Kit isoliert.

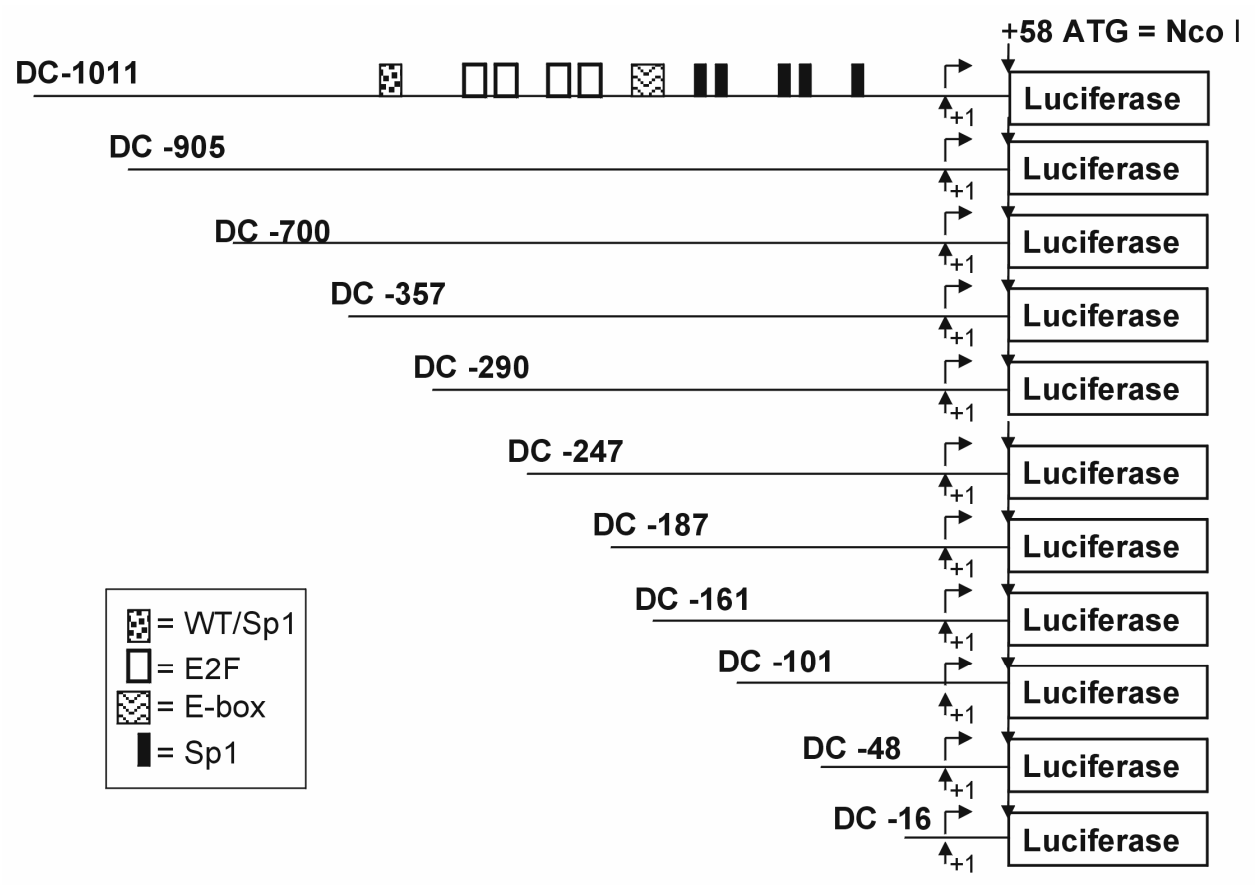

Abbildung 2.1: Schematische Darstellung der elf Deletionskonstrukte des hTERTPromotors mit Position der wichtigsten Transkriptionsfaktor-Bindungsstellen

Der Vektor pGL3-Basic (Abbildung 2.2) wurde ebenfalls mit den Restriktionsendonukleasen Nhe I und Nco I geschnitten, auf ein Agarosegel aufgetragen und mit Hilfe des Qiagen Gel Extraction Kit isoliert. Danach wurden die präparierten Deletionskonstrukte mit einer T4-DNA-Ligase (New England BioLabs) im Verhältnis 1:2, in einem $10 \mu 1$ Reaktionsansatz, 10 min bei RT unter Verwendung des beiliegenden Protokolls in dieses linearisierte Plasmid ligiert. 

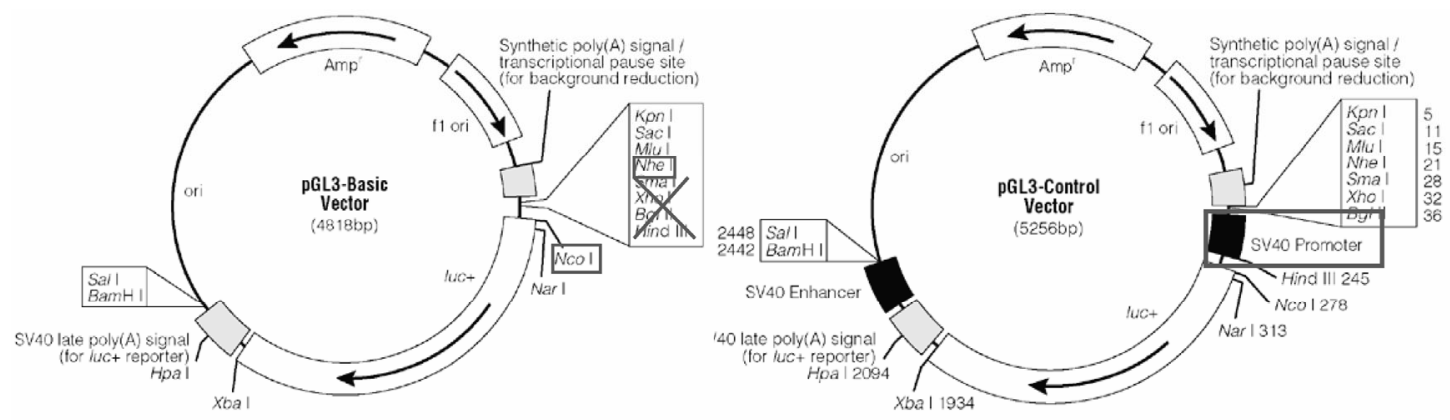

Abbildung 2.2: Schematische Darstellung der verwendeten Plasmide: Negativkontrolle pGL3-BasicVector (links) mit Angabe der verwendeten Schnittstellen Nco I und Nhe I zur Ligation der Deletionskonstrukte in das Plasmid und Positivkontrolle pGL3-Control-Vector (rechts) mit SV40 Promotor.

$5 \mu 1$ der so hergestellten Plasmide wurden mit $66,6 \mu 1$ E. coli Max Efficiency ${ }^{\circledR}$ DH5 $\alpha^{\mathrm{TM}}$ Competent Cells (Invitrogen) unter Verwendung des beiliegenden Protokolls transformiert und $30 \mathrm{~h}$ auf LB-Ampicillin-Agarplatten kultiviert. Je $3 \mathrm{ml}$ LB-Medium (mit $100 \mu \mathrm{g} / \mathrm{ml}$ Ampicillin) wurden mit 5 bis 10 der transformierten E. coli-Kolonien angeimpft und im Schüttelinkubator bei $37^{\circ} \mathrm{C}$ inkubiert. Nach ca. $4 \mathrm{~h}$ wurde aus $500 \mu \mathrm{l}$ Bakteriensuspension durch Hitzeinaktivierung und Zentrifugieren DNA isoliert. Mittels PCR mit je $3 \mu \mathrm{l}$ Sense und Antisense Primer und $10 \mu$ DNA als Template (Gesamtvolumen: $60 \mu \mathrm{l}$ ), unter Verwendung des Invitrogen Platinum Pfx-DNAPolymerase Protokolls, wurde das Vorhandensein der jeweiligen Deletionskonstrukte in den Plasmiden kontrolliert.

Nach 8-10 h Inkubation wurden weitere $300 \mu$ Bakteriensuspension aus den positiven Kulturen in $300 \mathrm{ml}$ LB-Medium (mit $100 \mu \mathrm{g} / \mathrm{ml}$ Ampicillin) transferiert. Die Inkubation erfolgte für $12-16 \mathrm{~h}$ bei $37^{\circ} \mathrm{C}$ im Schüttelinkubator. Die Plasmid-DNA wurde nach dem Qiagen Protokoll für Maxi Präparation isoliert. Das luftgetrocknete DNA-Pellet wurde in 100 $\mu 1-500 \mu 1$ TE-Puffer aufgenommen

Nach der photometrischen Messung zur Quantifizierung und Reinheitsbestimmung der DNA, bei einer Wellenlänge von $260 \mathrm{~nm}$ und $280 \mathrm{~nm}$, wurden die Deletionskonstrukte in einer Endkonzentration von $1 \mu \mathrm{g} / \mu \mathrm{l}$ TE-Puffer aufgenommen. Durch erneuten Restriktionsverdau mit Nhe I und Nco I wurde die Identität der Plasmid-DNA und der korrekte Einbau der Deletionskonstrukte überprüft. Vor den Transfektionsexperimenten wurden die elf Plasmide mit einem Primer, $40 \mathrm{bp} \mathrm{3'}$ des Translationsstartes der Luziferase, sequenziert (Microsynth, Balgach, Schweiz) und mit dem Programm Pubmed Blast2Sequences mit dem veröffentlichten hTERT-Promotor verglichen. 


\subsection{Transiente Transfektionen}

Unter transienter Transfektion versteht man das Einschleusen fremder DNA in Form eines Plasmids in eine eukaryonte Zelle. Ziel ist die vorübergehende Expression fremder Gene in der Zelle. Für das Einbringen von Fremd-DNA in Säugetierzellen stehen verschiedene Möglichkeiten wie die DEAE-Dextran-Methode, CalziumPhosphat-Kopräzipitation, Elektroporation sowie einige kommerziell erhältliche Methoden zur Verfügung. Die Transfektion wurde in diesem Fall mit dem Transfektionsreagenz Effectene Transfektion Reagent (Qiagen), einer auf Lipofektamin basierenden Methode durchgeführt. Mittels eines Luziferase-Reporter Plasmids (pGL3) wurden die subklonierten Deletionskonstrukte und der gesamte hTERT-Promotor in den $\mathrm{zu}$ untersuchenden Zellen nach einem modifizierten Protokoll jeweils im Triplikat transient transfiziert. Eine Standardisierung wurde über die Zellzahl pro Ansatz und durch Koexpression von Positiv- (pGL3 mit SV40-Promotor) und Negativkontrolle (pGL3 als Leervektor) erreicht. Der Transfektionsvorgang wurde lichtmikroskopisch auf morphologische Veränderungen beobachtet.

$24 \mathrm{~h}$ vor Transfektion wurden die Zellen in einer Zellkonzentration ausplattiert, damit innerhalb von 72 h eine Konfluenz von 40-60\% erreicht werden konnte. Im Falle von EPC-hTERT und EPC-D1 waren $2 \times 10^{5}$ Zellen für eine 6-well Schale $(2 \mathrm{~cm})$, bei EPC und EPC- $\Delta \mathrm{p} 53,5 \times 10^{4}$ Zellen für eine 24-well Schale $(1 \mathrm{~cm})$ notwendig. Die Tumorzellen (TE-12) wurden mit $1 \times 10^{5}$ Zellen in einer 6-well Schale $(2 \mathrm{~cm})$ ausgesät. $4 \mathrm{~h}$ vor Transfektion wurde ein Mediumwechsel durchgeführt. Zur Transfektion (Tabelle 2.3) wurden in einem 1,5 ml Eppendorf-Rörchen, im Gesamtvolumen von 100 $\mu 1$, EC-Puffer und 3,2 $\mu 1$ Enhancer vorgelegt, mit Plasmid-DNA (1 $\mu \mathrm{g}$ Plasmid für EPCD1, EPC-hTERT und TE-12 sowie 0,5 $\mu$ g Plasmid für EPC und EPC- $\Delta$ p53) vermischt und 10 min bei RT inkubiert. $10 \mu \mathrm{l}(5 \mu \mathrm{l})$ "Effectene Transfection Reagent" wurden hinzugegeben und der Ansatz wiederum 15 min bei RT inkubiert. In der Zwischenzeit wurden die Zellen zweimal mit PBS gewaschen und mit $1200 \mu 1$ Medium pro 6-well oder $350 \mu 1$ pro 24 -well versetzt. Der Reaktionsansatz wurde danach mit $600 \mu 1$ (350 $\mu 1)$ Medium vermischt und sofort gleichmäßig in die „wells“ verteilt. Nach 14-16 h wurden die Zellen gründlich gewaschen und mit neuem Medium versehen. Weitere 24-30 h später und ca. 48 Stunden nach Beginn der Transfektionsreaktion wurden die Zellen unter Verwendung des Protokolls "Luziferase Assay Substrate TM" (Promega; Madison, USA) ,geerntet“, indem sie mit $250 \mu$ Reporter Lysis Puffer 30 min bei $4^{\circ} \mathrm{C}$ 
inkubiert, von den Kulturschalen abgelöst und schließlich abzentrifugiert wurden. Die Quantifizierung der Luziferaseaktivität erfolgte im Luminometer mit Luziferase Assay Substrate TM (Promega, Madison, USA) nach Mischung des Gesamtzellextraktes mit Reagenzlösung im Verhältnis 1:1. Bei der Luziferasemessung handelt es sich um eine Chemolumineszenzreaktion, bei der die Leuchtkäferluziferase, die in pGL3Reporterplasmiden kodiert ist, das Substrat Luziferin umwandelt, so dass Photonen emittiert werden, die mit einem Luminometer gemessen werden können.

Tabelle 2.3

\begin{tabular}{|c|c|c|c|}
\hline Reagenz & $\begin{array}{l}\text { Menge für EPC-hTERT, EPC-D1 } \\
\text { und TE-12 }\end{array}$ & $\begin{array}{l}\text { Menge für EPC und } \\
\text { EPC- } \Delta \text { p53 }\end{array}$ & Schritt \\
\hline DNA & $1 \mu \mathrm{g}$ in $1 \mu \mathrm{l}$ & $0,5 \mu \mathrm{g}$ in $1 \mu 1$ & vortexen und $10 \mathrm{~min}$ inkubieren \\
\hline EC-Puffer & $95,8 \mu 1$ & $57,4 \mu 1$ & \\
\hline Enhancer & $3,2 \mu 1$ & $1,6 \mu 1$ & \\
\hline Effectene & $10 \mu 1$ & $5 \mu 1$ & 15 min inkubieren \\
\hline Medium "complete" & $600 \mu 1$ & $350 \mu 1$ & $\begin{array}{l}\text { mischen und gleichmäßig in ,wells“ } \\
\text { verteilen }\end{array}$ \\
\hline Medium an Zellen & $1200 \mu 1$ & $350 \mu 1$ & $\begin{array}{l}\text { Zellen waschen und Ansatz } \\
\text { dazufügen }\end{array}$ \\
\hline
\end{tabular}

Pipettierschema für die transiente Transfektion von EPC, EPC- $\Delta$ p53, EPC-D1, EPC-hTERT und TE12. Aufgezählt sind die einzelnen Schritte mit den erforderlichen Mengen- und Zeitangaben

\subsection{EMSA (Electro Mobility Shift Assay)}

Die „Bandshift-Analyse“ (EMSA) dient der sensitiven und quantitativen in vitro Analyse von Protein-DNA-Bindungen. Am häufigsten wird diese Methode zur Identifizierung von Transkriptionsfaktoren sowie der von ihnen gebundenen DNAElemente (Promotoren, Enhancer, Silencer) verwendet. Dabei wird die Migrationsgeschwindigkeit radioaktiv markierter DNA-Fragmente im nativen PAA-Gel (Polyacrylamid) durch die Anlagerung von DNA-bindenden Proteinen herabgesetzt, was wiederum durch autoradiografische Verfahren sichtbar gemacht werden kann. Aufgrund der Transfektionsergebnisse wurden unter Berücksichtigung der bekannten Transkriptionsfaktor-Bindungsstellen verschiedene Doppelstrang-Oligonukleotide (Tabelle 2.4) mit den Restriktionsenzymen Nhe 1 als 3' Überhang und Nco 1 als 5', Überhang hergestellt. Zusätzlich wurden Mutanten hergestellt, um die spezifische Protein-DNA-Bindung nachzuweisen. Die Spezifität eines Protein-DNA-Komplexes konnte anhand von Kompetitionsexperimenten nachgewiesen werden. Hierzu wurde der Inkubationslösung zusätzlich $\mathrm{zu}$ den radioaktiv markierten DNA-Fragmenten ein Überschuss an nicht markierten Fragmenten (Kompetitor) zugesetzt. Bindet der Kompetitor das Protein, nimmt die Signalintensität des spezifischen Komplexes ab. Der 
Supershift stellt ein Modifikation der „Bandshift-Analyse“ dar, bei der ein im Ansatz zugegebener Antikörper Proteine spezifisch erkennt und so zu einer zusätzlichen Verlangsamung des Komplexes im PAA-Gel führt.

Die komplementären Einzelstränge der Oligonukleotide wurden jeweils hybridisiert und danach in einem nativen PAA-Gel (5\% Acrylamid/Bisacrylamid (19:1), 0,04\% TEMED und $0,06 \%$ APS in $1 \mathrm{x}$ TBE) aufgereinigt. Die ausgeschnittenen DoppelstrangOligonukleotide wurden in $0,3 \% \mathrm{NaOAc}-L o ̈ s u n g$ aus dem Gel extrahiert $\left(24 \mathrm{~h}, 37^{\circ} \mathrm{C}\right.$ $250 \mathrm{rpm}$ ) und mittels Phenol/Chloroform-Extraktion isoliert. Zur radioaktiven Markierung der Überhänge wurden je 10 pmol der Wildtyp- und MutantenOligonukleotide mittels Klenow-Fragment $\left(3^{\prime} \rightarrow 5^{\prime}\right)$ mit $\left[\alpha \mathrm{P}^{32}\right]$ dCTP markiert und in $100 \mu 1$ 0,05 x TBE Endvolumen aufgenommen.

Die Protein-Kernextrakte (NE) wurden nach dem Protokoll von Schreiber präpariert (Schreiber et al. 1989). Vier $10 \mathrm{~cm}-K u l t u r s c h a l e n$ wurden bis zur Konfluenz von 60\% mit den Zellen kultiviert und dann mit einem Zell-Schaber abgenommen. Nach zweimaligem Waschen mit PBS wurden die Zellen in $4 \mathrm{ml}$ PBS resuspendiert und zu gleichen Teilen auf vier Eppendorf-Tubes verteilt. Die Proben wurden zentrifugiert und in je $1 \mathrm{ml}$ eiskaltem Puffer A (10 mM HEPES, $10 \mathrm{mM} \mathrm{KCl,} \mathrm{0,1} \mathrm{mM} \mathrm{EDTA,} \mathrm{0,1} \mathrm{mM}$ EGTA, $1 \mathrm{mM}$ DTT, 0,5 mM PMSF, pH 7,4) resuspendiert. Nach einer fünfzehnminütigen Inkubation auf Eis wurden $65 \mu 1 \mathrm{NP}-40(10 \% \mathrm{v} / \mathrm{v})$ zugesetzt und die Ansätze ,gevortext“. Schließlich wurden die Ansätze erneut zentrifugiert und die Sedimente in jeweils $125 \mu$ Puffer C (20 mM HEPES, 0,4 M NaCl, 1 mM EDTA, 1 mM EGTA, 1 mM DTT, pH 7,9) aufgenommen und im Kühlraum vorsichtig für 15 min geschüttelt. Nach Zentrifugation des Extraktes $(5 \mathrm{~min})$ wurden die Überstände in Aliquots schockgefroren und bei $-80^{\circ} \mathrm{C}$ gelagert.

Für die DNA-Bindungsreaktion wurden in $20 \mu$ Reaktionsvolumen 1 x DNABindungspuffer (10 mM Tris- $\mathrm{HCl}, 50 \mathrm{mM} \mathrm{NaCl}, 1 \mathrm{mM}$ Dithiothreitol, $1 \mathrm{mM}$ EDTA, 10\% Glycerol) mit $1 \mu \mathrm{g}$ Poly(dA-dT) (Amersham Pharmacia Biotech), $2 \mu \mathrm{g}$ Kernextrakte mit je 5 fmol Wildtyp Oligonukleotid, 5 fmol Wildtyp Oligonukleotid plus Wildtyp Kompetitor, 5 fmol Wildtyp Oligonukleotid plus „Mutante“-Kompetitor, 5 fmol Wildtyp Oligonukleotid plus spezifischen Antikörper oder 5 fmol mutiertes Oligonukleotid neben einer Leerkontrolle angesetzt und für $45 \mathrm{~min}$ bei $4^{\circ} \mathrm{C}$ inkubiert. Als Kompetitor der DNA-Protein-Bindungsreaktion zwischen Wildtyp Oligonukleotid und Kernextrakt wurden nicht radioaktiv markierte Wildtyp oder mutierte 
Oligonukleotide in 100facher Konzentration verwendet. In der „Supershift-Reaktion“ wurden die spezifischen Antikörper (Tabelle 2.5) zwischen $1 \mathrm{~h}$ und $12 \mathrm{~h}$ bei $4^{\circ} \mathrm{C}$ mit

Tabelle 2.4

\begin{tabular}{|c|c|c|c|}
\hline $\mathbf{N r}$ & Name (DS) & Sequenz & Komplementäre Sequenz \\
\hline 1 & GKLF WT (-1190) & CTAGCcctccggcagtttctgaaagtaggaaaggttacC & catggGTAACCTTTCCTACTTTCAGAAACTGCCGGAGGg \\
\hline 2 & GKLF MT (-1190) & CTAGCcctccggcagtttctgaaagtaggaactgttacC & catggGTAACAGTTCCTACTTTCAGAAACTGCCGGAGGg \\
\hline 3 & NF-kB WT (-1011) & CTAGCgccggggecccaggtctggaC & catggTCCAGACCTGGGGCCCCGGCg \\
\hline 4 & NF-kB MT (-1011) & CTAGCgccggggecccetttctggaC & catggTCCAGAAAGGGGGCCCCGGCg \\
\hline 5 & ERE WT (-953) & CTAGCgctggaagtcgggectccta $\mathrm{C}$ & catggTAGGAGGCCCGACTTCCAGCg \\
\hline 6 & ERE MT (-953) & CTAGCgctggaggtcttgcctactaC & catggTAGTAGGCAAGACCTCCAGCg \\
\hline 7 & CMYB WT (-819) & CTAGC cagggtcaaggccgttgtggctggC & catggCCAGCCACAACGGCCTTGACCCTGg \\
\hline 8 & CMYB MT (-819) & CTAGC cagggtcaaggecgecatggctggC & catggCCAGCCATGGCGGCCTTGACCCTGg \\
\hline 9 & WT/SP1 WT (-291) & CTAGCgcgagcggegcgcgggcggggC & catggCCCCGCCCGCGCGCCGCTCGCg \\
\hline 10 & WT/SP1 MT (-291) & CTAGCgcgagcggegcgcgttttgggC & catggCCCAAAACGCGCGCCGCTCGCg \\
\hline 11 & E2F WT (-202) & CTAGCcacagacgcccaggaccgcgcttC & catggAAGCGCGGTCCTGGGCGTCTGTGg \\
\hline 12 & E2F MT (-202) & CTAGCcacagacgeccaggacttttcttC & catggAAGAAAAGTCCTGGGCGTCTGTGg \\
\hline 13 & E-box WT (-177) & CTAGCccacgtggeggaC & catggTCCGCCACGTGGg \\
\hline 14 & E-box MT (-177) & CTAGCccctttggeggaC & catggTCCGCCAAAGGGg \\
\hline 15 & SP1 WT (-99) & CTAGCcagctccgectcctcegcgeggaccecgeccegtccC & catggGGACGGGGCGGGGTCCGCGCGGAGGAGGCGGAGCTGg \\
\hline 16 & SP1 MT1 (-99) & CTAGCcagctccaattcetcegcgeggacccegccecgtccC & catggGGACGGGGCGGGGTCCGCGCGGAGGAATTGGAGCTGg \\
\hline 17 & SP1 MT2 (-99) & CTAGCcagctcegcetcetcegcgeggaccttacccegtccC & catggGGACGGGGTAAGGTCCGCGCGGAGGAGGCGGAGCTGg \\
\hline 18 & SP1 MT1+2 (-99) & CTAGCcagctccaattcctccgegcggacettaccccgtccC & catggGGACGGGGTAAGGTCCGCGCGGAGGAATTGGAGCTGg \\
\hline 19 & SP1 WT (-48) & CTAGCcggeccagcccectecgggeccteccagcccctcC & catggGAGGGGCTGGGAGGGCCCGGAGGGGGCTGGGCCGg \\
\hline 20 & SP1 MT1 (-48) & CTAGCcggeccattaccetccgggecctcccagcccctcC & catggGAGGGGCTGGGAGGGCCCGGAGGGTAATGGGCCGg \\
\hline 21 & SP1 MT2 (-48) & CTAGCcggeccagccecetccgggecetcccattacctcC & catggGAGGTAATGGGAGGGCCCGGAGGGGGCTGGGCCGg \\
\hline 22 & SP1 MT1+2 (-48) & CTAGCcggeccattaccetcegggecetcceattacctcC & catggGAGGTAATGGGAGGGCCCGGAGGGTAATGGGCCGg \\
\hline 23 & E2F WT (-259) & CTAGCccagaccccegggtccgcceggC & catggCCGGGCGGACCCGGGGGTCTGGg \\
\hline 24 & E2F MT (-259) & CTAGCccagacctgtccetcegcceggC & catggCCGGGCGGAGGGACAGGTCTGGg \\
\hline 25 & WT/SP1 WT (-291)kurz & CTAGCgcgcgggcggggC & catggCCCCGCCCGCGCg \\
\hline 26 & WT/SP1 MT (-291)kurz & CTAGCgcgcttttgggC & catggCCCAAAAAGCGCg \\
\hline 27 & E2F WT (-281) & CTAGCaagcgeggecC & ctaggGGCCGCGCTTg \\
\hline 28 & E2F MT (-281) & CTAGCaagtttgccC & ctaggGGCAAAACTTg \\
\hline 29 & E2F WT (-266) & CTAGCcceccgggtcC & catggGACCCGGGGGg \\
\hline 30 & E2F MT (-266) & CTAGCcctgtttttcC & catggGAAAAACAGGg \\
\hline 31 & SP1 WT (-121) & CTAGCgctcegectcctC & catggAGGAGGCGGAGCg \\
\hline 32 & SP1 MT (-121) & CTAGCgctccttttcctC & catggAGGAAAAGGAGCg \\
\hline 33 & SP1 WT (-101) & CTAGCgaccecgeccegtC & catggACGGGGCGGGGTCg \\
\hline 34 & SP1 MT (-101) & CTAGCgacttttcttcgtC & catggACGAAGAAAAGTCg \\
\hline 35 & SP1 WT (-66) & CTAGCtccceggeccagccecetC & catggAGGGGGCTGGGCCGGGGAg \\
\hline 36 & SP1 MT (-66) & CTAGCtcettggttcatttcctC & catggAGGGAAATGAACCAAGGAg \\
\hline 37 & E2F WT (-188) & CTAGCgaccgcgcttcC & catggGAAGCGCGGTCg \\
\hline 38 & E2F MT (-188) & CTAGCgacttttcttcC & catggGAAGAAAAGTCGg \\
\hline 39 & E2F WT (-210) & CTAGCgattcgcgggcaC & catggTGCCCGCGAATCg \\
\hline 40 & E2F MT $(-210)$ & CTAGCgattttttggcaC & catggTGCCAAAAAATCg \\
\hline
\end{tabular}

Auflistung aller hergestellten Oligonukleotide für EMSA mit entsprechendem Namen und Sense und Antisense Sequenz der doppelsträngigen DNA. Die angefügten Basenpaare entsprechen der Nhe I Restriktionsenzym Schnittstelle. 
den Oligonukleotiden vorinkubiert. Die DNA-Protein-Komplexe wurden bei $4^{\circ} \mathrm{C}$ in einem nativen PAA-Gel (6\% Acrylamid/Bisacrylamid (19:1), 0,04\% TEMED und $0,06 \%$ APS in 0,25x TBE), das vor der Beladung einem Vorlauf $\left(1 \mathrm{~h}, 15 \mathrm{~mA} / \mathrm{Gel}, 4^{\circ} \mathrm{C}\right.$ in $1 \mathrm{x}$ TBE) unterzogen wurde, aufgetrennt $\left(2 \mathrm{~h}, 15 \mathrm{~mA} / \mathrm{Gel}, 4^{\circ} \mathrm{C}\right.$ in $\left.1 \mathrm{x} \mathrm{TBE}\right)$. Nach der Auftrennung wurde das Gel auf zwei Lagen Whatmanpapier im Geltrockner bei $80^{\circ} \mathrm{C}$ für $1 \mathrm{~h}$ getrocknet. Die Detektion radioaktiver Banden erfolgte durch Exposition eines „Phosphoimager-Screens“ für mindestens 20 min bei RT und anschließendem Einlesen der Daten im Phosphoimager und/oder Röntgenfilmexposition (Kodak X-AT bei $-80^{\circ} \mathrm{C}$ für $12 \mathrm{~h}$ ).

\section{Tabelle 2.5}

\begin{tabular}{llllcc}
\hline Name & Katalog Nr. & Eigenschaft & Hersteller & EMSA & Western Blot \\
\hline c-myc & sc-764 X & rabbit anti human polyclonal & Santa Cruz & $1: 10$ & $1: 2000$ \\
SP1 & sc-420 & mouse anti human monoclonal & Santa Cruz & $1: 10$ & $1: 2000$ \\
p53 & 554147 & mouse anti human monoclonal & Becton Dickinson & - & $1: 2000$ \\
pRb & 554236 & mouse anti human monoclonal & Becton Dickinson & - & $1: 2000$ \\
E2F-1 & sc-193 X & rabbit anti human polyclonal & Santa Cruz & $1: 10$ & $1: 2000$ \\
E2F-6 & sc-8176 X & goat anti human polyclonal & Santa Cruz & $1: 10$ & - \\
Cyclin D1 & sc-753 & rabbit anti human polyclonal & Santa Cruz & - & $1: 2000$ \\
anti rabbit Ig & NA 934 & donkey anti rabbit, sek.AK & Amersham & - & $1: 5000$ \\
anti mouse Ig & NA 931 & sheep anti mouse, sek. AK & Amersham & - & $1: 5000$ \\
\hline
\end{tabular}

Antikörper für Western-Blot und EMSA mit verwendeter Verdünnung

\subsection{MSP (Methylierungs Spezifische PCR)}

Die Methylierungs spezifische PCR (MSP) ist eine einfache und schnelle Methode um den Methylierungstatus von sog. CpG-Inseln in einem Gen oder Promotor zu bestimmen. CpG-Inseln sind definiert als DNA-Sequenzen mit einem sehr hohen Gehalt an Cytosin und Guanin, deren Methylierung die Expression eines bestimmten Gens unterdrücken kann. Um eine Unterscheidung zwischen methylierten und unmethylierten Promotorregionen zu ermöglichen, werden die zu untersuchenden DNA Abschnitte mit Natriumbisulfit behandelt, das nur unmethyliertes Cytosin in Urazil umwandelt und mit methylierten Cytosinen nicht reagieren kann. Diese Technik erlaubt es in der nachfolgenden PCR den Methylierungsstatus der ausgewählten Promotorregion zu bestimmen, indem man zwei verschiedene Primer-Paare spezifisch entweder für unmethylierte DNA (mit in Uracil umgewandeltem Cytosin) oder für methylierte DNA (mit erhaltenem Cytosin), verwendet. 
Zuerst haben wir den hTERT-Promotor mittels „MethPrimer“ auf CpG-Inseln untersucht, die einen GC-Gehalt von mehr als 50\% haben und länger als 100 bp sind (www.dahiyaurology.com/cgi-bin/methprimer.cgi). Aus den möglichen drei CpG-Inseln wurden die beiden 5' gelegenen ausgesucht, um diese als potenzielle Silencer Regionen genauer zu untersuchen. Region I liegt zwischen -852 bp und -728 bp und Region II zwischen -635 bp und -438 bp. Die entsprechenden spezifischen Primer wurden ebenfalls mit dem Programm „,MethPrimer" hergestellt (Tabelle 2.6).

\begin{tabular}{|c|c|c|}
\hline Name MSP Primer & Nukleotidsequenz & Temperatur (variiert) \\
\hline hTERTmeth 390sense & 5' GTGTCGGGGTTTAGGGTTAAGGTC 3' & $65,6^{\circ} \mathrm{C}\left(62^{\circ} \mathrm{C}\right)$ \\
\hline hTERTmeth390antisense & $5^{\prime}$ TCTATTAATCACCCACCGAAACGAT 3' $^{\prime}$ & $65,6^{\circ} \mathrm{C}\left(62^{\circ} \mathrm{C}\right)$ \\
\hline hTERTunmeth390sense & 5' TGTTGGGGTTTAGGGTTAAGGTTGT 3' & $64,3^{\circ} \mathrm{C}\left(62^{\circ} \mathrm{C}\right)$ \\
\hline hTERTunmeth390antisense & 5' TCTATTAATCACCACCAAAACAAT 3' & $64,3^{\circ} \mathrm{C}\left(62^{\circ} \mathrm{C}\right)$ \\
\hline hTERTmeth607sense & 5' GGAAGTGTTGTAGGGAGGTATTTC 3' & $67,4^{\circ} \mathrm{C}\left(64^{\circ} \mathrm{C}\right)$ \\
\hline hTERTmeth607antisense & 5' CTTTAACCGCTAACCTAATCCG 3' & $67,4^{\circ} \mathrm{C}\left(64^{\circ} \mathrm{C}\right)$ \\
\hline TERTunmeth607sense & 5' GGAAGTGTTGTAGGGAGGTATTTT 3' & $66,2^{\circ} \mathrm{C}\left(64^{\circ} \mathrm{C}\right)$ \\
\hline hTERTunmeth607antisense & 5' CCTTTAACCGCTAACCTAATCCAAA $3^{\prime}$ & $66,2^{\circ} \mathrm{C}\left(64^{\circ} \mathrm{C}\right)$ \\
\hline
\end{tabular}

Primer für MSP mit jeweils einem spezifischen Primer für methylierte und unmethylierte Proben der Regionen I von -852 bp bis -728 bp (390) und II von -635 bp bis -438 bp (607). Rechts sind die unterschiedlichen Annealing Temperaturen angegeben, in Klammern steht der verwendete Wert.

2,5 $\mu \mathrm{g}$ genomische DNA der fünf Zelltypen wurden in $50 \mu 1$ destilliertem Wasser aufgenommen und mit $5,5 \mathrm{ml} 2 \mathrm{M} \mathrm{NaOH}$ für 10 min bei $37^{\circ} \mathrm{C}$ inkubiert. Danach wurden $30 \mu 10 \mathrm{mM}$ Hydrochinone und $520 \mu 13 \mathrm{M}$ Natriumbisulfit dazugegeben und der Ansatz $18 \mathrm{~h}$ bei $50^{\circ} \mathrm{C}$ inkubiert. Dem Protokoll des Herstellers folgend wurden dann $1 \mathrm{ml}$ „DNA WIZARD cleanup“ (Promega A7280) dazugegeben, die Mischung auf eine Vakuum Miniprep Säule gegeben und mittels Vakuumpumpe filtriert. Der Filter wurde zweimal mit $80 \%$ Isopropanol gewaschen und die DNA mit $50 \mu 170^{\circ} \mathrm{C}$ heißem Wasser eluiert. Mittels Ethanolpräzipitation bei $-80^{\circ} \mathrm{C}$ wurde die DNA präzipitiert und in $30 \mu 1$ TE-Puffer (pH 7,6) gelöst. Die PCR wurde mit Heißstart bei $94^{\circ} \mathrm{C}$, mit 1 Unit TaqPolymerase und je 10 pmol/1 Primer in einem $50 \mu \mathrm{l}$ Ansatz, mit zwei verschiedenen PCR-Programmen (Tabelle 2.7), jeweils spezifisch für die methylierten und unmethylierten Proben, durchgeführt. Nach Beendigung der PCR wurden die Amplifikationsprodukte (124 bp und 197 bp) auf einem 2\% Agarosegel ausgewertet. 
Tabelle 2.7

\begin{tabular}{lcccc}
\hline RT-PCR Schritt & Zyklen & Region I & Region II & Zeit \\
\hline Vorabdenaturierung & 1 & $94^{\circ} \mathrm{C}$ & $94^{\circ} \mathrm{C}$ & $5 \mathrm{~min}$ \\
Denaturierung & 35 & $94^{\circ} \mathrm{C}$ & $94^{\circ} \mathrm{C}$ & $30 \mathrm{sec}$ \\
Annealing & 35 & $62^{\circ} \mathrm{C}$ & $64^{\circ} \mathrm{C}$ & $30 \mathrm{sec}$ \\
Extension & 35 & $72^{\circ} \mathrm{C}$ & $72^{\circ} \mathrm{C}$ & $30 \mathrm{sec}$ \\
Extension & 1 & $72^{\circ} \mathrm{C}$ & $72^{\circ} \mathrm{C}$ & $10 \mathrm{~min}$ \\
Kühlen & 1 & $4^{\circ} \mathrm{C}$ & $4^{\circ} \mathrm{C}$ & $\infty$
\end{tabular}

PCR-Programm für Methylierungs spezifische PCR. Region I reicht von 852 bp bis -728 bp und Region II von -635 bp bis -438 bp. Zwei Programme waren notwendig, da die Primer für die beiden Regionen nicht identische Annealing Temperaturen hatten.

\subsection{RT-PCR (Reverse Transkriptase Polymerase Chain Reaction)}

Die Reverse Transkriptase Polymerase Kettenreaktion (RT-PCR) ist eine empfindliche Methode zum Nachweis spezifischer mRNA. Die für die Präparation benötigten Chemikalien wurden ausschließlich für diesen Zweck verwendet. Als Lösungsmittel wurde steriles pyrogenfreies Wasser verwendet. Alle Präparationsschritte wurden auf Eis durchgeführt. Nachdem die Zellen trypsiniert, mit PBS gewaschen und abzentrifugiert waren, wurde die RNA-Isolierung nach dem Qiagen RNeasy Protokoll durchgeführt. Nach Trypsinierung und Waschen mit PBS wurden $1 \times 10^{6}$ Zellen mit 350 $\mu l$ Puffer RLT resuspendiert und nach Zugabe von $350 \mu$ l 70\% Ethanol auf eine RNeasy Minisäule gegeben und zentrifugiert. Die Minisäule wurde auf ein neues Sammelgefäß transferiert, mit $700 \mu 1$ Puffer RW1 zentrifugiert und zweimal mit $500 \mu 1$ Puffer RPE gewaschen. Nach Transfer der Minisäule auf ein frisches 1,5 ml EppendorfGefäß und nach Zugabe von $30 \mu 1$ RNase-freiem Wasser wurde bei RT 5 min inkubiert und 2 min zentrifugiert. Dieser Elutionsschritt wurde wiederholt. Nach der photometrischen Messung zur Quantifizierung und Reinheitsbestimmung bei einer Wellenlänge von $260 \mathrm{~nm}$ wurde die mRNA auf eine Konzentration von $0,5 \mu \mathrm{g} / \mu \mathrm{l}$ eingestellt und bei $-80^{\circ} \mathrm{C}$ aufbewahrt. Die RNA wurde mittels Superscript ${ }^{\mathrm{TM}} \mathrm{RNase}^{-}$ Reverse Transkriptase System von Invitrogen unter Verwendung des beiliegenden Protokolls in cDNA umgewandelt. $10 \mu \mathrm{g} / \mu \mathrm{l}$ Gesamt-RNA wurden in Gegenwart von 1 $\mu 1$ oligo p(dT)15-Primer und $1 \mu 110 \mathrm{mM}$ dNTP's für 5 min bei $65^{\circ} \mathrm{C}$ inkubiert. Danach wurden $4 \mu 15$ x First Strand Puffer (250 mM Tris-HCl, pH 8,3 bei RT; $375 \mathrm{mM} \mathrm{KCl}$; $15 \mathrm{mM} \mathrm{MgCl} 2$ ), $2 \mu \mathrm{l}$ 0,1 M DTT und $1 \mu \mathrm{RNase-Inhibitor} \mathrm{für} 2 \mathrm{~min}$ bei $37^{\circ} \mathrm{C}$ inkubiert. Die cDNA-Erststrangsynthese wurde durch Zugabe von $2 \mu$ l (200 U) Superscript Reverse Transkriptase und 50 min Inkubation bei $37^{\circ} \mathrm{C}$ durchgeführt. Die nachfolgende 
PCR wurde mit einem Gesamtvolumen von $50 \mu 1$ mit je $1 \mu 1$ der Primer hTRTF3 und hTRTR7 und $2 \mu \mathrm{l}$ cDNA durchgeführt (Tabelle 2.8). Nach Beendigung der RT-PCR erfolgte die Auswertung der Amplifikationsprodukte (250 bp) mittels 2\% Agarosegel.

\begin{tabular}{|c|c|c|c|}
\hline RT-PCR Schritt & Zyklen & Temperatur & Zeit \\
\hline Vorabdenaturierung & 1 & $94^{\circ} \mathrm{C}$ & $5 \mathrm{~min}$ \\
\hline Denaturierung & 30 & $94^{\circ} \mathrm{C}$ & $45 \mathrm{sec}$ \\
\hline Annealing & 30 & $60^{\circ} \mathrm{C}$ & $45 \mathrm{sec}$ \\
\hline Extension & 30 & $72^{\circ} \mathrm{C}$ & $90 \mathrm{sec}$ \\
\hline Extension & 1 & $72^{\circ} \mathrm{C}$ & $15 \mathrm{~min}$ \\
\hline Kühlen & 1 & $4^{\circ} \mathrm{C}$ & $\infty$ \\
\hline
\end{tabular}

\subsection{Real Time PCR}

Das Real Time PCR-System basiert auf dem kontinuierlichen Monitoring und der damit verbundenen quantitativen Bestimmung eines Leuchtstoffreporters, dessen Signal sich direkt proportional zur Menge des PCR-Produktes in vorgegebener Reaktion erhöht. Indem man die Menge der Fluoreszenzemission jedes Zyklus registriert, ist es möglich, die PCR-Reaktion während der exponentialen Phase zu überwachen und so die Expression einer mRNA zu bestimmen.

Die RNA wurde wie zuvor beschrieben aus allen fünf Zelltypen isoliert, in cDNA umgewandelt und auf eine Konzentration von $100 \mathrm{ng} / \mu \mathrm{l}$ eingestellt. Als Probe und Primer wurde ein von Applied-Biosystems hergestellter Assay on Demand für die Expression von Telomerase verwendet. Der für die PCR erforderliche Master Mix mit Farbstoff (TAMRA), Polymerase, Puffer und dNTP's wurde von der Firma ABgene verwendet. Nachdem der Standard für die quantitative PCR-Reaktion mit einer Verdünnungsreihe im Verhältnis 1:4, 1:16, 1:64, 1:256 und 1:1024 der cDNA von TE12 Zellen, die hier als Positivkontrolle verwendet wurden, eingestellt war, wurde die quantitative PCR im Triplikat mit je 100 ng cDNA der fünf Zelltypen durchgeführt. Die Reaktion beinhaltete $15 \min 95^{\circ} \mathrm{C}$ und 40 Zyklen mit $45 \sec 95^{\circ} \mathrm{C}$ und $60 \sec 60^{\circ} \mathrm{C}$. Die Ergebnisse wurden mit dem Programm ABI SDS 1.9.1 ausgewertet und ausgedruckt. 


\subsection{TRAP-Assay (Telomeric Repeat Amplification Protocol)}

Der TRAP (telomeric repeat amplification protocol)-Assay beruht auf der Entdeckung, dass Telomerase in der Lage ist, nicht nur natürliche Telomere mit den entsprechenden Telomer-Hexameren zu verlängern, sondern auch künstlich angebotene Oligonukleotide zu erkennen und zu verlängern.

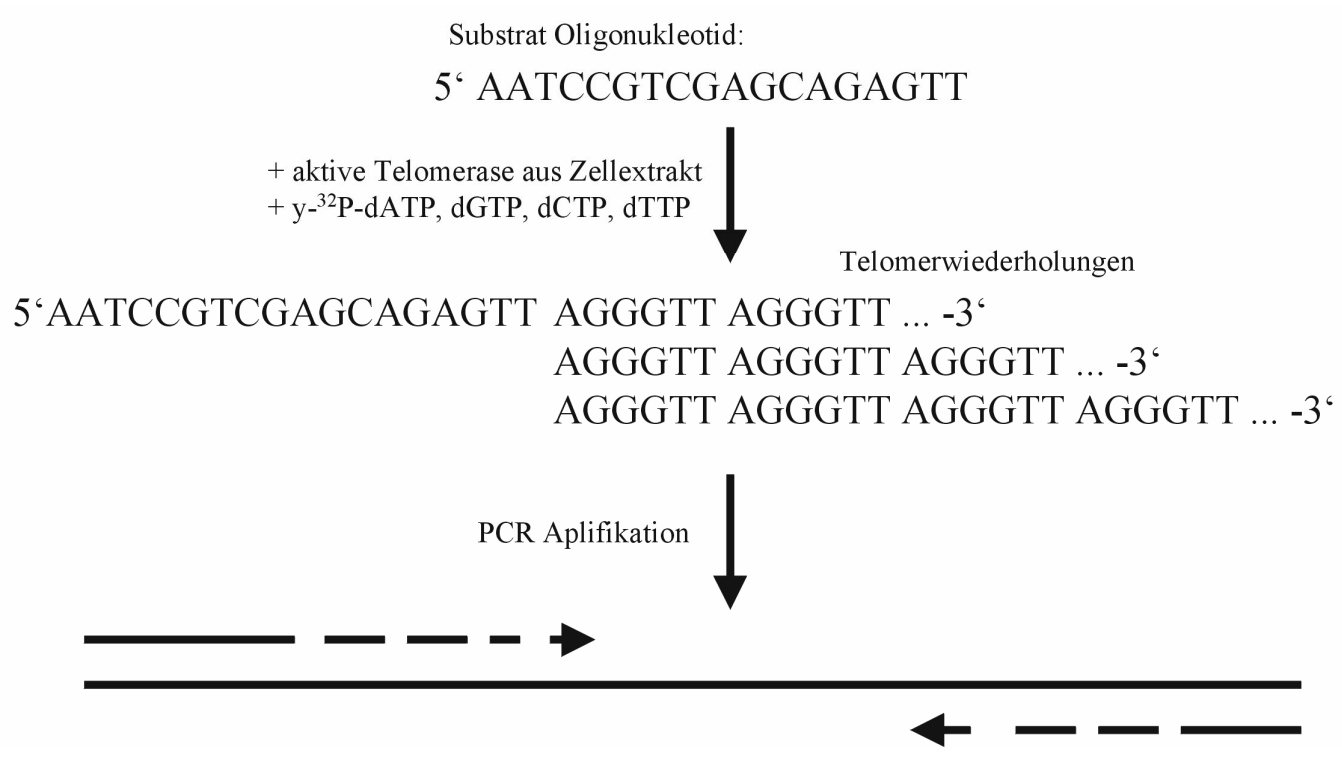

Abbildung 2.3: Schematische Darstellung des TRAP-Assay

Proteinextrakt aus den verwendeten Zellen wird zu einem solchen Oligonukleotid als „Template“ gegeben und mit ausreichend Nukleotiden inkubiert (Abbildung 2.3). Wenn im Proteinextrakt Telomerase vorhanden ist, wird das „Template“ verlängert, die verschieden langen Produkte anschließend mittels PCR amplifiziert und auf einem Polyacrylamid-Gel dargestellt. Die Intensität der sichtbaren Bandenleiter entspricht der Aktivität der Telomerase im verwendeten Zellextrakt.

Um den für die Amplifikation von 14 Doppelansätzen notwendigen TS-Primer (5' AATCCGTCGAGCAGAGTT 3') radioaktiv zu markieren wurden unter Verwendung des „TRAPeze ${ }^{\circledR}$ “ Protokolls von Intergen $36 \mu$ TS-Primer mit 7,2 $\mu 1$ T4-Kinase-Puffer (10x, New England BioLabs), $9 \mu 1 \gamma_{-}{ }^{32} \mathrm{P}-\mathrm{ATP}$ (Amersham), $20 \mathrm{U}$ T4-Kinase und $\mathrm{H}_{2} \mathrm{O}$ auf $72 \mu \mathrm{l}$ Gesamtzvolumen gebracht und $20 \mathrm{~min}$ bei $37^{\circ} \mathrm{C}$ inkubiert. Anschließend wurde die Probe mittels Nucleotid Removal Kit von Qiagen aufgereinigt und mit EBPuffer auf $200 \mu \mathrm{l}$ verdünnt. Nach dem TRAPeze ${ }^{\circledR}$-Protokoll wurde ein Master Mix für die Telomerase Reaktion und die anschließende PCR mit je $2 \mu 1{ }^{32} \mathrm{P}$-TS Primer Mix, 5 
$\mu 1$ TRAP 10 x Puffer, $1 \mu 150$ x dNTP Mix, $1 \mu 1$ TRAPeze ${ }^{\circledR}$ Primer Mix, 2 U TaqPolymerase und 38,6 $\mu \mathrm{ldd} \mathrm{H}_{2} \mathrm{O}$ angesetzt und $\mathrm{zu}$ je $500 \mu \mathrm{g}$ hitzeinaktiviertem oder nicht mit Hitze behandeltem Proteinextrakt hinzugegeben. Als allgemeine Reaktionskontrollen wurde ein vom Hersteller mitgelieferter Telomerase positiver Zellextrakt mit je 500 Zellen, eine Leerkontrolle mit nur CHAPS Lysis Puffer und zur Intensitätsbestimmung je $1 \mu 1$ und $2 \mu 1$ mitgeliefertes Kontrolltemplate verwendet. Die Telomerase Reaktion wurde 30 min bei $30^{\circ} \mathrm{C}$ im PCR-Block durchgeführt, bevor die PCR mit $94^{\circ} \mathrm{C}$ für $5 \mathrm{~min}, 27$ Zyklen mit je $30 \mathrm{sec} 94^{\circ} \mathrm{C}$ und $59^{\circ} \mathrm{C}$ und einer Extension von 10 min bei $72^{\circ} \mathrm{C}$ verlief. Das PCR-Produkt wurde in einem nativen PAA-Gel $(6 \%$ Acrylamid/Bisacrylamid (19:1), 0,04\% TEMED und 0,06\% APS in 0,5 x TAE) aufgetrennt ( 2 h, $300 \mathrm{~V}$ in 0,5 x TAE). Das Gel wurde nach der Auftrennung auf zwei Lagen Whatmanpapier im Geltrockner bei $80^{\circ} \mathrm{C}$ für $1 \mathrm{~h}$ getrocknet. Die Detektion radioaktiver Banden erfolgte durch Exposition eines Phosphoimager-Screens für mindestens 20 min bei RT und anschließendes Einlesen der Daten im Phosphoimager und/oder Röntgenfilmexposition (Kodak X-OMAT bei $-80^{\circ} \mathrm{C}$ für $12 \mathrm{~h}$ ).

\subsection{TRF (Telomere Restriction Fragments)}

Zur DNA-Gewinnung wurden die jeweiligen Zellen trypsiniert, pelletiert und die DNA aus dem Zellpellet mit dem Purgene DNA Extraction Kit nach Angabe des Herstellers isoliert. Dazu wurden $5 \times 10^{6}$ Zellen mit $300 \mu$ Cell Lysis Solution 30 min auf Eis lysiert, mit $1,5 \quad \mu \mathrm{l}$ RNase A für 5 min bei $37^{\circ} \mathrm{C}$ inkubiert, mit Proteinpräzipitationslösung versetzt und zentrifugiert. Die DNA wurde mit 100\% Isopropanol aus dem Überstand präzipitiert, zentrifugiert, mit 70\% Ethanol gewaschen und nach 10 min Trocknen in $50 \mu \mathrm{l}$ DNA Hydration Solution eine Stunde bei $65^{\circ} \mathrm{C}$ und dann über Nacht bei RT gelöst. Nach der photometrischen Messung zur Quantifizierung und Reinheitsbestimmung bei einer Wellenlänge von $260 \mathrm{~nm}$ und $280 \mathrm{~nm}$ wurden $5 \mu \mathrm{g}$ DNA mit den Restriktionsendonukleasen Hinf I und Rsa I und Puffer 2 (New England BioLabs) über Nacht verdaut und der Verdau durch Gelelektrophorese kontrolliert. Nach der Southern Blot Methode wurden die DNA-Fragmente mit AgaroseGelelektrophorese $(0,5 \%)$ aufgetrennt, denaturiert und auf eine immobilisierende Nylonmembran übertragen. Nach Auftrennung der DNA durch Gelelektrophorese wurde das Gel unter UV-Licht mit angelegtem Lineal fotografiert. Danach wurde das Gel für jeweils 15 min in $\mathrm{HCl}, 45$ min in Denaturierungslösung und zweimal 20 min in Neutralisierungslösung geschwenkt und im Anschluss nach Schema (Abbildung 2.4) 
mit 20 x SSC (Transferpuffer) über Nacht auf eine Nylonmembran (Hybond $\mathrm{N}+$ ) „geblottet“. Eine Hybridisierung ermöglicht es, mit einer markierten DNA-Sonde Nukleinsäuremoleküle in einer Ziel-DNA nachzuweisen, deren Sequenzen komplementär zur Basenfolge der Sonde sind. Dafür wurde die „DNA-Seite“ der Membran markiert, durch UV-Bestrahlung (20 sec) fixiert (,,cross-link“) und in eine Glasröhre gerollt. Vor der eigentlichen Hybridisierung inkubiert man die Membran mit der fixierten DNA für einige Stunden mit einer Prähybridisierungslösung $(15 \mathrm{ml}$ Hybmix, Stratagene) ohne Zugabe einer Sonde. In der Zwischenzeit wurde die Sonde mit 5 pmol Primer (TRF) in einer $20 \mu 1$ T4-Kinase Reaktion $\left(2 \mu 1\right.$ Puffer, $5 \mu 1$ [p $^{32} \gamma$ ATP]) radioaktiv markiert, mittels Nucleotid Removal Kit aufgereinigt und mit $300 \mu 1$ Häringsperma versetzt. Nachfolgend wurde das radioaktiv markierte Oligonukleotid in den „Hybmix Puffer“ gegeben und $4 \mathrm{~h}$ im Rotationsofen bei $37^{\circ} \mathrm{C}$ inkubiert. Die Membran wurde dann 30 min mit 2x SSC, 0,1\% SDS und anschließend 2 x 8 min mit $0,2 \mathrm{SSC}, 0,1 \%$ SDS jeweils bei $42^{\circ} \mathrm{C}$ gewaschen. Die Membran wurde feucht in Plastikfolie verpackt und in einer Filmkassette bei $-80^{\circ} \mathrm{C}$ mit einem Kodak X-OMAT AR-Röntgenfilm autoradiographiert.

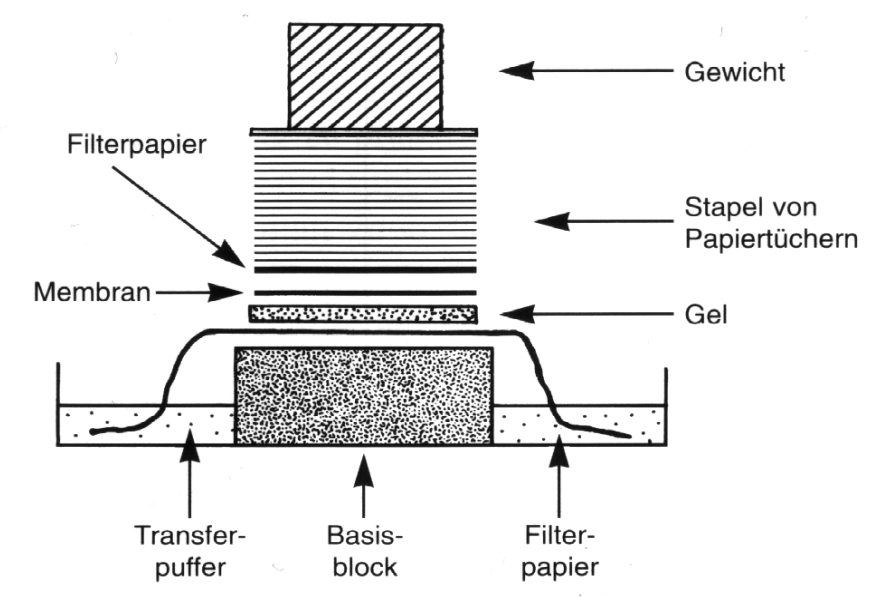

Abbildung 2.4

Blot-Aufbau (Nicholl 1995):

- Transferpuffer $=10 \times \mathrm{SSC}$

- Basis-Block = Schwamm

- Filterpapier = 3 Schichten MMWhatmanpapier

- Gel = Agarosegel mit aufgetrennter DNA

- Membran = Hybond N+Filter

- Gewicht $=300-500 \mathrm{~g}$ Bleigewicht

\subsection{Western Blot Analyse}

Zur Detektion von Proteinen mit einem spezifischen Antikörper wurde ein Western Blot durchgeführt. Dabei wird ein zellulärer Proteinextrakt elektrophoretisch aufgetrennt, auf eine Membran überführt und dort einer Nachweisreaktion unterzogen. Die Proteine werden hierbei auf der Membranoberfläche immobilisiert. Das Basisprotokoll umfasst die Proteinauftrennung mittels denaturierender, diskontinuierlicher SDSGelelektrophorese, den elektrophoretischen Transfer auf eine Membran, das 
anschließende Blockieren, die Inkubation mit primärem und sekundärem Antikörper sowie die Chemolumineszenzreaktion.

Die Zellkulturplatte der jeweiligen Zellen wurde zweimal mit kaltem PBS gewaschen, die Zellen mit $1 \mathrm{ml}$ ELB-Puffer versetzt (DTT (2 mM), PMSF (20 mM) und ProteaseInhibitor-Cocktail) und auf Eis mit einem Zellschaber möglichst vorsichtig von der Platte gelöst. Nach 20 min Inkubation auf Eis wurde der Überstand vorsichtig abgenommen, in ein zweites $1,5 \mathrm{ml}$-Rörchen pipettiert und bei $-80^{\circ} \mathrm{C}$ gelagert oder die Proteinextrakte direkt weiter verwendet.

Tabelle 2.9

\begin{tabular}{|c|c|c|c|}
\hline Reagenzien & $\begin{array}{c}\text { 6\%-Separierungsgel } \\
\left(, \text { unteres Gel }{ }^{6}\right)\end{array}$ & $\begin{array}{c}\text { 10\%-Separierungsgel } \\
\left(, \text { unteres Gel }{ }^{\circ}\right)\end{array}$ & $\begin{array}{c}5,6 \%-S D S-P a g e \\
\left(, 0 b e r e s \text { Gel }{ }^{66}\right)\end{array}$ \\
\hline Aqua bidest & $4,1 \mathrm{ml}$ & $2,7 \mathrm{ml}$ & $6,6 \mathrm{ml}$ \\
\hline 30\% Acrylamid (BioRad) & $1,8 \mathrm{ml}$ & $3,33 \mathrm{ml}$ & $1,87 \mathrm{ml}$ \\
\hline $1 \mathrm{M}$ Tris- $\mathrm{HCl}, \mathrm{pH} 8,7$ & $3,8 \mathrm{ml}$ & $3,8 \mathrm{ml}$ & - \\
\hline $1 \mathrm{M}$ Tris- $\mathrm{HCl}, \mathrm{pH} 6,8$ & - & - & $1,25 \mathrm{ml}$ \\
\hline $10 \% \mathrm{SDS}$ & $100 \mu \mathrm{l}$ & $100 \mu \mathrm{l}$ & $100 \mu \mathrm{l}$ \\
\hline $10 \%$ Ammoniumpersulfat & $100 \mu \mathrm{l}$ & $100 \mu \mathrm{l}$ & $100 \mu \mathrm{l}$ \\
\hline TEMED (BioRad) & $10 \mu \mathrm{l}$ & $10 \mu \mathrm{l}$ & $10 \mu \mathrm{l}$ \\
\hline
\end{tabular}

Schema zur Herstellung der verschiedenen Separierungsgele und des Kamm-Gels bei der Western BlotAnalyse. 10\% Gele wurden für Proteine kleiner $80 \mathrm{kDa}$ und 6\% Gele für Proteine größer $80 \mathrm{kDa}$ gewählt. Das obere Gel wurde nur zur Herstellung der Taschen zur Probenaufnahme genutzt.

Es wurde zunächst ein SDS-Polyacrylamid-Gel als Separierungsgel (Prozentangabe siehe Tabelle 2.9) und ein 5,6\% ,oberes“ SDS-Polyacrylamid-Gel mit Kamm gegossen. Die Proteinproben wurden 1:1 im $20 \mu$ Ansatz mit Ladepuffer versetzt und 5 min bei $95^{\circ} \mathrm{C}$ hitzeinaktiviert. Das Gel wurde mit den Proben geladen und die ProteinElektrophorese (z.B. $90 \mathrm{~V}$ für ca. 120 min) mit 1 x „Running“-Puffer in einer BioRad Gelkammer für Western Blot durchgeführt. Nach der Elektrophorese wurde das Gel in 1 x Transferpuffer 30 min equilibriert. In der BioRad Transferkassette, im sog. „Blotsandwich“, wurden die Proteine vom Gel auf eine PVDF-Membran in $1 \mathrm{x}$ Transferpuffer bei in $4^{\circ} \mathrm{C}$ transferiert $(150 \mathrm{~V})$. Nach dem 75 -minütigem Transfer wurde die Membran, um eine unspezifische Bindung zu vermeiden, zunächst in $1 \mathrm{x}$ TBST gewaschen und dann in 10\% TBST-Milch für $6 \mathrm{~h}$ bei RT blockiert. Nach Zugabe des Primärantikörpers (Tabelle 2.5) erfolgte die Inkubation in 1\% TBST-Milch über Nacht bei $4^{\circ} \mathrm{C}$. Am nächsten Tag wurde die Membran dreimal für 20 min in TBST gewaschen und schließlich der Sekundärantikörper in TBST ca. 45-75 min bei RT inkubiert. 
Danach folgten drei Waschschritte à $5 \mathrm{~min}$. Die Detektion erfolgte über eine Chemolumineszenzreaktion mit ECL Plus Western Blot Detection Reagent (Amersham Biosciences). Die Membran wurde mit 8,0 ml ECL Reagenz und $200 \mu$ Substrat für 5 min bei RT inkubiert, auf einem Röntgenfilm exponiert (Chemolumineszenz) und ausgewertet.

\subsection{Lösungen und Reagenzien}

\section{Kulturmedien}

Medium zur Kultivierung von EPC, EPC-D1, EPC- $\Delta$ p53 und EPC-hTERT

$500 \mathrm{ml}$ Keratinocyte-SFM

$18,7 \mathrm{mg}$ Rinderhypophysenextrakt (BPE)

$15 \mu 1 \mathrm{rEGF}$

$5 \mathrm{ml}$ L-Glutamin

$5 \mathrm{ml}$ Penicillin/Streptomycin

Medium vor Gebrauch vier Stunden bei $4^{\circ} \mathrm{C}$ inkubiert

Medium zum Einfrieren von EPC, EPC-D1, EPC- $\Delta$ p53 und EPC-hTERT

$15 \mathrm{ml}$ DMEM-F12

$5 \mathrm{ml}$ FBS

$5 \mathrm{ml} \mathrm{DMSO}$

Medium bei $-20^{\circ} \mathrm{C}$ lagern und nur langsam auftauen.

Medium zur Kultivierung von Tumorzellen TE-12

$500 \mathrm{ml}$ DMEM

$50 \mathrm{ml} \mathrm{FBS}$

$5 \mathrm{ml} \mathrm{L-Glutamin}$

$5 \mathrm{ml}$ Penicillin/Streptomycin

Medium zum Einfrieren von Tumorzellen TE-12

$10 \mathrm{ml}$ DMEM

2,5 ml FBS

2,5 $\mathrm{ml}$ DMSO

Medium bei $-20^{\circ} \mathrm{C}$ lagern und nur langsam auftauen.

PBS (Invitrogen) $\quad 8 \mathrm{~g} / 1 \mathrm{NaCl}$

$0,2 \mathrm{~g} / 1 \mathrm{KCl}$

$1,15 \mathrm{~g} / 1$ Dinatriumhydrogenphosphat

0,2 g/1 Kaliumdihydrogenphosphat, $\mathrm{pH} 7,4$ 


\section{Lösungen}

$50 \times$ TAE

$5 \times$ TBE

$20 \times$ SSC

0,5 M EDTA

$1 \mathrm{M}$ Tris $\mathrm{HCl}$

$10 \times \mathrm{TE}$

Agarosegel-Probenpuffer $10 \mathrm{mM}$ Tris

1 mM EDTA

$50 \%(\mathrm{w} / \mathrm{v})$ Glycerin

0,05\% (w/v) Bromphenolblau, $\mathrm{pH} 7,2$

$2 \mathrm{M}$ Tris

1 M Essigsäure

100 mM EDTA, pH 8,1

$54 \mathrm{~g}$ Tris Base

27,5 g Borsäure

$5 \mathrm{ml} \mathrm{0,5} \mathrm{M}$ EDTA

$175,3 \mathrm{~g} \mathrm{NaCl}$

88,2 g Na-Citrat

wurden in 1,0 $1 \mathrm{H}_{2} \mathrm{O}$ bidest. gelöst, $\mathrm{pH}$ 7,0

181,1 g Dinatriumdiamintetraacetat x $2 \mathrm{H}_{2} \mathrm{O}$ wurden in $800 \mathrm{ml} \mathrm{ddH}_{2} \mathrm{O}$ gelöst, der $\mathrm{pH}$ mit konzentrierter Natronlauge auf 8,0 eingestellt, das Volumen auf 11 aufgefüllt und autoklaviert.

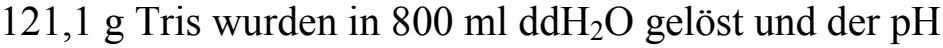
mit konzentrierter $\mathrm{HCl}$ auf 7,2 bis 9,0 eingestellt, das Volumen auf 1,0 1 aufgefüllt und autoklaviert.

$100 \mathrm{mM}$ Tris-HCl (pH 7,6)

$10 \mathrm{mM}$ EDTA

\section{Sammelgelpuffer SDS-PAGE (Stammlösung)}

$0,5 \mathrm{M}$ Tris- $\mathrm{HCl}$

$0,4 \%(\mathrm{w} / \mathrm{v}) \mathrm{SDS}, \mathrm{pH} 6,8$ 


\section{Trenngelpuffer SDS-PAGE (Stammlösung)}

1,5 M Tris-HCl

$0,4 \%(\mathrm{w} / \mathrm{v})$ SDS, $\mathrm{pH} 8,8$

Laufpuffer SDS-PAGE $\quad 30,0 \mathrm{~g}$ Tris base

$$
144,0 \text { g Glycin }
$$

100,0 ml 10\% SDS-Lösung

auf 1,0 Liter mit dd $\mathrm{H}_{2} \mathrm{O}$ auffüllen

SDS-PAGE-Probenpuffer $2 \mathrm{ml}$ Sammelgelpuffer

$2 \mathrm{ml} \mathrm{16 \% (w/v)} \mathrm{SDS}$

$4 \mathrm{ml}$ Glycerin

$2 \mathrm{ml} \mathrm{0,2 \% (w/v)} \mathrm{Bromphenolblau,}$

2 ml 2-Mercaptoethanol, $\mathrm{pH} \mathrm{6,8}$

ELB-Puffer

$100 \mathrm{ml}$ HEPES $50 \mathrm{mM}$

$0,5 \mathrm{ml} \mathrm{NaCl} 250 \mathrm{mM}$

$5 \mathrm{ml}$ EDTA $5 \mathrm{mM}$

ad $500 \mathrm{ml} \mathrm{dd} \mathrm{H}_{2} \mathrm{O}$

nach Autoklavieren 0,5 ml NP 40 0,1\% Nonidet

Western Blot Transferpuffer

$24,2 \mathrm{~g}$ Tris base

108,1g Glycin

auf 1,0 Liter mit dd $\mathrm{H}_{2} \mathrm{O}$ auffüllen

$10 \times$ TBST buffer (Tris bufferd saline + Tween ${ }^{\circledR} 20$ )

$8,0 \mathrm{~g} \mathrm{NaCl}$ (Natriumchlorid)

$0,2 \mathrm{~g} \mathrm{KCl}$ (Kaliumchlorid)

3,0 $\mathrm{g}$ Tris base

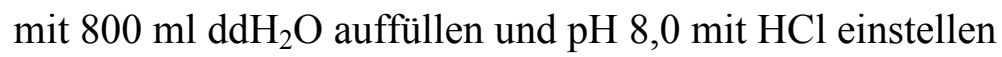


10\% APS (Ammoniumpersulfat)

1,0 g Ammonium Persulfat (Pulver)

$10,0 \mathrm{ml} \mathrm{dd} \mathrm{H}_{2} \mathrm{O}$ dazu pipettieren und gut durchmischen

Aliquotieren: $1000 \mu \mathrm{l} / 1,5 \mathrm{ml}$ - Tube; Lagerung bei $-20^{\circ} \mathrm{C}$

$10 \%$ SDS (Sodium lauryl sulfate)

25,0 g Elektrophoresegrade - SDS (sehr rein)

mit 225,0 ml dd $\mathrm{H}_{2}$ Oauffüllen, pH 7,2

Denaturierungslösung $\quad 180 \mathrm{ml} 5 \mathrm{M} \mathrm{NaCl}$

$60 \mathrm{ml} 5 \mathrm{M} \mathrm{NaOH}$

$260 \mathrm{ml} \mathrm{dd} \mathrm{H}_{2} \mathrm{O}$

Neutralisierungslösung $\quad 180 \mathrm{ml} 5 \mathrm{M} \mathrm{NaCl}$

$300 \mathrm{ml} 1 \mathrm{M}$ Tris $(\mathrm{pH} 7,0)$

1,2 ml 0,5 M EDTA (pH 8,0)

$118,8 \mathrm{ml} \mathrm{dd} \mathrm{H}_{2} \mathrm{O}$

LB-Medium

$10 \mathrm{~g} / 1 \mathrm{NaCl}$

$10 \mathrm{~g} / \mathrm{l}$ Bacto-Trypton

$5 \mathrm{~g} / 1$ Hefeextrakt, $\mathrm{pH} 7,5$

LB-Amp

LB-Medium mit $100 \mu \mathrm{g} / \mathrm{ml}$ Ampicillin

SOC

20 mM Glukose

$20 \mathrm{~g} / 1$ Trypton

$5 \mathrm{~g} / \mathrm{l} \mathrm{Hefeextrakt}$

$0,5 \mathrm{~g} / 1 \mathrm{NaCl}$

$10 \mathrm{mM} \mathrm{MgCl}_{2}$,

$10 \mathrm{mM} \mathrm{MgSO}_{4}, \mathrm{pH} 7,5$ 


\section{Chemikalien}

Alle Chemikalien besaßen den Reinheitsgrad pro analysi.

1,4-Dithiothreitol (DTT)

2- Mercaptoethanol

6x Ladepuffer

Acrylamid 30\%/Bis Solution

Acrylamid 40\%/Bis Solution

Agarose

Ammoniumpersulfat

Bacto- Agar

Bacto-Hefe-Extract

Bacto-Trypton

BioRad Protein Assay

Borsäure

Bovines Serum Albumin BSA

Bromophenolblau

Chef DNA Size Standards 8-48 kb

Chloroform

Cyclohexamide

DEPC

Dimethylsulfoxid (DMSO)

Dinatriumdiamintetraacetat

DNA Leiter $1 \mathrm{~kb}$

DNA Leiter Plus 100 bp

DNA Sizer III 21 kb- 0,21 kb

Essigsäure

Ethanol

Ethidiumbromid

Formaldehyd

Formamid

Glycerol

HybMix

Hybond- N+ Nylonmembran
Biomol, Hamburg

Sigma, Steinheim

Fermentas, Litauen

BioRad, Hercules, CA, USA

BioRad, Hercules, CA, USA

Sigma, Steinheim

BioRad, Hercules, CA, USA

Difco, Detroit, MI, USA

Difco, Detroit, MI, USA

Difco, Detroit, MI, USA

BioRad, Hercules, CA, USA

Merck, Darmstadt

BioLabs, Schwalbach

Sigma, Steinheim

BioRad, Hercules, CA, USA

Merck, Darmstadt

Sigma, Steinheim

Sigma, Steinheim

Sigma, Steinheim

Gibco BRL, Eggenstein

PeqLab, Erlangen

PeqLab, Erlangen

PeqLab, Erlangen

Merck, Darmstadt

Merck, Darmstadt

Sigma, Steinheim

Merck, Darmstadt

Fluka, Neu - Ulm

Serva, Heidelberg

Stratagene, La Jolla, CA, USA

Amersham Biosciences, UK 
Isopropanol

Kaliumacetat

Luria Broth Base

Magnesiumacetat

Methanol

Natriumacetat

Natriumbutyrat

Natriumchlorid

Natriumcitrat

Natriumhydrogenphosphat

Natriumhydroxid

Paraformaldehyd

Propidiumiodid

Salzsäure $\mathrm{HCl}$

Sephadex G-50

Sodiumdodecylsulfat

TEMED

Tris Base

Tris-Acetat

Triton

Tween 20

Xylencyanol

\section{Reaktions-Kits:}

Genomic DNA Purification Kit

Plasmid Mini Kit

Plasmid Maxi Kit

QIAquick Nukleotid Removal- Kit

QIAquick Gel Extraction Kit

RNeasy Mini Kit

TRAPeze ${ }^{\circledR}$ Telomerase Detection Kit
Merck, Darmstadt

Merck, Darmstadt

Gibco BRL, Eggenstein

Merck, Darmstadt

Fluka, Neu - Ulm

Merck, Darmstadt

Sigma, Steinheim

Merck, Darmstadt

Merck, Darmstadt

Merck, Darmstadt

Merck, Darmstadt

ICN Biomedicals, Irvine, CA, USA

Sigma, Steinheim

Merck, Darmstadt

Pharmacia, Freiburg

Sigma, Deisenhofen

BioRad, Hercules, CA, USA

Merck, Darmstadt

Sigma, Steinheim

Sigma, Steinheim

BioRad, Hercules, CA, USA

Sigma, Steinheim

Gentra, Minneapolis, MN, USA

Qiagen, Hilden

Qiagen, Hilden

Qiagen, Hilden

Qiagen, Hilden

Qiagen, Hilden

Intergen, Burlington, MA, USA 


\section{Ergebnisse}

\subsection{Generierung definierter ösophagealer Keratinozyten}

Um die transkriptionelle Regulation der humanen Telomerase in-vitro zu analysieren, haben wir ein Modell aus fünf verschiedenen Zelltypen aufgebaut. Zuerst wurden normale humane Ösophagusepithelzellen aus chirurgischem Material etabliert und durch ihre morphologischen, zytogenetischen und biochemischen Eigenschaften als normale primäre Zellen definiert. In diese Zellen wurden danach dominant negatives p53, hTERT oder Cyclin D1 retroviral transduziert. Die Zelltypen wurden als EPC, EPC- $\Delta$ p53, EPC-hTERT und EPC-D1 bezeichnet und zusammen mit der Tumorzelllinie TE-12 für die weiteren Versuche verwendet.

Dieses Modell genetisch alterierter ösophagealer Plattenepithelzellen sollte dazu dienen, die transkriptionelle Regulation der humanen Telomerase im Prozess der malignen Transformation des Ösophaguskarzinoms zu untersuchen. Normale und genetisch alterierte ösophageale Keratinozyten wurden hierfür in einem speziell modifizierten "keratinocyte serum-free medium" (ker-sfm) kultiviert. Dieses Medium erlaubt eine Subkultivierung von primären Keratinozyten ohne sog. "Feeder-layer", muss aber mit verschiedenen Wachstumsfaktoren, einschl. BPE und EGF supplementiert werden. Zusätzlich ist eine Kalziumkonzentration von $0,4 \mathrm{mM}$ notwendig, um der Zelle die Ausbildung von Cadherinen und Desmosomen vermittelten Zell-Zell-Kontakten zu erlauben. Diese Kalziumkonzentration ist niedrig genug, um die Proliferation von humanen oralen Keratinozyten nicht negativ zu beeinflussen.

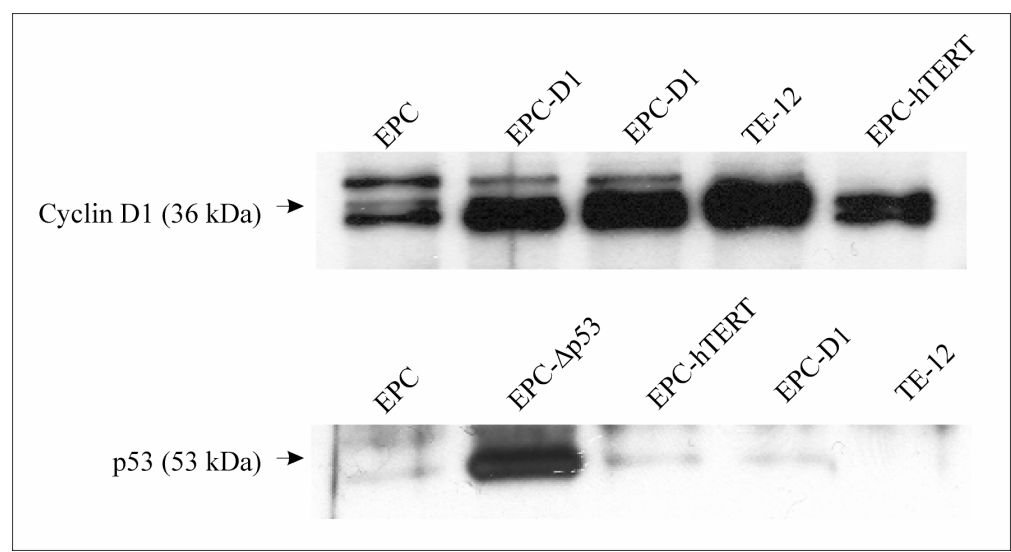

Abbildung 3.1: Kontrolle der Überexpression von Cyclin D1 und dominant negativem p53 in EPC-D1 oder EPC- $\Delta$ p53 im Vergleich zu den anderen Zellen. 
Die Überexpression von dominant negativem p53 und Cyclin D1 wurde mittels Western Blot kontrolliert. Abbildung 3.1 zeigt eine Bande bei $53 \mathrm{kDa}$ in EPC- $\Delta \mathrm{p} 53$, die einer Stabilisierung des p53 Proteins durch die dominant negative Mutante entspricht. In TE12 ist dagegen keine Bande nachweisbar, was für eine minimale oder fehlende Expression von p53 in der Tumorzelllinie spricht. Cyclin D1 ist in EPC-D1 und TE-12 überexprimiert (Abbildung 3.1). Eine hTERT-Überexpression ist im Western Blot nicht nachweisbar.

Die Morphologie der Zellen wurde regelmäßig unter dem Mikroskop observiert und die wichtigsten Charakteristika wie Konfluenz, Aussehen und Wachstumsverhalten dokumentiert. Bei der Kultivierung der verschiedenen Zellen wurde darauf geachtet, dass EPC eine Konfluenz von 25-30\% nicht überschritt, um die Zellen nicht differenzieren zu lassen. EPC- $\Delta$ p53 wurden bis maximal 40\% Konfluenz, EPC-D1 und EPC-hTERT bis maximal 50\% Konfluenz kultiviert, bevor sie neu passagiert wurden. TE-12 konnten bis zu einer Konfluenz von über $80 \%$ kultiviert werden.

Tabelle 3.1

\begin{tabular}{llcc}
\hline Zellen & Charakterisierung & max. Populationsdopplungen & max. Konfluenz \\
\hline EPC & primäre Zellen & $40-50$ & $25-30 \%$ \\
EPC- $\Delta$ p53 & genetisch veränderte Zellen & $60-80$ & $30-40 \%$ \\
EPC-D1 & immortale Zellen & $>440$ & $40-50 \%$ \\
EPC-hTERT & immortale Zellen & $>400$ & $40-50 \%$ \\
TE-12 & Tumorzellen & $>800$ & $80-100 \%$ \\
\hline
\end{tabular}

Charakterisierung der replikativen Lebenszeit und proliferativen Eigenschaften der verschiedenen Zellen in der Zellkultur.

Tabelle 3.1 zeigt die replikative Lebenszeit der primären EPC, der genetisch veränderten Zellen (EPC- $\Delta$ p53, EPC-D1 und EPC-hTERT) und der Tumorzellen (TE12). Eine Passage entspricht bei Keratinozyten etwa vier Populationsdopplungen, bei TE-12 etwa zehn Populationsdopplungen (PD).

Im Verlauf der in vitro Kultivierung (Abbildung 3.2) der fünf Zelltypen konnte ein exponentielles Wachstum der Tumorzellen (TE-12) und der immortalen Zellen (EPCD1 und EPC-hTERT) beobachtet werden. TE-12 erreichten pro Passage mehr Populationsdopplungen als alle anderen Zellen und replizierten sich mit mehr als 800 PD in 400 Tagen. EPC-D1 und EPC-hTERT wiesen ebenfalls ein exponentielles Wachstum in der Zellkultur mit bis über 400 PD auf und sind somit als immortal zu bezeichnen. Es zeigte sich, dass sich EPC-D1 mit über 440 PD in 400 Tagen bei ähnlicher Anzahl von PD pro Passage und Konfluenz etwas schneller replizierten als 
EPC-hTERT, die nur ca. 400 PD in 400 Tagen erreichten. Die primären Epithelzellen konnten bis ungefähr 40-50 PD kultiviert werden. Sie zeigten ab Passage 10-12 morphologische Zeichen der Seneszenz, wie deutlich langsameres Wachstum, Vergrößerung der Zellen und schließlich Wachstumsstop. EPC- $\Delta$ p53 zeigten mit 80 PD keine signifikant erhöhte replikaktive Lebenszeit und gingen ab Passage 18 in das Stadium der Seneszenz über.

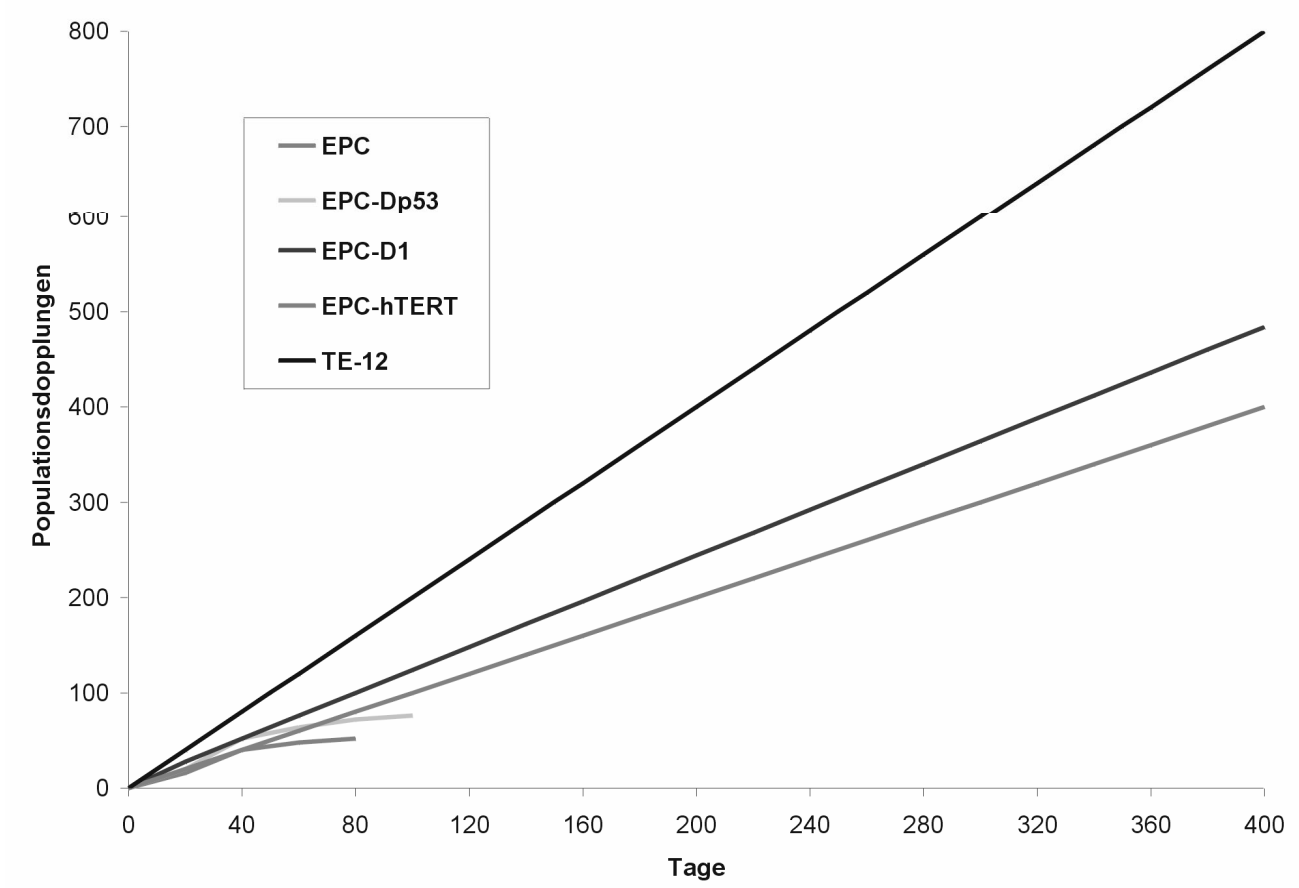

Abbildung 3.2: Replikative Lebenszeit der einzelnen Zelltypen im Vergleich. Zu sehen sind in der X-Achse die Tage der in-vitro Kultivierung, in der Y-Achse die erreichten Populationsdopplungen in dieser Zeit.

Die Zellemorphologie der einzelnen Zelltypen wurde fotographisch dokumentiert. Abbildung 3.3 zeigt die verschiedenen Zelltypen in Kultur. EPC und EPC- $\Delta$ p53 wuchsen in kleinen Kolonien mit bis zu 15 Zellen und zeigten keinen Zellkontakt zwischen den einzelnen Zellen. Der Zellkern war im Vergleich zum Zytoplasma klein. Die Zellen wurden aber mit den Populationsdopplungen flacher und zeigten immer mehr zytoplasmatische Fortsätze als morphologisches Zeichen der Seneszenz. EPC-D1 und EPC-hTERT zeigten eine ähnliche Form wie EPC und EPC- $\Delta$ p53 vor dem Stadium der Seneszenz, erreichten aber nie ein Stadium der Seneszenz. Zusätzlich zeigten EPCD1 und EPC-hTERT einen vergrößerten Zellkern und ein verändertes Kern-PlasmaVerhältnis. Im Gegensatz zu EPC und EPC- $\Delta$ p53 wuchsen diese Zellen in wesentlich 
größeren Kolonien und zeigten Zell-Zell-Kontakt, der bei ausreichender Kultivierung zu einer dichten Konfluenz innerhalb einer Kolonie führte. TE-12 zeigten von Beginn an ein sehr dichtes Wachstum in Kolonien. Die verschiedenen Kolonien wuchsen ineinander und es konnte sogar ein Wachstum „aus der Zellkulturplatte heraus“ ohne Kontakt zur Oberfläche beobachtet werden.
Abbildung 3.3: Morphologie der Zellen
A: EPC Passage 6,
B: EPC Passage 13 (in Seneszenz),
C: EPC- $\Delta$ p53 Passage 8,
D: EPC- $\Delta$ p53 Passage 17 (in Seneszenz),
E: EPC-hTERT Passage 76 (1 Tag nach Plattierung),
F: EPC-hTERT Passage 76 (nach 3-4 Tagen auf einer Platte),
G: EPC-D1 Passage 88 (1 Tag nach Plattierung),
H: EPC-D1 Passage 88 (nach 2-3 Tagen auf einer Platte),
I: TE-12 Passage 60 (1 Tag nach Plattierung);
J: TE-12 Passage 60 (3-4 Tage auf einer Platte). 

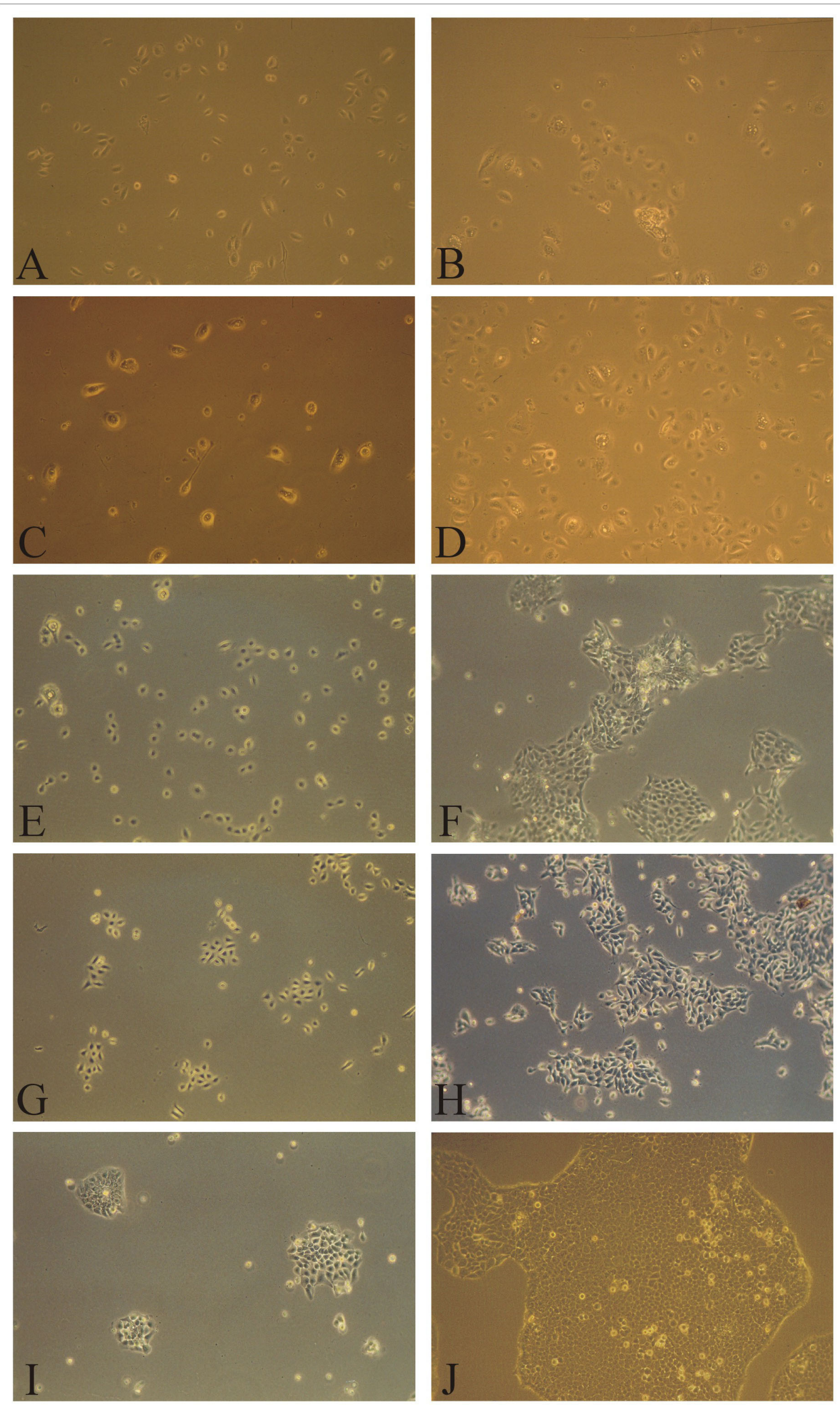


\subsection{Charakterisierung der Telomerbiologie}

\subsubsection{Telomeraseexpression}

Um die transkriptionelle Regulation der humanen Telomerase zu analysieren, wurde zuerst die Expression der Telomerase mittels RT-PCR und Real Time RT-PCR in den verschiedenen Zelltypen untersucht. Die Reverse Transkription von RNA, gefolgt von einer PCR (RT-PCR), ist eine sensitive Methode, um spezifische mRNA zu detektieren und zu quantifizieren. Aus Geweben oder Zellen isolierte RNA wird im ersten Schritt als "Template" für die Reverse Transkription in komplementäre DNA (cDNA) umgeschrieben. Die cDNA wird wiederum als Template für die folgende PCR verwendet, die mit spezifischen Primern eine bestimmte cDNA-Region amplifiziert. Die Reverse Transkriptase-PCR (Abbildung 3.4) zeigte eine hTERT Expression in allen fünf Zelltypen. Besonders deutlich war die Expression in den Cyclin D1 überexprimierenden EPC-D1. Die Expression in TE-12 und EPC-hTERT war etwas schwächer. EPC und EPC- $\Delta$ p53 zeigten eine sehr schwache Expression in der RT-PCR.

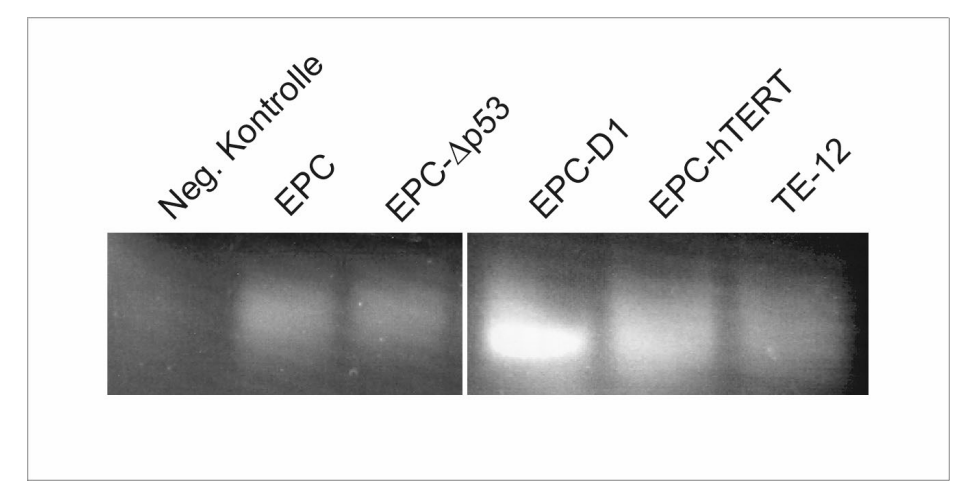

Abbildung 3.4: Reverse Transkriptase-PCR für Telomerase. $\mathrm{Zu}$ sehen ist die spezifische Bande im 1\% Agarosegel für alle fünf Zelltypen und neg. Kontrolle.

Da durch die semiquantitative RT-PCR nur ein grober Vergleich der Expression der Telomerase gemacht werden kann, wurde die Expression zusätzlich quantitativ, mittels Real Time RT-PCR untersucht. Die quantitative Real Time PCR basiert auf dem kontinuierlichen Monitoring einer Fluoreszenzprobe. Die Probe ist mit zwei Fluoreszenz-Markern markiert, einem als Reporter am 5'-Ende (FAM) und einem zweiten am 3'-Ende (TAMRA). Bei Amplifikationen löst die 5'-3' Exonuclease der TaqDNA-Polymerase den Reporter von der Probe, dessen Emission dann messbar wird. Die 
quantitative Bestimmung der hTERT-Expression in den fünf Zelltypen mit quantitativer Real Time Reverse Transkriptase-PCR ergab das in den Abbildungen 3.5 und 3.6 dargestellte Ergebnis.

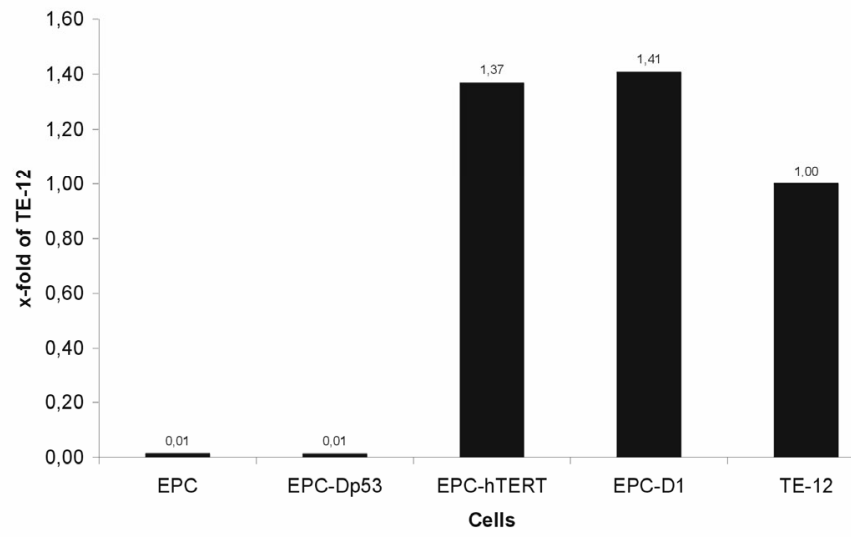

Abbildung 3.5: Ergebnis der quantitativen Real Time-PCR im Verhältnis zur relativen Menge an cDNA von TE-12 (CT-Wert).

In Korrelation zur RT-PCR zeigten EPC und EPC- $\Delta$ p53 eine sehr geringe Telomeraseexpression. Im Kurvendiagramm war nur eine minimal ansteigende Konzentration unter dem CT-Wert von 0,01 zu erkennen. TE-12 wurden als Positivkontrolle verwendet. In EPC-D1 wurde hTERT erstaunlicherweise 1,41 mal stärker exprimiert als in TE-12, in EPC-hTERT zeigte die hTERT Expression einen 1,37 fachen Wert an.

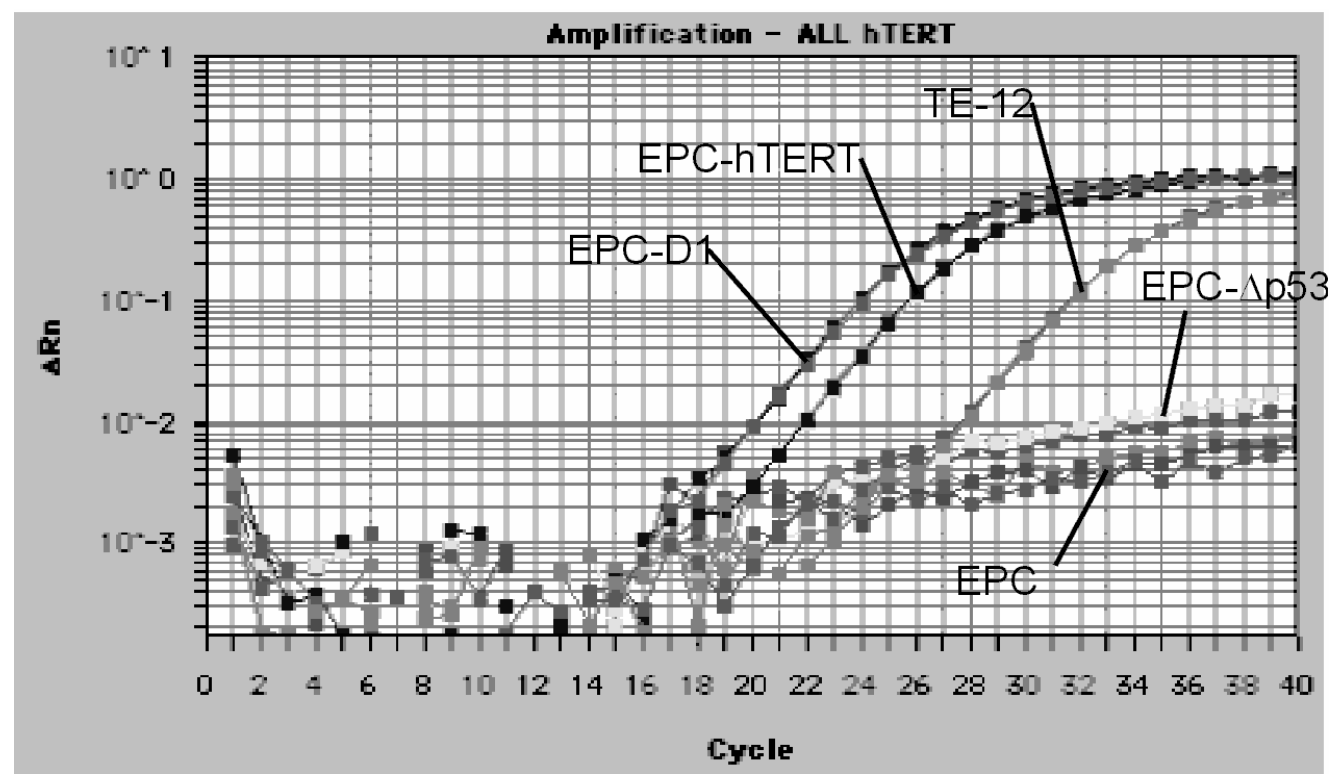

Abbildung 3.6: Ergebnisse der quantitative Real Time-PCR im Verlauf der 40 Zyklen von je drei Proben der einzelnen Zelltypen. 


\subsubsection{Telomeraseaktivität}

Die Telomeraseaktivität in EPC, deren Derivaten und TE-12 wurde mittels TRAPAssay ermittelt. Bei dieser auf PCR basierenden Methode wird ein potentiell Telomerase haltiger Proteinextrakt der Zellen zu einem Oligonukleotid gegeben. An dieses wird mittels der Telomerase Reaktion eine den Telomeren identische, radioaktiv markierte repetitive Sequenz (TTAGGG) angehängt. Als Negativkontrolle dient ein hitzeinaktivierter Zellextrakt. Danach wird eine Zweistufen-PCR mit PCR-Primern, die spezifisch für das entstandene Produkt der aktiven Telomerase sind, durchgeführt. Das PCR-Produkt wird auf einem PAGE aufgetragen, so dass bei vorhandener Telomeraseaktivität eine Leiter von Banden, im Abstand dieser an das vorgegebene Oligonukleotid angehängten 6 Basen, zu sehen ist.

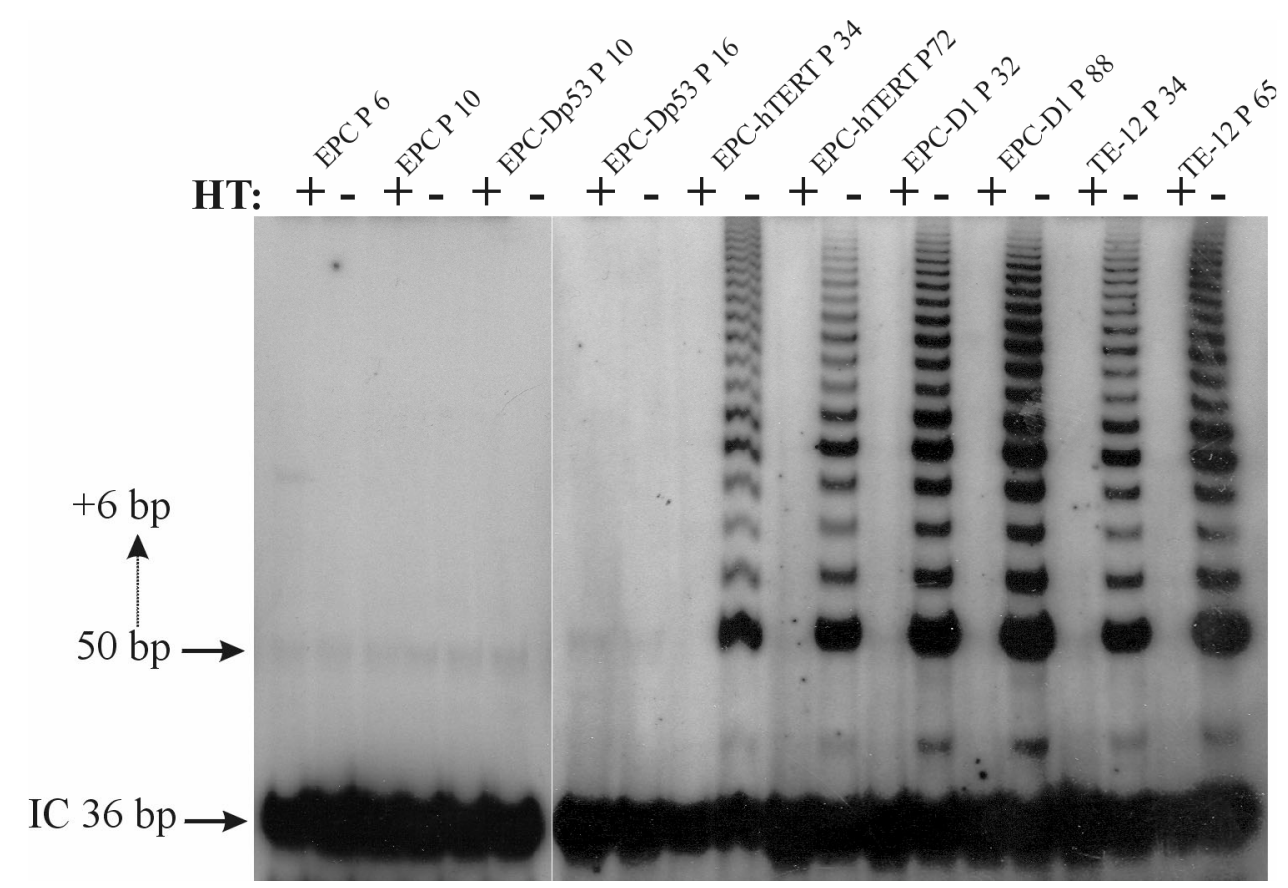

Abbildung 3.7: Telomeric Repeat Amplification Protocol (TRAP)-Assay-Ergebnisse der fünf Zelltypen (jeweils niedrige bzw. hohe Passage). HT: Hitzeinaktivierung durchgeführt (+) oder nicht durchgeführt (-); IC 36 dient als interne Kontrolle für die PCR, die "Bandenleiter" beginnt bei 50 bp, der Länge des vorgegebenen Templates, und zeigt die vorhandene Telomeraseaktivität an. Anhand der Intensität lässt sich die Aktivität der Telomerase ungefähr abschätzen.

Der TRAP-Assay wurde jeweils von einer niedrigen und einer hohen Passage der fünf Zelltypen durchgeführt. Die Proben sind, jeweils zusammen mit einer vor der Telomerase Reaktion hitzeinaktivierten Probe, auf das Gel aufgetragen worden. In 
Abbildung 3.7 zeigen die primären EPC sowohl in der frühen Passage 6 als auch in der späten Passage 10, kurz vor Beginn der Seneszenz, keine „Bandenleiter“ und somit keine messbare Telomeraseaktivität. Das Gleiche gilt für die frühe Passage 10 und die späte Passage 16 von EPC- $\Delta$ p53. EPC-hTERT und EPC-D1 zeigen „Bandenleitern“. Es ist kein Unterschied zwischen der jeweils frühen und späten Passage zu erkennen. TE12 liegen mit der Intensität der „Bandenleiter“ zwischen EPC-D1 und EPC-hTERT. Hier lässt sich eine leicht höhere Intensität der späten Passage 65 gegenüber der frühen Passage 34 erkennen. EPC-D1, EPC-hTERT und TE-12 weisen eine weitgehend konstante Telomeraseaktivität auf.

\subsubsection{Telomerlänge}

Die Länge der Telomere aller Chromosomen eines Genoms kann mittels Southern-Blot Analyse mit dem Telomere Restriction Fragment (TRF)-Assay bestimmt werden. Vor dem Southern Blot wird die genomische DNA der Zellen isoliert und mit Restriktionsendonukleasen komplett verdaut (Abbildung 3.8). Nach der elektrophoretischen Auftrennung und Blot wird die verdaute DNA mit einer ${ }^{32} \mathrm{P}$ markierten telomerischen Probe, komplementär zu der repetitiven Sequenz der Telomere (TTAGGG), hybridisiert und mittels Röntgenfilmexposition die Länge der Telomere beurteilt.

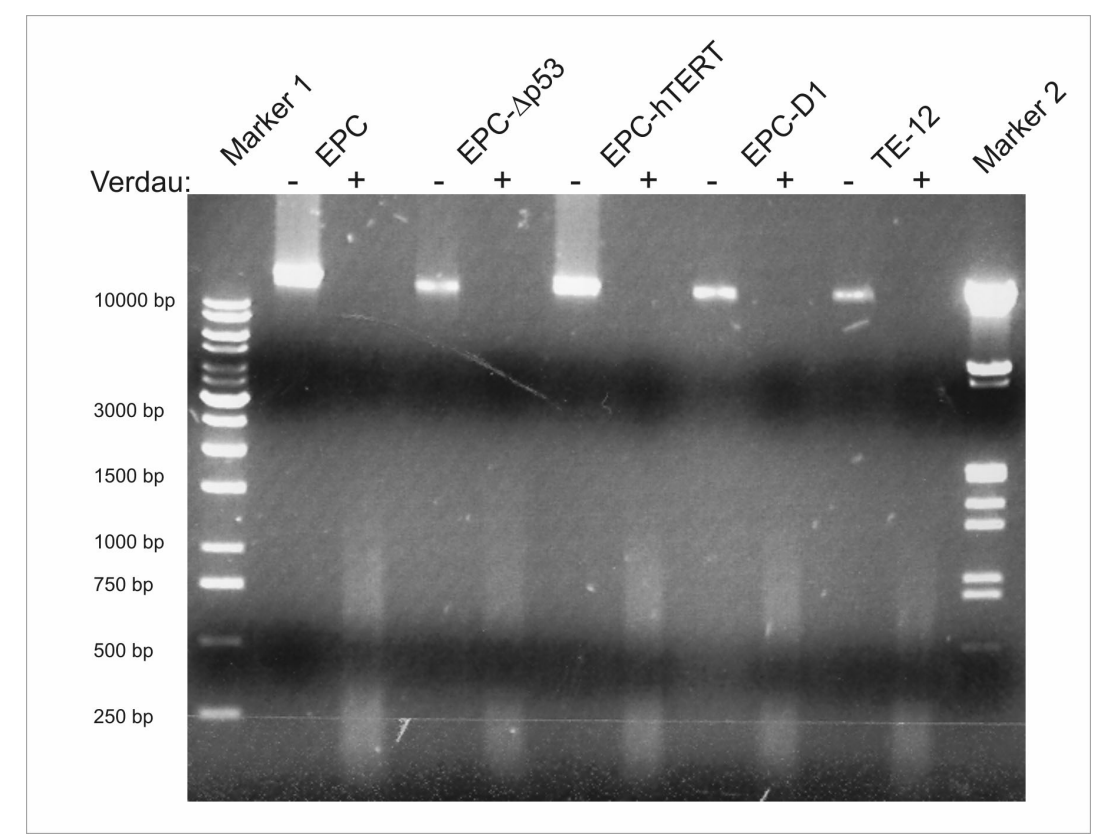

Abbildung 3.8: Beispiel der Kontrolle des Verdaus vor Southern-Blot mit Rsa I und Hinf I für Telomere Restriction Fragment (TRF) Assay 


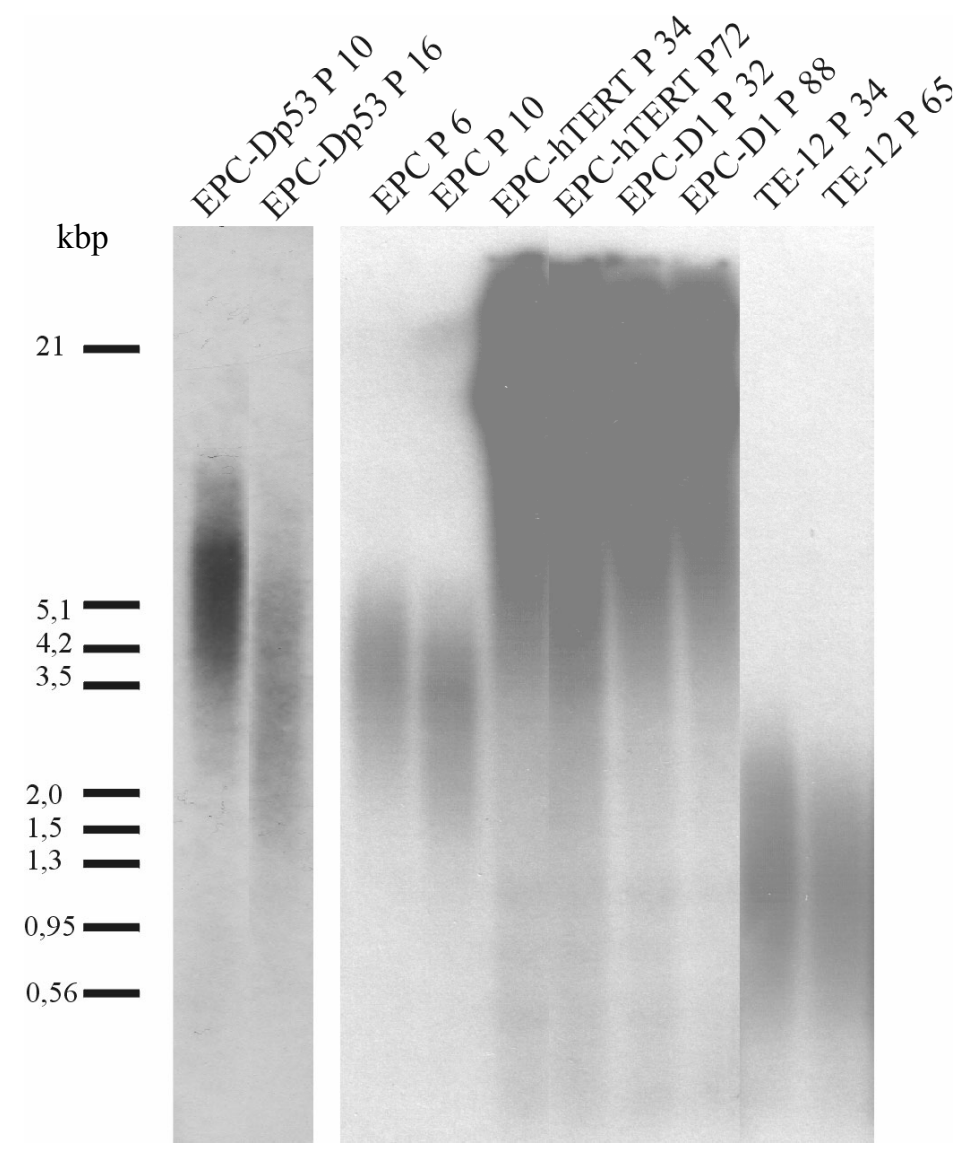

Abbildung 3.9: Telomere Restriction Fragment (TRF) Assay von jeweils einer frühen und einer späten Passage der fünf Zelltypen. Die breiten Banden geben die Verteilung der Telomerlängen in dem Genom der einzelnen Zellen wieder. Links steht die Längenangabe in kbp.

Abbildung 3.9 zeigt die Telomerlängen der einzelnen Zellen in je einer frühen und einer späten Passage der Zellkultur. Die Bandenbreite gibt die Verteilung der Telomerlängen innerhalb des Genoms zwischen den Chromosomen der einzelnen Zellen an. Als Proben wurde DNA der selben Zellen, wie im TRAP-Assay, verwendet. EPC-hTERT zeigten mit bis zu $20 \mathrm{kbp}$ langen Telomeren in sowohl der frühen Passage 34 als auch der späteren Passage 72 ein sehr homogenes Bild in Korrelation zur Telomeraseaktivität. Ebenso waren die Banden von EPC-D1 in beiden Passagen, P 32 und P 88, und weiteren beobachteten Passagen konstant in dem Bereich von $20 \mathrm{kbp}$ lokalisiert. Die konstante Verlängerung der Telomere auf eine homogene Länge korreliert mit den immortalen Wachstumseigenschaften dieser Zellen. Im Gegensatz zu diesem Ergebnis waren die Telomere von TE-12 interessanterweise $2 \mathrm{kbp}$ bis 0,5 kbp lang. Die Analyse der frühen Passage 34, der späten Passage 65 und weiterer, hier nicht gezeigter Passagen zeigte eine sehr konstante Telomerlänge ohne weitere Abnahme. Die Telomerlänge der Passagen 6 und 10 von EPC lagen im Bereich von 5 kbp bis 1,5 kbp. 
Zusätzlich zu der beobachteten mittleren Telomerlänge zeigten EPC im Verlauf eine Abnahme der Telomerlänge zwischen der Etablierung invitro und dem Übergang in Seneszenz, die mit Passage 12 bis 14 einherging (Abbildung 3.9). EPC- $\Delta$ p53 zeigten mit Telomeren im Bereich von $10 \mathrm{kbp}$ bis 3,5 kbp in Passage 10 und im Bereich von 5 kbp bis 1,5 kbp in Passage 16, dass heißt beim Übergang in Seneszenz, ebenso eine Verkürzung der Telomere. Die Abnahme der Telomerlänge konnte auch hier im Verlauf von frühen zu späten Passagen beobachtet werden und korrelierte wie bei EPC mit der kurzen replikativen Lebenszeit und morphologischen Veränderungen beim Übergang in Seneszenz.

\section{3 hTERT-Promotor Analysen}

Der hTERT-Promotor wurde auf Interaktionen mit möglichen Transkriptionsfaktoren untersucht und in elf verschiedene Deletionskonstrukte unterschiedlicher Länge aufgeteilt. Bevor die Deletionskonstrukte hergestellt und subkloniert werden konnten, wurden die einzelnen Plasmide, pGL3-hTERT, pGL3-basic und pGL3-SV40, auf ihre Restriktionsendonuklease-Schnittstellen überprüft.

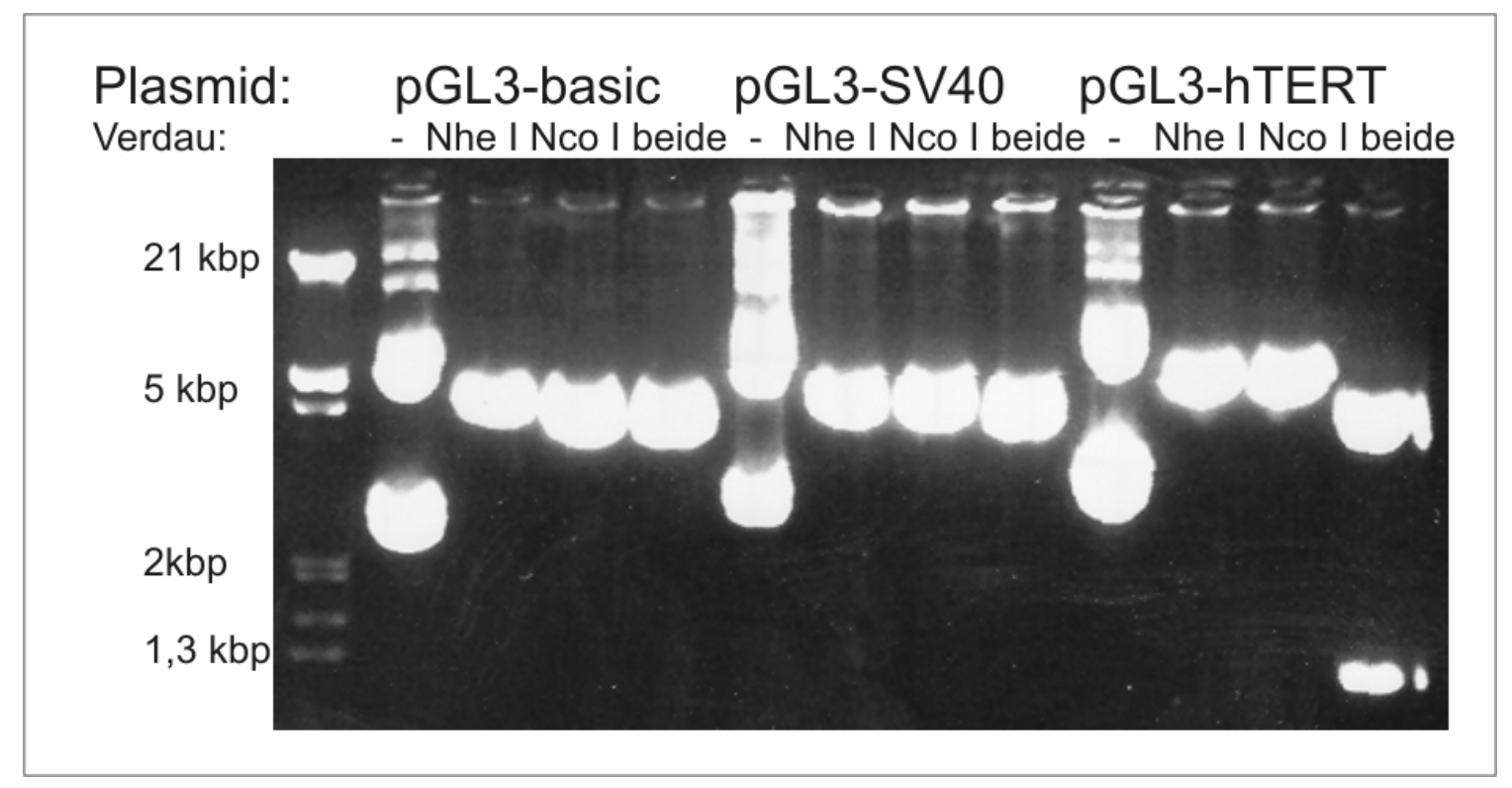

Abbildung 3.10: Kontrollverdau der drei verwendeten Plasmide (pGl3-Basic, pGL3-SV40 und pGL3hTERT) mit je Nhe I und Nco I, einzeln und zusammen

Abbildung 3.10 zeigt das elektrophoretische Ergebnis des Verdaus mit den für die Subklonierung wichtigen Schnittstellen Nhe I und Nco I. Die erste von vier Proben ist jeweils das unverdaute Plasmid, die zweite der singuläre Verdau mit Nhe $I$, die dritte 
der mit Nco I und die vierte ist ein Doppelverdau mit beiden Enzymen. In den drei verdauten Proben sieht man in allen drei Plasmiden das liniearisierte Plasmid. Das liniearisierte Plasmid war bei pGL3-basic ca. 5000 bp und bei pGL3-SV40, das den SV40-Promotor enthält, ca. 5200 bp groß. Das linearisierte pGL3-hTERT Plasmid misst ca. 6100 bp, da es den 1242 bp langen hTERT-Promotor enthält. In diesem Plasmid sieht man beim Doppelverdau den ausgeschnittenen hTERT-Promotor bei 1242 bp und das linearisierte Plasmid bei ca. 4900 bp.

Nachdem für jedes Deletionskonstrukt entsprechende Primer entworfen waren, wurden mittels PCR die Deletionskonstrukte des hTERT-Promotors mit dem Plasmid pGL3hTERT als "Template" amplifiziert. Das PCR-Produkt wurde an den Enden mit Nhe I und Nco I geschnitten und mittels Gelelektrophorese gereinigt. Abbildung 3.11 zeigt die erwartete Leiter der DNA-Banden, die das Verhältnis der unterschiedlich langen Deletionskonstrukte aufzeigt. Das linke Gel zeigt zuerst eine Bande von 700 bp, gefolgt von $247 \mathrm{bp}, 161 \mathrm{bp}, 101 \mathrm{bp}$ und schließlich 16 bp. Dies repräsentiert die Größen der vorgesehenen Deletionskonstrukte, die für die anschließende Subklonierung verwendet werden konnten. Das rechte Gel zeigt zwei dicht beieinander liegende Konstrukte bei 1011 bp und 905 bp, gefolgt von 357 bp, 290 bp, 187 bp und 48 bp, die in einem zweiten Versuchsansatz hergestellt wurden. Ganz rechts ist das mit Nhe I und Nco I verdaute Plasmid pGL3-hTERT in seiner liniearisierten Form zusammen mit dem ausgeschnittenen hTERT-Promotor zu sehen.

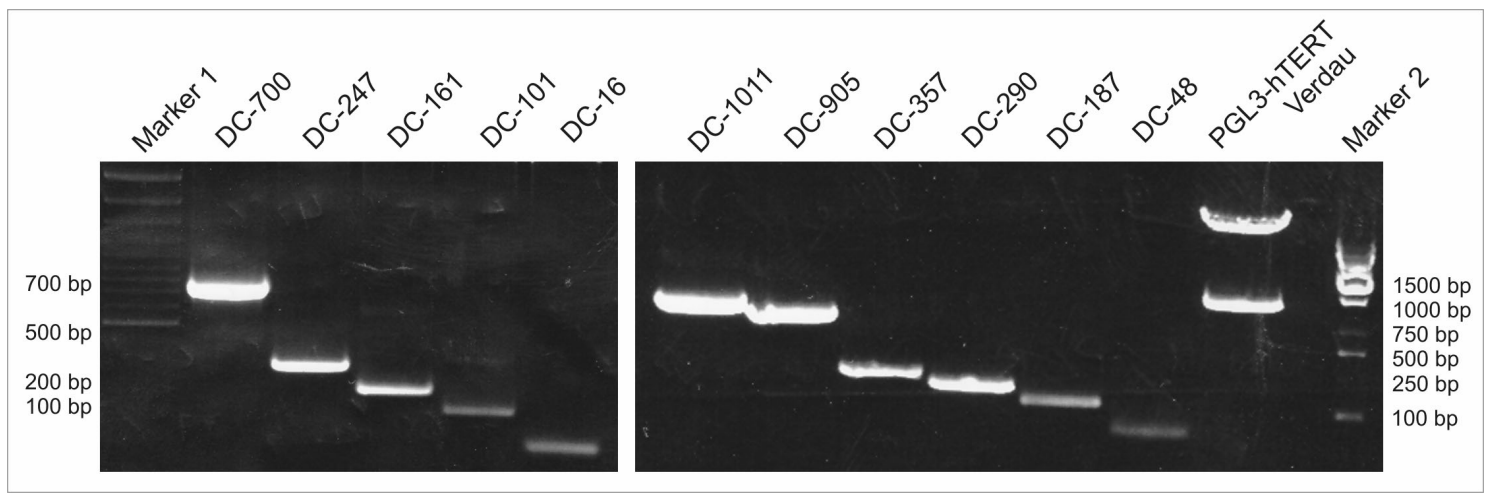

Abbildung 3.11: PCR-Produkte nach Herstellung der elf Deletionskonstrukte und Verdau mit Nhe I und Nco I vor der Ligation der Deletionskonstrukte in das, rechts dargestellte, linearisierte Plasmid pGL3hTERT, nachfolgender Transformation und Maxi Prep zur Vervielfältigung und Aufreinigung.

Die PCR-Amplifikate wurden aus dem Gel ausgeschnitten, extrahiert und zur Herstellung der Deletionskonstrukte in das linearisierte Plasmid ligiert. Die so 
hergestellten Luziferase Reporter Gen Vektoren wurden in E. coli Max Efficiency ${ }^{\circledR}$ DH5 $\alpha^{\mathrm{TM}}$ Competent Cells transformiert und kultiviert. Bevor sie aufgereinigt und wiederum mit Gelelektrophorese kontrolliert wurden, wurden aus den kultivierten Bakterienkolonien mittels PCR-Amplifikation diejenigen Kolonien ermittelt, die das „richtige“ Deletionskonstrukt als Plasmid enthielten. Die fertigen Plasmide wurden zur weiteren Kontrolle sequenziert.

\subsection{Transiente Transfektion der hTERT-Deletionskonstrukte}

\subsubsection{Vergleich der hTERT-Promotoraktivität}

Für das Einbringen von Fremd-DNA in die fünf Zelltypen wurde eine Lipofektamin Methode (Effectene, Qiagen) für primäre Keratinozyten optimiert und etabliert. Nachdem die transiente Transfektion des 1242 bp langen hTERT-Promotors mit Negativkontrolle (pGL3-basic) und Positivkontrolle (pGL3 mit SV40-Promotor) etabliert war, wurde der hTERT-Promotor in die elf oben genannte Deletionskonstrukte unterteilt. Die mittels PCR hergestellten Deletionskonstrukte hatten ihr 5' Ende $1011 \mathrm{bp}$, 905 bp, 700 bp, 357 bp, 290 bp, 247 bp, 187 bp, 161 bp, 101 bp, 48 bp, und 16 bp 5' der Transkriptions-Startstelle. Alle Deletionskonstrukte wurden wie bereits beschrieben in den Luziferase Reporter Gen Vektor subkloniert und in EPC, EPC- $\Delta$ p53, EPC-hTERT, EPC-D1 und TE-12 Zellen transient transfiziert. Zur Auswertung der Ergebnisse der transienten Transfektionen wurde die hTERT-Promotoraktivität des kompletten hTERT-Promotors (1242 bp) 100\% und die Aktivität der elf Deletionskonstrukte relativ hierzu angegeben. Eine Standardisierung wurde über die Zellzahl pro Ansatz und durch den Vergleich mit Positiv- (pGL3 mit SV40-Promotor) und Negativkontrolle (pGL3 als Leervektor) erreicht.

Vergleicht man die transienten Transfektionsergebnisse des hTERT-Promotors mit Positivkontrolle (SV40-Promotor) und Negativkontrolle (pGL3-basic), so zeigte sich in EPC eine 40fache Erhöhung der Luziferaseaktivität zwischen Negativkontrolle und hTERT-Promotor. Gleichzeitig betrug die Aktivität des hTERT-Promotors 29\% der Positivkontrolle. In TE-12 war die hTERT-Promotoraktivität etwa 27\% der Aktivität der Positivkontrolle. Da der hTERT-Promotor in TE-12 die höchste Luziferaseaktivität erreichte, wurden die Promotoraktivitäten in allen anderen Zellen mit dieser verglichen. Abbildung 3.12 zeigt, dass EPC 13\% der Aktivität von TE-12 erreicht. EPC- $\Delta$ p53 zeigten 22\%, EPC-D1 29\% und EPC-hTERT 30\% der Promotoraktivität von TE-12. 


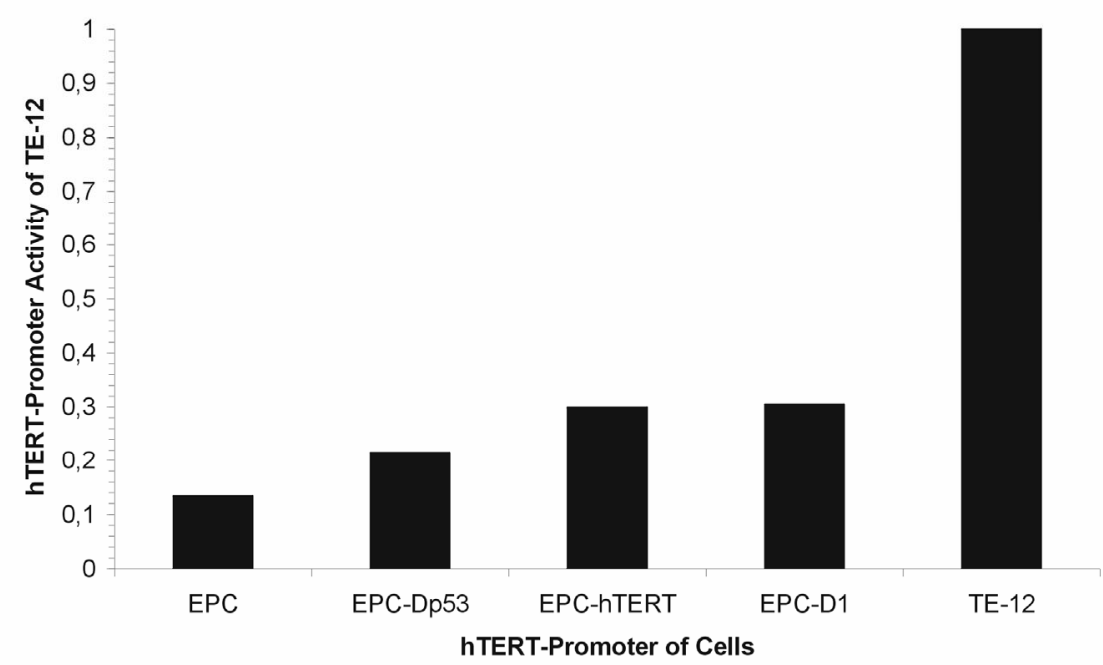

Abbildung 3.12: Vergleich der hTERT-Promotoraktivität der einzelnen Zelltypen untereinander.

\subsubsection{Transiente Transfektion von EPC}

In EPC (Abbildung 3.13) zeigten die beiden ersten Deletionskonstrukte, -1011 und -905 eine deutlich geringere Promotoraktivität von 71\% (-1011 Konstrukt) und 45\% (-905 Konstrukt) als das -1242 hTERT-Promotor Konstrukt (100\%). Danach war die Aktivität wieder bei $92 \%$ im -700 Konstrukt und bei $98 \%$ im -357 Konstrukt, bevor wieder eine geringere Aktivität mit $71 \% \quad(-290 \quad$ Konstrukt $) \quad \mathrm{zu}$ beobachten war.

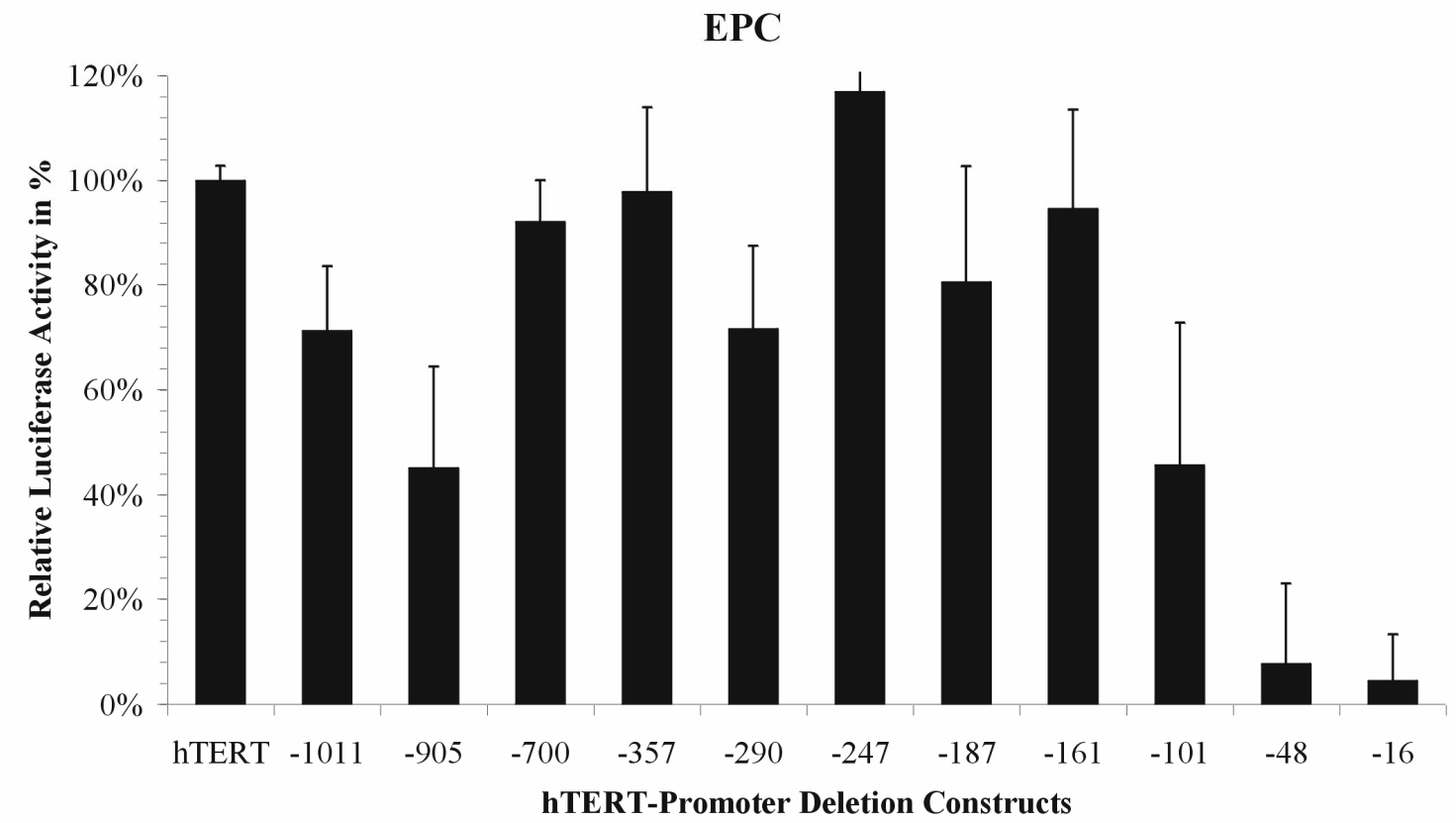

Abbildung 3.13: Relative Luziferaseaktivität der einzelnen Deletionskonstrukte in \%, im Vergleich zu hTERT (1242 bp) in EPC 
Im -247 Konstrukt erreicht die Promotoraktivität in EPC 117\% des hTERT-Promotors. Mit dem -101 Konstrukt, das mögliche Sp1-Bindungsstellen enthält, war eine signifikante Reduktion der Promotoraktivität auf 45\% zu beobachten, bevor die Aktivität in einem zweiten Schritt mit dem -48 Konstrukt bei 7\% lag. Mit dem -16 Konstrukt war mit 4\% nur noch eine marginale Promotoraktivität festzustellen. Insgesamt wird der hTERT-Promotor in EPC demzufolge durch Regionen im -905 Konstrukt und im -101 Konstrukt reguliert. Die restlichen Deletionskonstrukte zeigen eine konstant hohe Promotoraktivität.

\subsubsection{Transiente Transfektion von EPC- $\Delta$ p53}

Auch in EPC- $\Delta$ p53 (Abbildung 3.14) war eine geringe Promotoraktivität mit den ersten beiden Deletionskonstrukten $\mathrm{zu}$ beobachten. Von 100\% (-1242 Konstrukt) fiel die Aktivität auf 68\% (-1011 Konstrukt) und 32\% (-905 Konstrukt). Mit dem -700 Konstrukt war ein signifikanter Anstieg der Promotoraktivität auf 145\% zu verzeichnen. Dieses Aktivitätsniveau blieb in den Konstrukten -357 (125\%), -290 (147\%), -247 $(133 \%),-187(172 \%)$ und $-161(157 \%)$ erhalten. Mit dem nachfolgenden -101 Konstrukt zeigte sich eine deutliche Reduktion der Promotoraktivität in einem einzigen Schritt (<40\%), korrelierend mit dem Verlust multipler Sp1-Bindungsstellen.

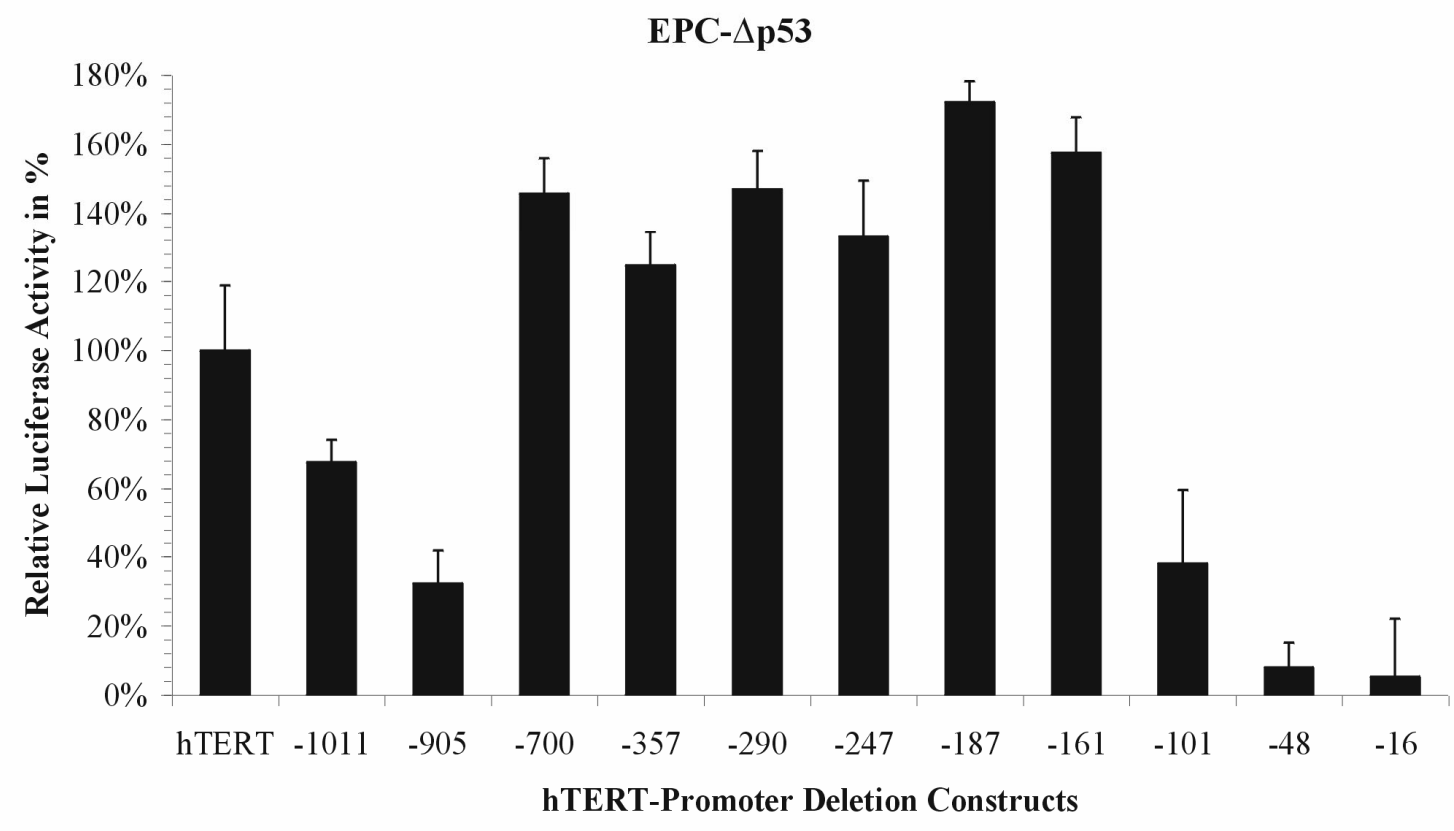

Abbildung 3.14: Relative Luziferaseaktivität der einzelnen Deletionskonstrukte in \%, im Vergleich zu hTERT (1242 bp) in EPC- $\Delta$ p53 
In den beiden Konstrukten -48 und -16 war nur noch eine marginale Aktivität von 10\% und $4 \% \mathrm{zu}$ beobachten. Zusammenfassend scheint die basale Aktivität des hTERTPromotors in EPC- $\Delta$ p53 hauptsächlich über eine Sequenz im Konstrukt -101 reguliert zu werden.

\subsubsection{Transiente Transfektion von EPC-hTERT}

In EPC-hTERT (Abbildung 3.15) war eine Reduktion der Promoteraktivität auf 64\% mit dem -1011 Konstrukt und auf 19\% mit dem -905 Konstrukt zu beobachten, was auf positiv regulatorische Elemente 5' hiervon hindeutet. Mit dem Konstrukt -700 erreichte die Promotoraktivität $160 \%$, was wiederum mit einer möglichen Silencer Region im Konstrukt -905 zu erklären wäre. Mit dem Konstrukt -357 stieg die Promotoraktivität auf $188 \%$ und reduzierte sich mit dem Konstrukt -290 auf 118\%. Dieses Konstrukt enthält eine potentielle E2F-Bindungsstelle. Weiter 3' im Konstrukt -247, eine Sequenz mit einer weiteren möglichen E2F-Bindungsstelle, stieg die Promotoraktivität auf mehr als das Doppelte des hTERT-Promotors an (231\%). Im nachfolgenden Konstrukt (-187), welches eine mögliche c-myc-Bindungsstelle enthält, sank die Aktivität leicht, aber nicht signifikant auf 188\% ab, gefolgt von einem weiteren Abfall auf 177\% mit dem Konstrukt -161, einem Konstrukt, das multiple Sp1-Bindungsstellen enthält. In dem darauf folgenden Konstrukt konnte ein Verlust der Promotoraktivität auf 45\% mit dem

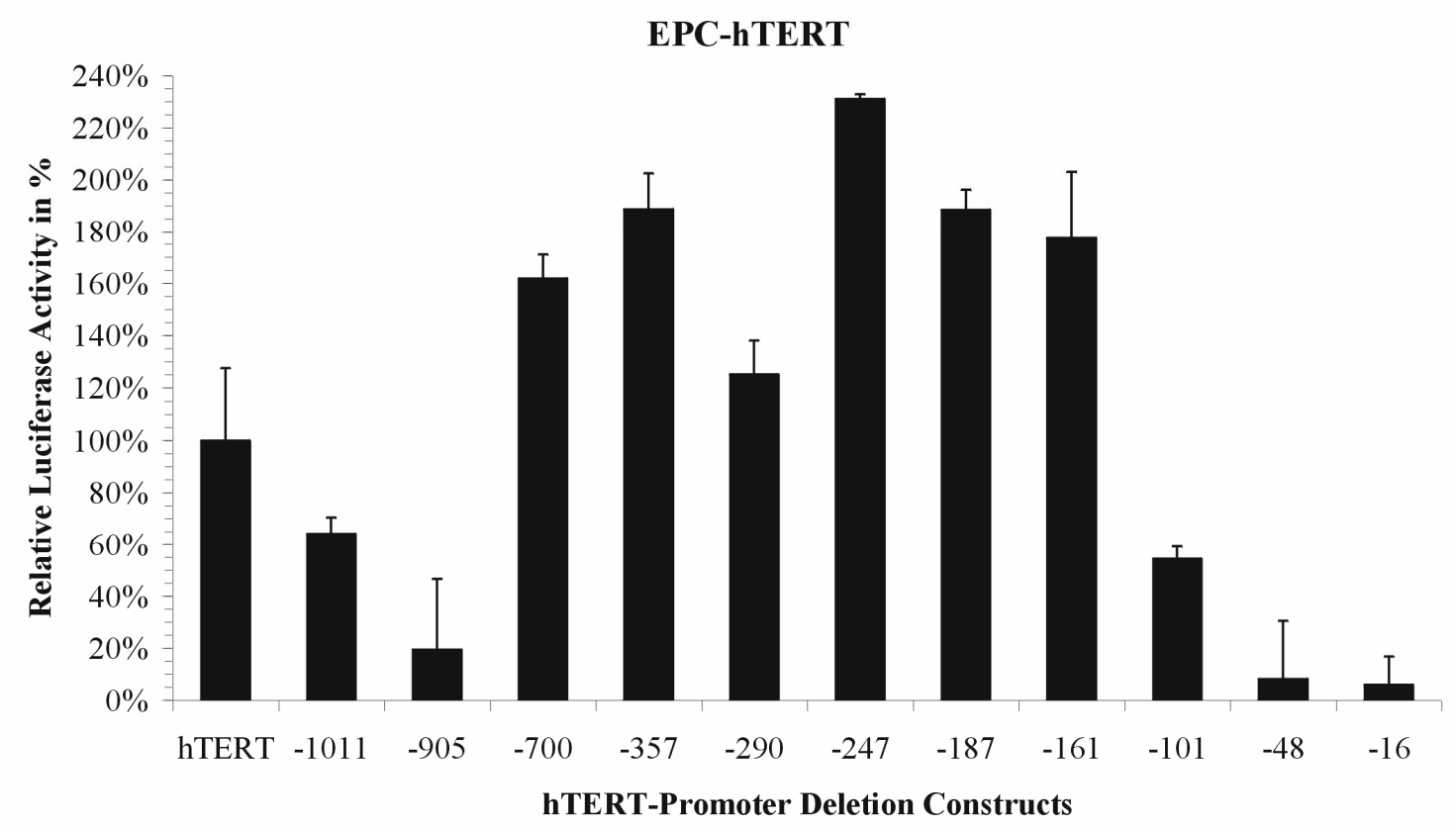

Abbildung 3.15: Relative Luziferaseaktivität der einzelnen Deletionskonstrukte in \%, im Vergleich zu hTERT (1242 bp) in EPC-hTERT 
-101 Konstrukt, einhergehend mit dem Verlust einer möglichen Sp1-Bindungsstellen, beobachtet werden. Die beiden Deletionskonstrukte -48 und -16 zeigten nur noch eine minimale Promotoraktivität von $8 \%$ und $6 \%$. Neben einer Silencer Region in der 5, Region des hTERT-Promotors wird die Promotoraktivität in EPC-hTERT somit hauptsächlich von der Sequenz der Konstrukte -247 bis -161 getragen, nach deren Verlust ein deutlicher Abfall der Aktivität zu verzeichnen war.

\subsubsection{Transiente Transfektion von EPC-D1}

Auch in EPC-D1 (Abbildung 3.16) zeigte sich eine geringe Promotoraktivität mit den beiden Deletionskonstrukten -1011 und -905 von $63 \%$ und $12 \%$. Im Gegensatz zu den anderen Zelltypen zeigten EPC-D1 aber mit dem Konstrukt -700 die höchste relative Promotoraktivität (251\%) im Vergleich zum hTERT-Promotor. Mit den darauf folgenden Konstrukten -357 und -290 konnte mit $191 \%$ und $118 \%$ ein positiv regulierendes Element in der Region 5' des Konstruktes -290 lokalisiert werden. Dieses Konstrukt enthält eine mögliche E2F-Bindungsstelle. Die Promotoraktivität mit dem 247 Konstrukt zeigte erneut einen hohen Wert (227\%), dieses Konstrukt enthält eine weitere mögliche E2F-Bindungsstelle. Mit dem folgenden Konstrukt (-187), das eine mögliche c-myc Bindungsstelle enthält, sank die Aktivität auf 193\%, gefolgt von einem weiteren signifikanten Abfall auf 103\% mit dem -161 Konstrukt. Dieser schrittweise

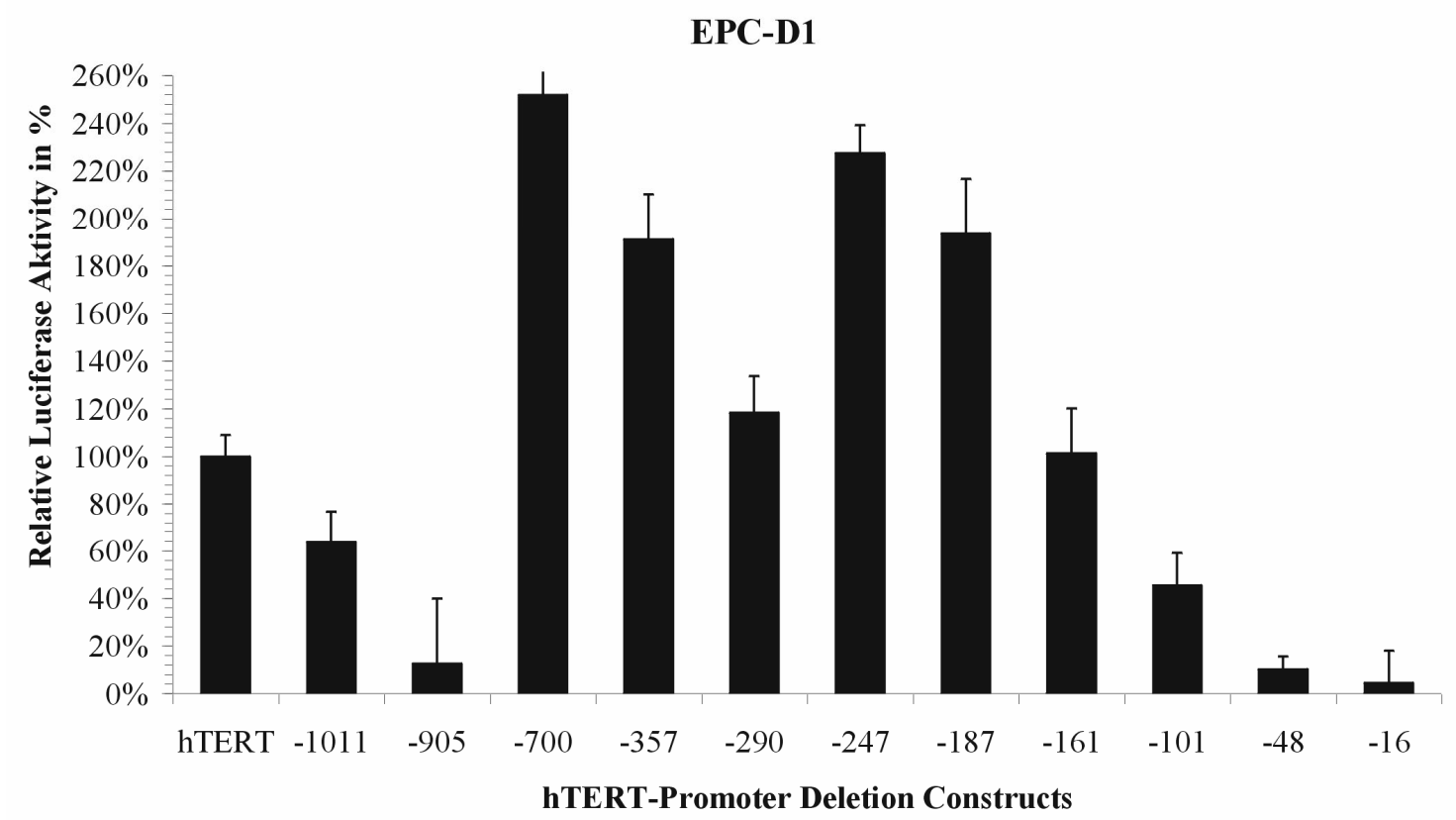

Abbildung4.16: Relative Luziferaseaktivität der einzelnen Deletionskonstrukte in \%, im Vergleich zu hTERT (1242 bp) in EPC-D1 
Abfall setzte sich mit den Konstrukten -101, -48 und -16 fort. Insgesamt zeigten EPCD1 eine im Vergleich zum gesamten hTERT-Promotor relative hohe Promotoraktivität in den Deletionskonstrukten. Mit dem Verlust der Konstrukte von -247 bis -48, korrelierend mit dem Verlust von möglichen c-myc und Sp1-Bindungsstellen, reduzierte sich diese Aktivität schrittweise.

\subsubsection{Transiente Transfektion von TE-12}

In TE-12 (Abbildung 3.17) war im Vergleich zu den verschiedenen Keratinozyten nur eine moderate Reduktion der Promotoraktivität mit den ersten beiden Konstrukten zu erkennen. Mit dem Konstrukt -1011 lag die Aktivität bei 69\% der Aktivität des hTERTPromotors. Im Gegensatz zu den anderen Zelltypen blieb die Aktivität mit den Konstrukten $-700,-357,-290$ und -247 in etwa stabil. Erst mit dem Konstrukt -187 , welches eine mögliche c-myc Bindungsstelle enthält, wurde ein Maximum der Promotoraktivität von $118 \%$ erreicht. Mit dem Konstrukt -161 waren noch $86 \%$, mit dem Konstrukt -101 noch 58\% und mit den Konstrukten -48 und -16 nur noch 8\% und 5\% der Aktivität des gesamten Promotors zu erkennen. Neben der hohen Aktivität des gesamten Promotors und einer weitgehend stabilen Aktivität zwischen den Konstrukten -1011 und -247 , konnte in TE-12 das Konstrukt -187 für die basale Promotoraktivität verantwortlich gemacht werden. Bei Verlust der c-myc Bindungsstelle kam es zu einer deutlichen Abnahme der Promotoraktivität.

TE-12

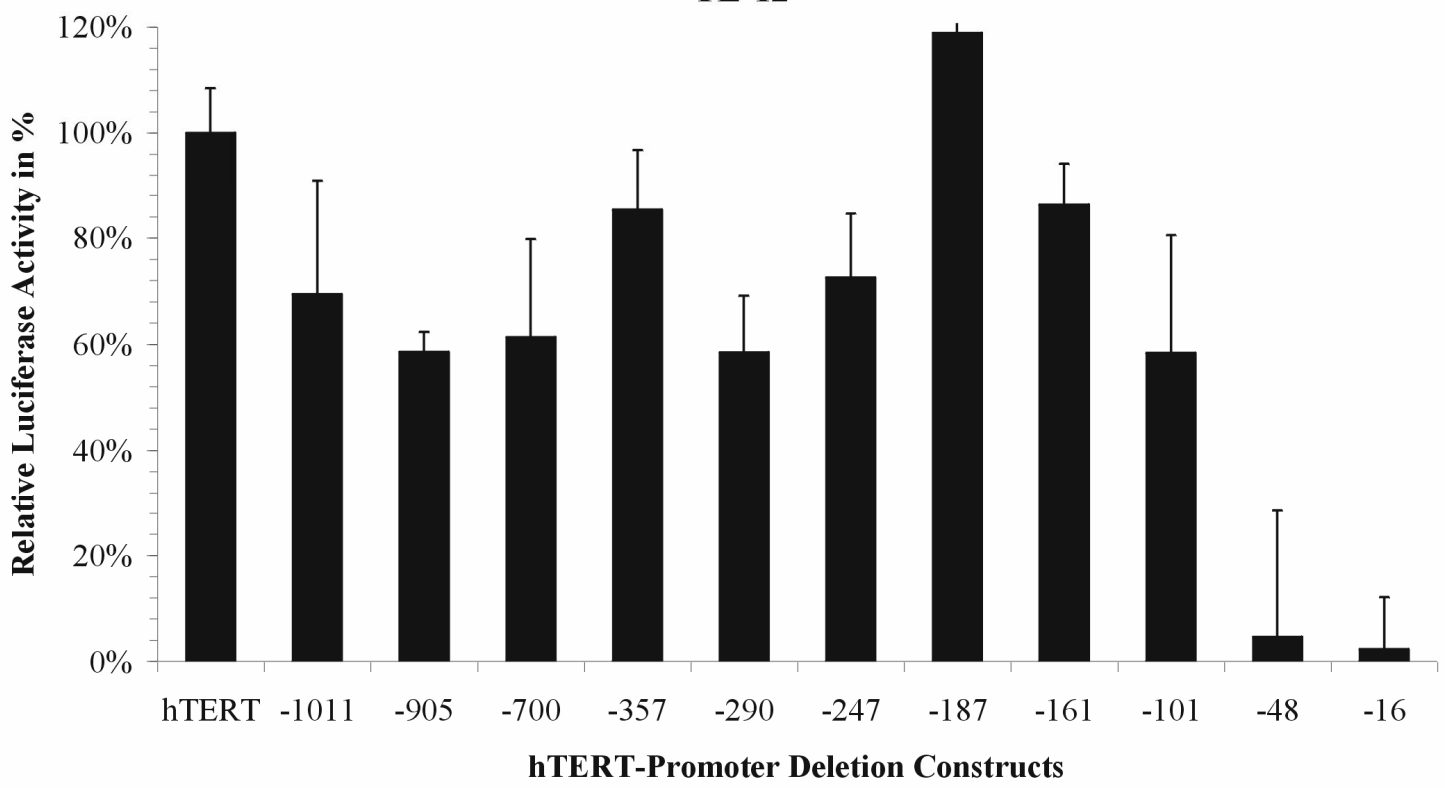

Abbildung4.17: Relative Luziferaseaktivität der einzelnen Deletionskonstrukte in \%, im Vergleich zu hTERT (1242 bp) in TE-12 


\subsection{Methylierung des hTERT-Promotors}

Die funktionelle Untersuchung des Methylierungsstatus eines Gens oder Promotors beruht auf der Annahme, dass durch eine Methylierung eines Promotors dessen Produkt nicht transkribiert und somit auch nicht exprimiert werden kann. CpG-Inseln sind DNASequenzen mit einem sehr hohen Gehalt an Cytosin und Guanin und Ziel der Methylierung. Der Methylierungsstatus einer DNA-Sequenz wird bestimmt, indem die zu untersuchenden DNA-Abschnitte zuerst mit Natriumbisulfit behandelt und danach mittels PCR amplifiziert werden. Natriumbisulfit wandelt nur unmethyliertes Cytosin in Uracil um und macht die DNA für methylierungsspezifische Primer unzugänglich. Methylierte Cytosine einer DNA-Sequenz bleiben erhalten. Das heißt, es können in der nachfolgenden PCR entweder nur unmethylierte oder methylierte Sequenzen mit den spezifischen Primerpaaren amplifiziert werden.

Der hTERT-Promotor ist ein sehr GC-reicher Promotor mit drei definierten CpG-Inseln in den ersten 1242 bp 5' der ATG Translations-Startstelle. Basierend auf den Erkenntnissen aus den transienten Transfektions-Studien sind zwei CpG-Inseln ausgewählt worden, zu denen spezifische PCR-Primer hergestellt wurden. Region 1 befindet sich zwischen -852 bp und -728 bp und Region 2 zwischen -635 bp und -438 bp 5' der Transkriptions-Startstelle der humanen Telomerase.

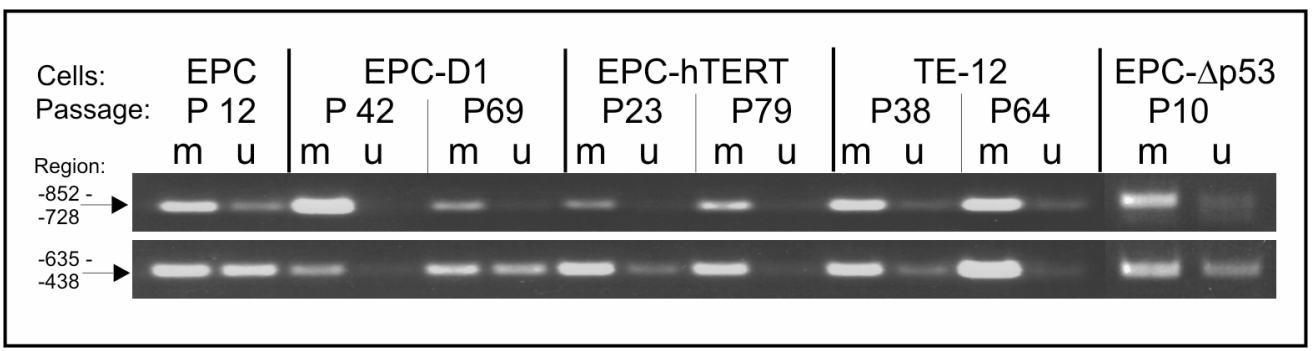

\footnotetext{
Abbildung 3.18: Die Methylierungs spezifische PCR von zwei Regionen des hTERTPromotors (Region 1: -852 bp bis -728 bp; Region 2: -635 bp bis -438 bp). Angegeben ist die Passage der jeweiligen Zellen, für die eine PCR für methylierte (m) und unmethylierte (u) CpG Inseln durchgeführt wurde.
}

In Region 2 (Abbildung 3.18) waren bei allen Zelltypen sowohl in der für methylierte DNA als auch in der für unmethylierte DNA spezifische PCR-Banden zu erkennen. Die DNA Sequenz der Region 2 war demnach in allen Zellen z.T. nicht methyliert und konnte somit als interne Kontrolle für die PCR genutzt werden. In EPC war auch Region 1 unmethyliert. EPC-D1, EPC-hTERT und TE-12 zeigten dagegen in hohen und 
niedrigen Passagen in Region 1 Banden bei der für methylierte DNA spezifischen PCR und waren somit in dieser Region methyliert. Auch EPC- $\Delta$ p53, die wie EPC aufgrund der frühen Seneszenz nur in einer Passage untersucht werden konnten, zeigten eine Methylierung in Region 1.

\subsection{Expression verschiedener Transkriptionsfaktoren}

Um die Proteinexpression der untersuchten Transkriptionsfaktoren mit den funktionellen Analysen der transienten Transfektionen und der Protein-DNAInteraktion $\mathrm{zu}$ vergleichen, wurde die Expression von pRb, E2F-1, c-myc und Sp1 mittels Western Blot untersucht (Abbildung 3.19). Die für c-myc charakteristische Doppelbande bei $62 \mathrm{kDa}$ war in allen fünf Zelltypen gleich stark. Ebenso war das ubiquitär exprimierte Protein Sp1 in allen Zelltypen bei $110 \mathrm{kDa}$ zu erkennen, zeigte aber in EPC eine etwas stärkere Expression. Hyperphosphoryliertes pRb, erkennbar an der oberen von zwei sichtbaren Banden im Bereich von 106 kDa, war in TE-12 und EPC-D1 exprimiert. In EPC- $\Delta$ p53 konnte ebenfalls eine schwache Bande des hyperphosphorylierten $\mathrm{pRb}$ gezeigt werden. In EPC-hTERT zeigte sich nur hypophosphoryliertes pRb bei $106 \mathrm{kDa}$. In den primären EPC zeigte sich keine $\mathrm{pRb}$ Expression. Für E2F-1 konnte in allen fünf Zelltypen eine Expression nachgewiesen werden. In TE-12, gefolgt von EPC-D1, war die E2F-1 Expression am stärksten.

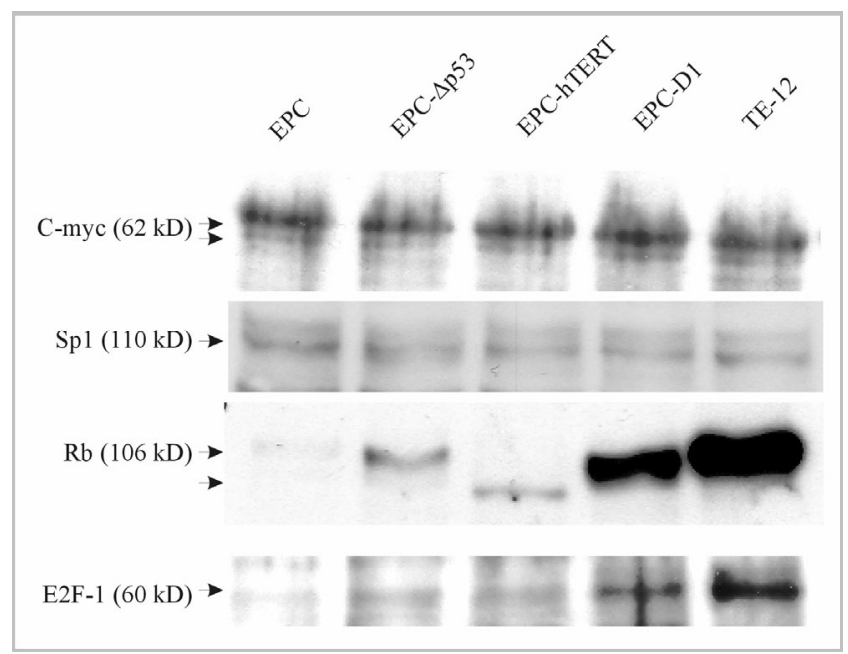

Abbildung 3.19: Western Blot der Transkriptionsfaktoren, c-myc, Sp1, pRb und E2F-1 für alle fünf Zelltypen. 


\subsection{Untersuchung der DNA-Protein-Bindung mittels EMSA}

\subsubsection{Transkriptionsfaktor-Bindungsstellen im hTERT-Promotor}

Aufgrund der unterschiedlichen Ergebnisse in den transienten Transfektionen im Vergleich der einzelnen Zelltypen wurde der hTERT-Promotor auf mögliche "transacting"-Faktoren untersucht und mittels EMSA eine mögliche Protein-DNA-Interaktion ermittelt. Dazu wurden nukleäre Proteinextrakte und radioaktiv markierte Oligonukleotide verschiedener Sequenzen des hTERT-Promotors inkubiert und mittels PAGE analysiert. Die Spezifität der Protein-DNA-Komplexe aus Transkriptionsfaktor und hTERT-Oligonukleotid wurde mit verschiedenen Kompetitoren (Wildtyp-, mutiertem und Consensus-Oligonukleotid) und Antikörpern bestimmt.

Das Screening des hTERT-Promotors auf mögliche TranskriptionsfaktorBindungsstellen zeigte multiple Sp1-Bindungsstellen im Bereich des Core-Promotors. Im Konstrukt -101 befanden sich zwei typische Sp1-Bindungsstellen bei -66 bp (CCCAGCCC) und bei -99 bp (CCGCC), die als SplcWT(-66) und SplbWT(-99) bezeichnet wurden. Im Konstrukt -161 war eine weitere Sp1-Bindungsstelle bei -121 bp mit der Sequenz CCCAGCCC zu erkennen, die SplaWT(-121) genannt wurde. Weiter 5' im Konstrukt -187 wurde ein E-box Motiv mit der Sequenz CACGTG bei -177 bp lokalisiert, das als E-boxWT(-177) bezeichnet wurde. Im nächsten, 5' gelegenen, Konstrukt -247 lagen zwei mögliche E2F-Bindungsstellen bei -188 bp und -210 bp in beiden Orientierungen (TTCGCG), E2FWT(-188) und E2FWT(-210). Auch im nächsten Konstrukt -290 waren zwei E2F-Bindungsstellen bei -266 bp und $-281 \mathrm{zu}$ finden (E2FWT(-266) und E2FWT(-281)). Das Konstrukt -357 enthielt bei -291 bp eine Sp1Bindungsstelle, die mit einer Wilms-Tumor-1 (WT-1) Bindungsstelle überlappte und somit als WT/Sp1WT(-291) bezeichnet wurde. Im Konstrukt -700 wurden keine relevanten Transkriptionsfaktor-Bindungsstellen gefunden. Die nächste Bindungsstelle war ein c-myb-Element bei -819 bp im Konstrukt -905 , das als c-mybWT(819) bezeichnet wurde. Im Konstrukt -1011 wurde eine mit dem Östrogenrezeptor interagierende Sequenz (Estrogen Responsive Element, ERE) bei -953 bp gefunden, die als EREWT(-953) bezeichnet wurde. Im 5' gelegenen Teil des untersuchten hTERTPromotors waren noch eine NF- $\kappa \beta$-Bindungsstelle bei -1011 bp und eine GKLFBindungsstelle bei $-1190 \mathrm{bp}$ zu finden, die entsprechend als $N F-\kappa \beta W T(-1011)$ und GKLFWT(-1190) bezeichnet wurden (Abbildungen 3.20 bis 3.25). 


\subsubsection{Transkriptionsfaktoren in EPC}

In EPC zeigte die transiente Transfektion, dass der hTERT-Promotor hauptsächlich über eine Sp1-Bindungsstelle reguliert wurde. Der größte Verlust der transkriptionellen Aktivität zeigte sich nach Deletion des Konstruktes -101, welches eine Sp1Bindungsstelle enthält. In EPC war demnach mit dem Oligonukleotid SplcWT(-66) ein deutlicher Protein-DNA-Komplex zu sehen (Abbildung 3.20 A). Dieser Komplex war sowohl durch dazu gegebenes Wildtyp Oligonukleotid als auch durch dazugegebnes Sp1-Consensus-Oligonukleotid, nicht aber durch mutiertes Oligonukleotid der entsprechenden Sequenz, eliminierbar und somit spezifisch. Zusätzlich war der Komplex zu einem erheblichen Teil durch den Sp1-Antikörper (1C6) eliminierbar und deswegen spezifisch für den Transkriptionsfaktor Sp1. Weiterhin wurde dieser Sp1 spezifische Protein-DNA Komplex komplett durch den p53-Antikörper (PAb-240) eliminiert. Die zweite, 5' gelegene Sp1-Bindungsstelle im Oligonukleotid Sp1bWT(-99) im Konstrukt -101 (Abbildung 3.20 B) zeigte zwei etwas schwächere Protein-DNAKomplexe, einen etwas intensiveren oberen (a) und einen weniger intensiven unteren (b) Komplex. Beide Komplexe waren wiederum durch Wildtyp und Sp1-Consensus Oligonukleotide, nicht aber durch mutierte Oligonukleotide eliminierbar. Nach Inkubation mit einem anti-Sp1 Antikörper waren sowohl der obere als auch der untere Komplex komplett eliminiert und somit spezifisch für Sp1. Auch eine p53-Bindung an diesen Sp1-Oligonukleotid Komplex kann durch die Eliminierung mit einem p53Antikörper (PAb 240) vermutet werden. Die dritte Sp1-Bindungsstelle, SplaWT(-121) (Abbildung 3.20 C), im Konstrukt -161 zeigte einen schwachen aber spezifischen Sp1Komplex (a). Mit allen anderen Oligonukleotiden konnte mit nukleärem Extrakt aus EPC keine DNA-Protein-Interaktion nachgewiesen werden. (Abbildung 3.22: Beispiel der c-myc Bindungsstelle, Abbildung 3.24: Beispiel der GKLF-Bindungsstelle).

\subsubsection{Transkriptionsfaktoren in EPC- $\Delta$ p53}

Auch in EPC- $\Delta$ p53 war der hTERT-Promotor hauptsächlich durch Sp1-Bindungsstellen reguliert, welche vor allem im Konstrukt -161 lagen. Infolgedessen war in EPC- $\Delta$ p53 der stärkste Protein-DNA-Komplex mit dem Oligonukleotid SplaWT(-121) (Abbildung 3.20 C) am intensivsten. Dieser Sp1-Komplex war sowohl durch ein Wildtyp Oligonukleotid als auch durch ein Sp1-Consensus Oligonukleotid, nicht aber durch ein mutiertes Oligonukleotid eliminierbar und somit spezifisch für die Bindung von Sp1. 
Zusätzlich war der Sp1-Komplex durch den Sp1 Antikörper (IC6) komplett eliminierbar. Die Eliminierung des Komplexes durch einen p53-Antikörper (PAb 240) lässt auch eine Interaktion mit p53 vermuten. Die 3' gelegenen Sp1-Bindungsstellen SplcWT(-66) und SplbWT(-99) im Konstrukt -101 (Abbildung 3.20 B, A) zeigten ebenso Sp1-Komplexe. Zusätzlich zur Eliminierung durch Sp1-Antikörper war auch hier eine Eliminierung durch p53-Antikörper zu sehen.

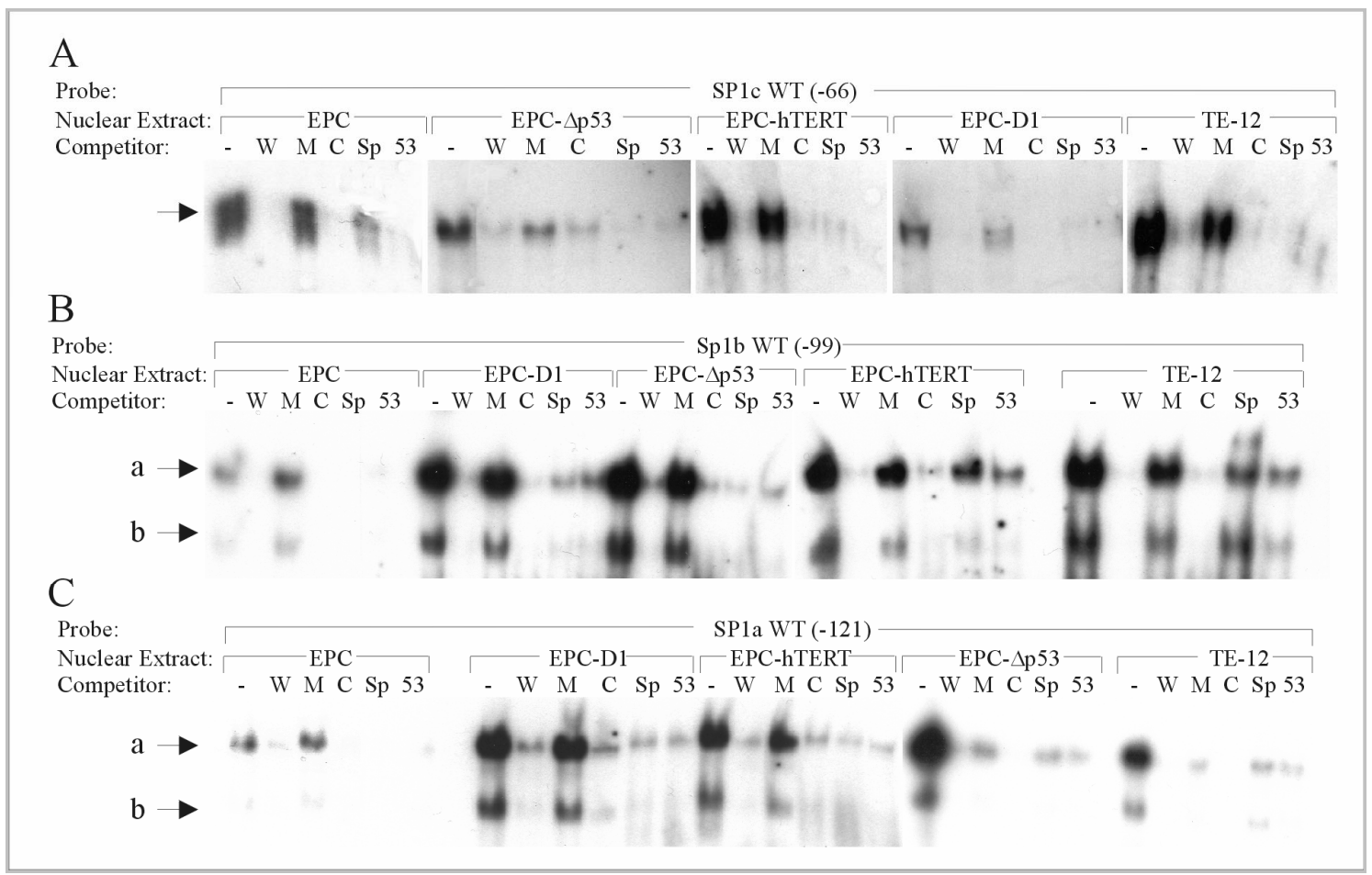

Abbildung 3.20: Electro mobility shift assay (EMSA) der Sp1-Bindungsstellen Sp1cWT(-66) (A), SplbWT(-99) (B) und SplaWT(-121) (C) von EPC, EPC-Ap53, EPC-hTERT, EPC-D1 und TE-12. Nukleärer Extrakt wurde mit je einem Oligonukleotid zusammen gegeben (-) und zusätzlich mit entweder Wildtyp (W), mutiertem (M) oder Sp1-Consensus Oligonukleotid (C) inkubiert, bevor sie im PAGE analysiert wurden. Supershift Assays wurden mit Sp1-Antikörper 1C6 (Sp) oder p53-Antikörper PAb-240 (53) durchgeführt.

\subsubsection{Transkriptionsfaktoren in EPC-hTERT}

In EPC-hTERT war bei der transienten Transfektion eine konstant hohe Promotoraktivität bis zu dem Konstrukt $-161 \mathrm{zu}$ beobachten. So zeigt die Sp1Bindungsstelle, SplaWT(-121) (Abbildung 3.20 C), einen oberen (a) und einen unteren (b) Sp1-Komplex, der zu einem erheblichen Teil durch den Sp1-Antikörper (1C6) eliminierbar war. Weiterhin wurde dieser Sp1-Komplex komplett durch den p53Antikörper (PAb-240) eliminiert. Auch Konstrukt -101 zeigte an der 3' gelegenen Sp1Bindungsstelle im Oligonukleotid SplcWT(-66) einen intensiven Protein-DNA- 
Komplex (Abbildung 3.20 A). Dieser Komplex wurde durch Kompetitions-Experimente und Interaktion mit dem Sp1-Antikörper als spezifisch für die Bindung von Sp1 definiert. Zusätzlich war der Sp1-Komplex auch durch den p53-Antikörper (PAb-240) eliminierbar. Die zweite, weiter 5' gelegene, Sp1-Bindungsstelle Sp1bWT(-99) des Konstruktes -101 (Abbildung 3.20 B) zeigte zwei deutliche Sp1-Komplexe. Durch den Sp1- oder p53-Antikörper war der obere Komplex aber nur geringfügig zu eliminieren. Die Bindung an die c-myc bindende E-box bei -177 bp (E-boxWT(-177)) zeigte in EPChTERT einen im Vergleich zu EPC- $\Delta$ p53 stärker ausgeprägten c-myc-Komplex (Abbildung 3.21). Eine deutliche, komplette Elimination durch den polyklonalen cmyc-Antikörper (N-262) zeigte die Spezifität des c-myc Komplexes an. Interessanterweise zeigte sich eine eher schwache Elimination durch den monoklonalen (C-33) c-myc-Antikörper.

\subsubsection{Transkriptionsfaktoren in EPC-D1}

In EPC-D1 zeigte die transiente Transfektion ein deutlich negatives cis-regulatorisches Element in Konstrukt -290, welches eine E2F-Bindungsstelle enthält. Die mit dem Konstrukt -247 wiedererlangte hohe Promotoraktivität reduzierte sich mit Deletion der Konstrukte von -247 bis -48 schrittweise, korrelierend mit dem Verlust einer möglichen c-myc- und diversen Sp1-Bindungsstellen. Infolgedessen zeigen die EMSAErgebnisse der 3' gelegenen E2F-Bindungsstelle E2FWT(-266) einen deutlichen E2FKomplex (Abbildung 3.21). Dieser Komplex wurde durch Kompetitions-Experimente als spezifischer E2F-Komplex definiert. Zusätzlich war der Komplex durch den E2F-1Antikörper (C-20) komplett eliminierbar, durch den E2F-6-Antikörper (K-20) nur teilweise eliminierbar. Die zweite, 5' gelegene, E2F-Bindungsstelle E2FWT(-281) des Konstruktes -290 (Abbildung 3.21) zeigte ebenfalls einen deutlichen und spezifischen E2F-Komplex. Dieser E2F-Komplex war auch durch den E2F-1-Antikörper (C-20) komplett und durch den E2F-6-Antikörper (K-20) teilweise eliminierbar.

Der an die E-box bindende spezifische c-myc-Komplex bei -177 bp (E-boxWT(-177)) war in EPC-D1 im Vergleich zu EPC und EPC- $\Delta$ p53 stärker ausgeprägt (Abbildung 3.22). Der c-myc-Komplex ließ sich durch den polyklonalen c-myc-Antikörper (N-262) komplett eliminieren.

Der weitere Verlust an Promotoraktivität in EPC-D1 ging mit der Sp1-Bindungsstelle SplaWT(-121) (Abbildung 3.20 C) des Konstruktes -161 einher. Auch hier war ein deutlicher und spezifischer oberer (a) und unterer (b) Sp1-Komplex zu erkennen, der 
jeweils durch den Sp1-Antikörper (1C6) und den p53-Antikörper (PAb-240) eliminierbar war. Die 5' gelegene Sp1-Bindungsstelle Sp1bWT(-99) des Konstruktes 101 (Abbildung 3.20 B) zeigte zwei Sp1-Komplexe. Durch Sp1- oder p53-Antikörper war der obere Komplex im Vergleich zu den anderen Zelltypen am geringsten eliminierbar. Die im Konstrukt -101 3' gelegene Sp1-Bindungsstelle Sp1cWT(-66) zeigte den schwächsten, aber dennoch spezifischen Sp1-Komplex (Abbildung 3.20 A).

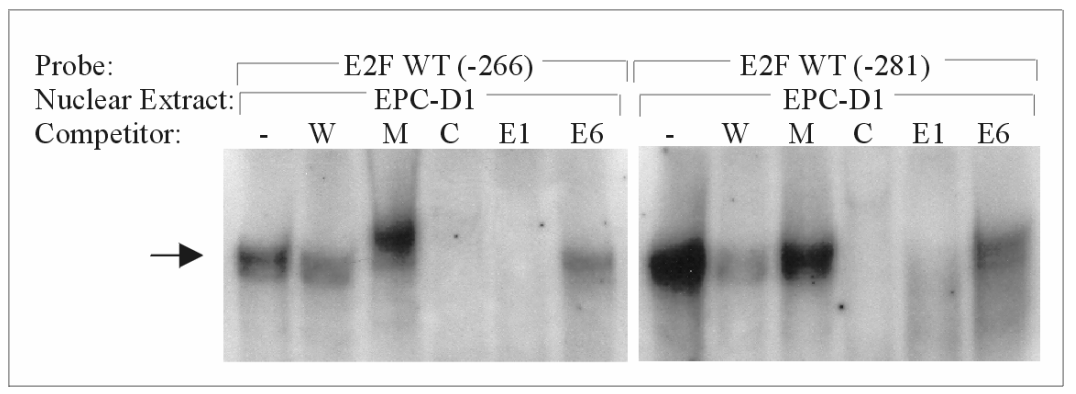

\begin{abstract}
Abbildung 3.21:: Electro mobility shift assay (EMSA) der E2FBindungsstellen E2F WT(-266) und E2F WT(-281) von EPC-D1. Nukleärer Extrakt wurde mit je einem Oligonukleotid zusammen gegeben (-) und zusätzlich mit entweder Wildtyp (W), mutiertem (M) oder E2F-Consensus Oligonukleotid inkubiert, bevor er im PAGE analysiert wurde. Supershift Assays wurden mit E2F-1 (E1) und E2F-6 (E6) Antikörper durchgeführt.
\end{abstract}

\title{
3.7.6 Transkriptionsfaktoren in TE-12
}

Die Promotoraktivität in TE-12 erreichte im Konstrukt -187 in der transienten Transfektion den höchsten Wert. Infolgedessen war auch die Bindung von c-myc an die E-box bei -177 bp $(E-b o x W T(-177))$ in TE-12 im Vergleich zu den verschiedenen Keratinozyten am stärksten ausgeprägt. Es war ein deutlicher Komplex zu sehen, der sich durch Wildtyp und mutierte Oligonukleotide eliminieren ließ und somit eine spezifische Bindung an die vorhandenen E-box zeigte (Abbildung 3.22). Zusätzlich unterstreicht die Eliminierung dieses c-myc-Komplexes durch den polyklonalen c-mycAntikörper (N-262) und den monoklonalen c-myc-Antikörper (C-33) die spezifische Bindung von c-myc an die Sequenz der E-box in TE-12.

TE-12 zeigten in Konstrukt -101 an der 3' gelegenen Sp1-Bindungsstelle Sp1cWT(-66) neben EPC den schwächsten, aber dennoch spezifischen Sp1-Komplex (Abbildung 3.20 A). Der Komplex war durch den Sp1-Antikörper (1C6) und den p53-Antikörper (PAb240) eliminierbar. Die zweite, 5' gelegene, Sp1-Bindungsstelle SplbWT(-99) des Konstruktes -101 (Abbildung 3.20 B) zeigte zwei Sp1-Komplexe. Beide Komplexe 
waren wiederum spezifisch. Der obere Komplex war durch Sp1- oder p53-Antikörper eliminierbar. Die dritte Sp1-Bindungsstelle, SplaWT(-121) (Abbildung 3.20 C), zeigte wiederum einen deutlichen und spezifischen Sp1-Komplex, der mit einer hohen Promotoraktivität der Transfektionsergebnisse korreliert. Eine Elimination durch Wildtyp und Sp1-Consensus-Oligonukleotide war in beiden Fällen möglich. Sowohl der Sp1-Antikörper als auch der p53-Antikörper konnten den Komplex zum größten Teil eliminieren.

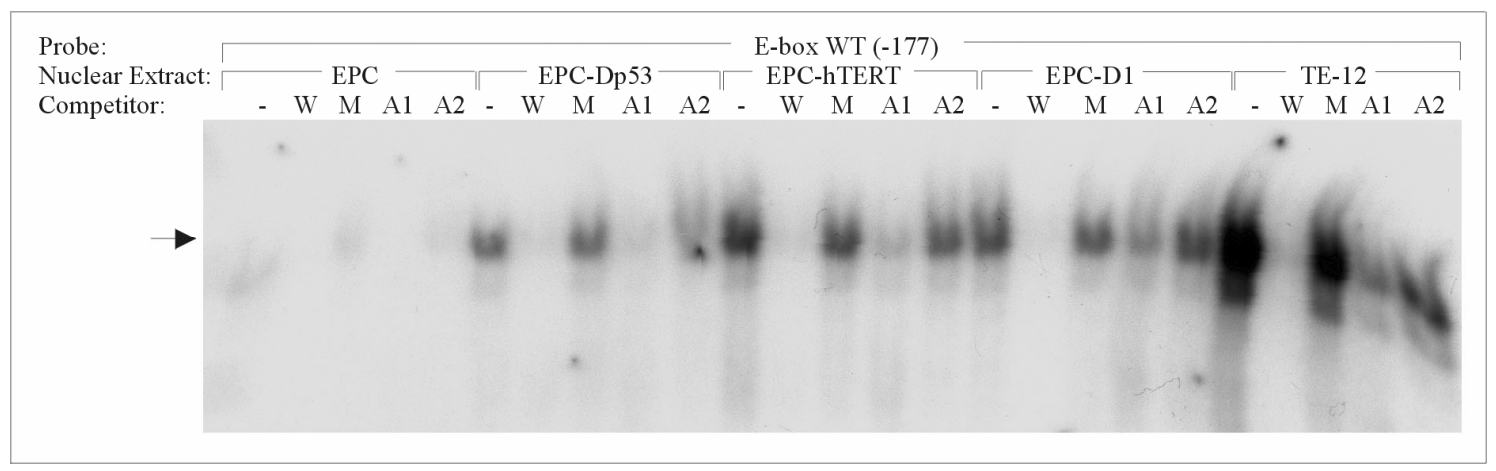

Abbildung 3.22: Electro mobility shift assay (EMSA) der c-myc Bindungsstelle E-boxWT(-177) von EPC, EPC- $\Delta$ p53, EPC-hTERT, EPC-D1 und TE-12. Nukleärer Extrakt wurde mit je einem Oligonukleotid zusammen gegeben (-) und zusätzlich mit entweder Wildtyp (W) oder mutiertem (M) Oligonukleotid inkubiert, bevor er im PAGE analysiert wurde. Supershift Assays wurden mit polyklonalem (N-262) und monoklonalem (C-33) c-myc Antikörper durchgeführt.

\subsubsection{Weitere nicht spezifische Transkriptionsfaktoren}

Wie in Abbildung 3.23 gezeigt, war auch im Konstrukt -357 in der Region einer möglichen Sp1/Wilms-Tumor-1-Bindungsstelle ein deutlicher Protein-DNA-Komplex zu erkennen. Dieser Komplex war nur in EPC-hTERT, EPC-D1 und TE-12 erkennbar und wurde nur teilweise durch den Wildtyp Kompetitor eliminiert. Zusätzlich wurde der Komplex auch durch das Oligonukleotid mit der mutierten Bindungsstelle von Sp1/WT1 eliminiert und war somit nicht spezifisch.

Die Untersuchungen der 5' gelegenen Konstrukte -905, -1011 und dem „full length“Promotor ergab keine spezifischen Bindungen an die jeweiligen in der Literatur angegebenen Transkriptionsfaktor-Bindungsstellen. Abbildung 3.24 zeigt hier exemplarisch die Ergebnisse des Mobility Shift Assays des Oligonukleotids GKLFWT(1190). Bei EPC-hTERT, EPC-D1 und TE-12 war ein deutlicher GKLF-Komplex zu sehen, dieser wurde aber durch Wildtyp-Kompetitor als auch durch mutiertes 
Oligonukleotid eliminiert. Zusätzlich $\mathrm{zu}$ den auch oben bereits beschriebenen Kompetitions Experimenten wurde hier noch ein mutiertes Oligonukleotid (R) als Probe eingesetzt, an dem keine DNA-Protein-Interaktion erwartet wurde, aber ein Komplex zu sehen war.

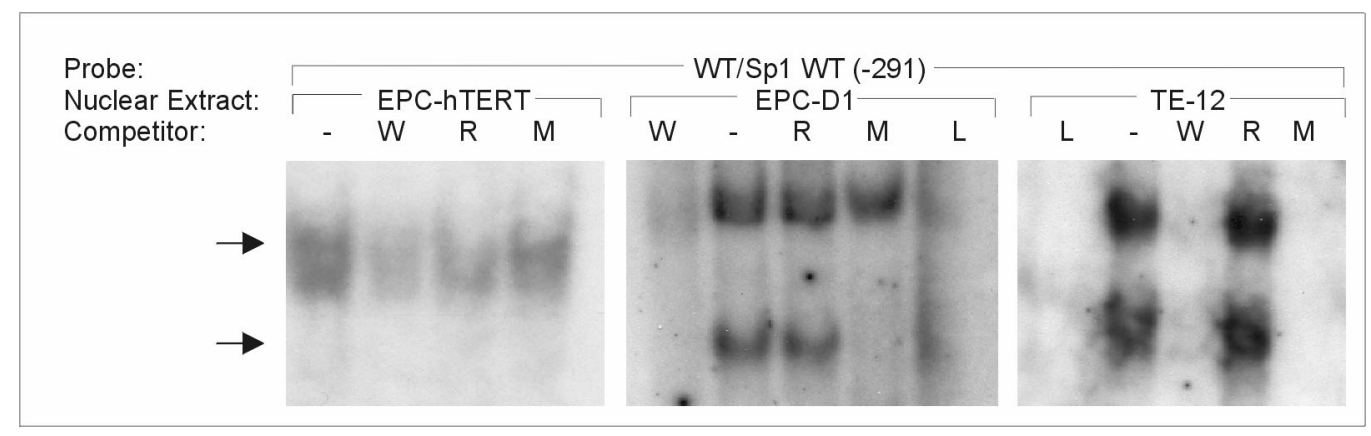

Abbildung 3.23: : Electro mobility shift assay (EMSA) der Wilms-Tumor-1/Sp1Bindungsstelle WT/Sp1 WT(-291) von EPC-hTERT, EPC-D1 und TE-12. Neben einer Leerprobe (L) wurde nuklearer Extrakt mit je einem Oligonukleotid zusammen gegeben (-) und zusätzlich mit entweder Wildtyp (W) oder mutiertem (M) Oligonukleotid inkubiert, bevor er im PAGE analysiert wurde.

Auch die DNA-Protein-Interaktion an den anderen Oligonukleotiden $c$-mybWT(819), EREWT(-953) und NF- $\beta$ ergab keine spezifischen Ergebnisse (Abbildung 3.25). Es war jeweils ein Komplex aus DNA und Oligonukleotid zu erkennen, jedoch war die Kompetition nicht spezifisch. Zusätzlich war ein Komplex in der markierten mutierten Probe $(\mathrm{R}) \mathrm{zu}$ erkennen.

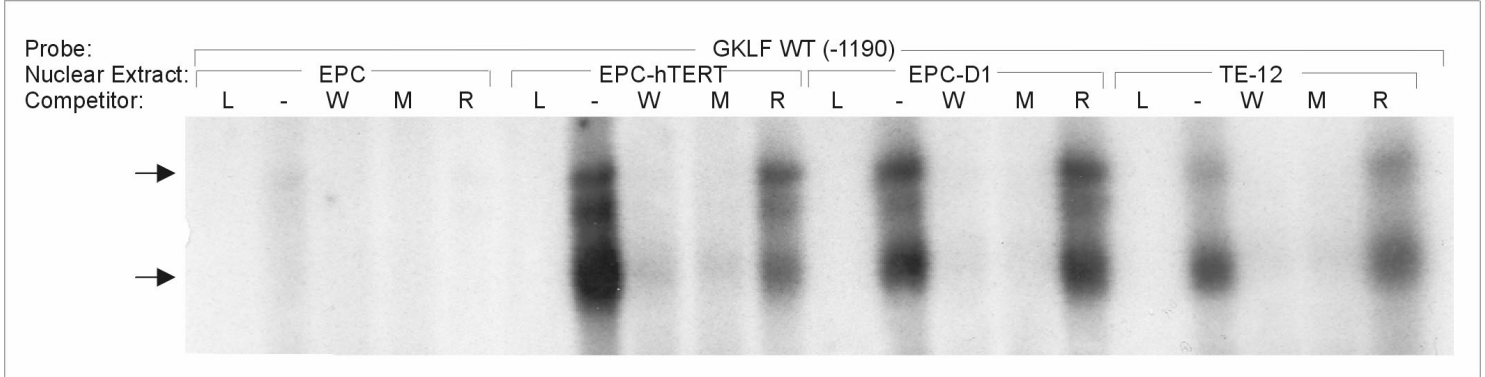

Abbildung 3.24: Electro mobility shift assay (EMSA) der GKLF Bindungsstelle GKLF WT(-1190) von EPC, EPC-hTERT, EPC-D1 und TE-12. Neben einer Leerprobe (L) wurde nukleärer Extrakt mit je einem Oligonukleotid zusammen gegeben (-) und zusätzlich mit entweder Wildtyp (W) oder mutiertem (M) Oligonukleotid inkubiert, bevor er im PAGE analysiert wurde. 
A

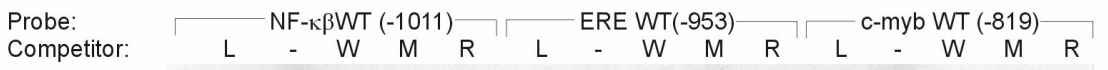

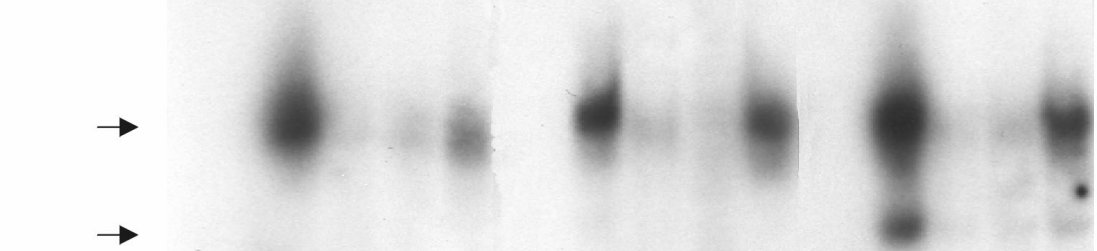

B

Probe:

Competitor:

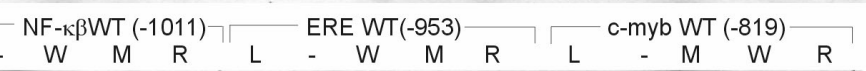

$\rightarrow$
$\rightarrow$

C

Probe:

Competitor:

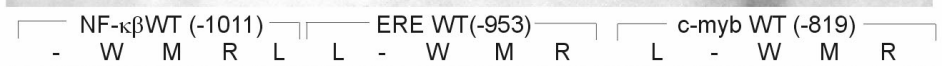

$\rightarrow$
$\rightarrow$

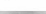

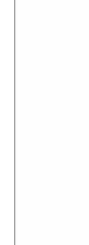

Abbildung 3.25: Electro mobility shift assay (EMSA) der NF-kb, ERE und c-myb Bindungsstellen NF-kb WT(-1011), ERE WT (-953) und c-myb WT (-819) von A: EPC-hTERT B: EPC-D1 und C. TE-12. Neben einer Leerprobe (L) wurde nukleärer Extrakt mit je einem Oligonukleotid zusammen gegeben (-) und zusätzlich mit entweder Wildtyp (W) oder mutiertem (M) Oligonukleotid inkubiert, bevor er im PAGE analysiert wurde. 


\section{Diskussion}

\subsection{Telomerase Regulation und maligne Transformation}

Tumore entstehen, wenn die existierenden Kontrollmechanismen einer Zelle umgangen werden und es dadurch zur unkontrollierten Proliferation kommen kann. Hierzu sind mehrere genetische Alterationen notwendig, weshalb man von der ,Multihit-Theorie“ der Krebsentstehung spricht. Diese besagt, dass in einer Zelle mehrere Mutationen akkumulieren müssen bevor sie maligne entartet (Weinberg 1989). Onkogenaktivierung und Inaktivierung von Tumorsuppressorgenen und vermutlich andere Veränderungen, die sich auf die Wachstumskontrolle einer Zelle auswirken, sind wichtige Alterationen im Prozess der malignen Transformation. Ein Kontrollmechanismus, der die Lebensdauer von Zellen mitbestimmt und dem sich Tumorzellen entziehen können, ist die abnehmende Länge der chromosomalen Telomere. Nur wenige Zellen, denen es gelingt ihre lebenswichtigen Telomere zu stabilisieren, können das Stadium der Seneszenz überwinden und in das Stadium der Immortalität eintreten (Counter et al. 1992). Immortalität ist jedoch eine wichtige Voraussetzung der malignen Transformation. Ohne Telomerase oder einen alternativen Mechanismus, die Telomere zu erhalten, kann eine Zelle das Mortalitätsstadium nach bisherigen Erkenntnissen nicht überwinden. Der Prozess der malignen Transformation von normalen sterblichen humanen Zellen zu unsterblichen, sich unkontrolliert teilenden Tumorzellen ist eng mit der Verlängerung der Telomere und mit der unkontrollierten Aktivierung der Telomerase verbunden. Diese Telomeraseaktivität wiederum wird hauptsächlich transkriptionell kontrolliert (Takakura et al. 1998). Obwohl auch andere Mechanismen wie post-transkriptionelle Regulation (Ulaner et al. 2001; Cerezo et al. 2002) oder posttranslationale Modifikationen (Liu et al. 2001; Aisner et al. 2002) beschrieben wurden, ist die transkriptionelle Kontrolle des hTERT Gens der limitierende Schritt in der Aktivierung der humanen Telomerase (Poole et al. 2001). Mit der Sequenzierung und Charakterisierung des hTERT-Promotors konnten ausführliche Untersuchungen zur transkriptionellen Regulation der humanen Telomerase durchgeführt und zahlreiche Transkriptionsfaktoren, einschließlich Onkogen und Tumorsuppressorgen-Produkte, charakterisiert werden (Takakura et al. 1999; Kyo et al. 2002). Diese Untersuchungen zur Regulation der humanen Telomerase wurden jedoch hauptsächlich an Tumorzellen, mit einer schon stabilen Telomerlänge und robusten Telomeraseaktivität ausgestattet 
sind, durchgeführt. In Tumorzellen finden sich jedoch eine große Anzahl an genetischen Veränderungen, die alle an der malignen Transformation und auch an der Aktivierung der Telomerase beteiligt sein könnten, so dass es schwierig ist, allein aus Tumorzellen etwas über die Regulation der Telomerase zu lernen.

Bei der Entstehung des Plattenepithelkarzinoms des Ösophagus sind, neben der Überexpression der Telomerase, die Überexpression des Zellzyklus regulierenden Proteins Cyclin D1 (Jiang et al. 1993; Bartkova et al. 1995) und der Verlust der Tumorsuppressorgene p53 und p16 die häufigsten genetischen Veränderungen. (Hollstein et al. 1990; Hollstein et al. 1991; Huang et al. 1993; Nobori et al. 1994). Ob diese Onkogene oder Tumorsupressorgene aber einen Einfluss auf die Aktivierung der Telomerase haben, ist jedoch unklar. Um dieser Frage nachzugehen, wurde in dieser Arbeit die transkriptionelle Regulation der funktionellen Untereinheit der humanen Telomerase, hTERT, in einem Modell untersucht. Dieses Modell reflektiert die unterschiedlichen genetischen Veränderungen, die im Prozess der malignen Transformation von Plattenepithelzellen des Ösophagus wichtig sind. Es besteht aus fünf verschiedenen Zelltypen, die eben diese entscheidenden genetischen Veränderungen im „Multi-Step“-Prozess der ösophagealen Karzinogenese repräsentieren. Dies sind primäre humane ösophageale Keratinozyten (EPC) und deren Derivate, in denen entweder Cyclin D1 (EPC-D1), humane Telomerase (EPC-hTERT) oder dominant negatives p53 Protein (EPC- $\Delta$ p53) überexprimiert wurde sowie die ösophageale Plattenepithel-Karzinom-Zelllinie TE-12.

Es konnte erstmals gezeigt werden, dass die Transkription und Aktivität der Telomerase in Abhängigkeit von den jeweiligen eingebrachten, genetischen Veränderungen unterschiedlich reguliert wird. Betrachtet man die wichtigsten Unterschiede in der Regulation der Telomerase der einzelnen Zellen, so lässt sich zunächst feststellen, dass der hTERT-Promotor in normalen Epithelzellen hauptsächlich über den ubiquitär exprimierten Transkriptionsfaktor Sp1 reguliert wird. Für Sp1 wurde in diesen Zellen eine leichte Überexpression gesehen. Die fehlende Telomeraseaktivität und die abnehmende Telomerlänge in EPC korrelierte mit einer sehr niedrigen Reporteraktivität, bzw. hTERT-Promotoraktivität. Interessanterweise wurden auch die p53 inaktivierten, aber sterblichen Zellen (EPC- $\Delta$ p53) hauptsächlich über Sp1 reguliert. Die Promotoraktivität war bei diesen Zellen deutlich höher als bei EPC und auch die RT-PCR zeigte eine leicht höhere Expression der mRNA. Bei empfindlicheren Untersuchungsmethoden hätte eventuell auch eine Telomeraseaktivität nachgewiesen 
werden können, über die die leicht verlängerte Lebenszeit zu erklären wäre. In den derzeit zur Verfügung stehenden Methoden lag diese Aktivität jedoch unterhalb der Nachweisgrenze. Im Gegensatz zu den beiden sterblichen Zelltypen EPC und EPC$\Delta \mathrm{p} 53$, waren in den unsterblichen Cyclin D1 überexprimierenden Zellen die Transkriptionsfaktoren c-myc und E2F zusätzlich zu Sp1 von Bedeutung. Obwohl EPCD1 die stärkste Telomeraseaktivität aufwiesen, deutlich verlängerte Telomere und die höchste hTERT-Expression zeigten, war die Promotoraktivität nicht so hoch wie die der Tumorzellen (TE-12). Auch die hTERT überexprimierenden, ebenfalls unsterblichen EPC-hTERT hatten eine vergleichbar hohe Telomeraseaktivität, lange Telomere und eine, wie erwartet starke hTERT-Expression, zeigten aber eine, im Vergleich zu den Tumorzellen, niedrigere Promotoraktivität. In EPC-hTERT wurde die Telomerase transkriptionell vorwiegend über E2F und Sp1 reguliert. Schließlich war bei den schnell wachsenden, unsterblichen und Telomerase positiven Tumorzellen (TE-12) die Regulation der Promotoraktivität hauptsächlich über das Onkogen c-myc, in Kombination mit Sp1, vermittelt. Dies ging mit einer sehr hohen Promotoraktivität einher.

\subsection{Charakterisierung der einzelnen Zelltypen}

Um die eingebrachten genetischen Veränderungen nachzuweisen, wurde die Expression von Cyclin D1 und p53 mittels Western Blot-Analyse kontrolliert. Es konnte gezeigt werden, dass Cyclin D1 in EPC-D1 und TE-12 deutlich exprimiert und p53 in EPC$\Delta$ p53 stabilisiert wird. TE-12 zeigten, mit der Überexpression von Cyclin D1 und dem Fehlen von p53, für das Ösophaguskarzinom charakteristische genetische Veränderungen. Die Analyse von EPC-hTERT zeigte, dass die Überexpression von hTERT weder eine vermehrte Expression von Cyclin D1 noch einen Verlust von p53 auslöst. Somit kann eine direkte Regulierung dieser beiden Proteine durch die funktionelle Untereinheit der humanen Telomerase, hTERT, weitgehend ausgeschlossen werden.

Da in dieser Arbeit die Regulation der Telomerase-Expression und -Aktivität an einem genetisch definierten Karzinogenese Modell analysiert werden sollte, mussten die einzelnen Zellen vorher auf ihre Telomerbiologie und Proliferationseigenschaften untersucht werden. Dazu wurden die Zellen zunächst kultiviert und morphologisch charakterisiert. Es konnte gezeigt werden, dass die primären Keratinozyten (EPC) nach etwa 40 Populationsdopplungen (PD) in das Stadium der Seneszenz übergingen und ein 
oder zwei Wochen danach apoptotisch wurden. Ähnlich verhielten sich trotz Inaktivierung von p53 auch EPC- $\Delta$ p53, die nach ca. 60 PD das Stadium der Seneszenz erreichten und kurz danach in Apoptose gingen. Dies wurde zuvor auch für orale Keratinozyten mit inaktiviertem p53 gezeigt (Opitz et al. 2001). Sowohl EPC-D1 als auch EPC-hTERT waren dagegen über weit mehr als 400 PD zu kultivieren und damit immortal. Dies zeigte sich auch in der Fähigkeit $\mathrm{zu}$ einem dichteren und kolonieförmigen Wachstum, welches im Gegensatz zu den isoliert wachsenden EPC und EPC- $\Delta$ p53 Zellen stand. In Ösophagusepithelzellen ist demnach eine Cyclin D1oder hTERT-Überexpression ausreichend, um diese Zellen zu immortalisieren (Harada et al. 2003). Wie erwartet, zeigten die Tumorzellen (TE-12) eine intensivere Proliferation und ein deutlich dichteres Wachstum. Diese Zellen erfüllten auch morphologisch Kriterien einer Tumorzelle.

In regelmäßigen Abständen wurden die einzelnen Passagen der Zellen aus der Zellkultur auf ihre Telomerbiologie untersucht. Dazu wurde die Expression der Telomerase in den fünf Zelltypen mittels RT-PCR und Real Time RT-PCR analysiert, die Telomeraseaktivität mit dem TRAP-Assay gemessen und die Telomerlänge der Chromosomen mittels TRF bestimmt. Es konnte gezeigt werden, dass EPC und EPC$\Delta$ p53 in allen Passagen eine nur minimale Telomerase-Expression aufwiesen. Zusätzlich korrelierten die kurzen, sich im Verlauf verkürzenden Telomere von EPC und EPC- $\Delta$ p53 mit einer unter der Nachweisgrenze liegenden Telomeraseaktivität. Die Tatsache, dass in der RT-PCR eine minimale Telomerase-Expression zu sehen ist, zeigt, dass auch normale Zellen eine geringe Telomeraseaktivität besitzen können. Erst kürzlich ist dies für Fibroblasten gezeigt worden, die eine Zellzyklus abhängige basale Telomeraseaktivität aufwiesen. Diese muss aber nicht zwingend zu einer Verlängerung der Telomere führen (Masutomi et al. 2003). In TE-12 war eine deutliche Telomeraseaktivität und -Expression nachweisbar, die interessanterweise mit einer sehr kurzen, aber stabilen Telomerlänge einherging. Es liegt die Vermutung nahe, dass die Telomerase in diesen humanen Tumorzellen erst spät im Prozess der malignen Transformation aktiviert wurde und somit die sogenannte „Crisis“ überwinden half (Wright et al. 1992; Harley et al. 1994; Kipling 1995). Die immortalisierten EPC-D1 und EPC-hTERT zeigten eine höhere Telomerase-Expression, die mit einer ebenfalls intensiven Telomeraseaktivität einherging und hier mit langen Telomeren korrelierte. Für EPC-hTERT konnte so gezeigt werden, dass die alleinige Überexpression von 
hTERT in diesen Zellen über eine Telomerverlängerung eine Immortalisierung der Epithelzellen induzieren kann. In EPC-D1 führt die Überexpression von Cyclin D1 zu einer direkten oder indirekten Telomerase-Aktivierung und damit zur Immortalisierung der Keratinozyten. Dies ist ein überraschendes und interessantes Ergebnis, da Cyclin D1 als genetische Alteration alleine eigentlich nicht für diese Immortalisierung verantwortlich sein sollte (Opitz et al. 2001). Sekundäre genetische Alterationen sind hier wahrscheinlich verantwortlich. Es war jedoch nicht Thema dieser Arbeit zu klären, warum die Überexpression von Cyclin D1 in EPC ausreicht, diese Zellen zu immortalisieren. EPC-D1 wurden lediglich als immortale Zellen charakterisiert und in dem Modell der malignen Transformation genutzt.

\subsection{Herstellung der hTERT-Promotor-Konstrukte}

Bevor die transkriptionelle Regulation der humanen Telomerase in den fünf Zelltypen untersucht werden konnte, wurde der 1242 bp lange hTERT-Promotor auf eventuelle, bereits bekannte, Transkriptionsfaktor-Bindungsstellen untersucht (Tabelle 5.1). Aufgrund dieser Ergebnisse wurde der Promotor in elf, unterschiedlich lange Fragmente aufgeteilt. Bisher wurde der hTERT-Promotor schon in Tumorzellen auf cisregulatorische Elemente hin untersucht (Cong et al. 1999; Horikawa et al. 1999; Takakura et al. 1999), deswegen erschien es sinnvoll, beschriebene Regulationsmechanismen aufzugreifen und in den unterschiedlichen Keratinozyten zu analysieren sowie mit der Regulation in der Tumorzelllinie TE-12 zu vergleichen.

Im Core-Promotor am 3' Ende des hTERT-Promotors, in den Deletionskonstrukten -48, -101 und -161 lagen multiple mögliche Sp1-Bindungsstellen, die in Kooperation mit c-myc zur Aktivierung der Transkription von hTERT beitragen können (Kyo et al. 2000). Weiterhin besitzt die Promotorsequenz von hTERT zwei wichtige c-mycBindungsstellen in den Deletionskonstrukten -187 und -16 . Einige Gruppen haben gezeigt, dass durch Überexpression von c-myc alleine die hTERT-Expression induziert werden kann (Oh et al. 1999; Wu et al. 1999). Eine Dysregulation des Onkogens c-myc durch Überexpression, Amplifikation, Translokation oder Mutationen des c-myc Gens ist eine häufige Alteration in Tumorzellen. Andere beschriebene Regulatoren der hTERT-Expression sind Östrogene, welche hTERT zum Teil über den c-myc Weg aktivieren können (Kyo et al. 1999) oder in Kooperation mit dem Transkriptionsfaktor

Sp1 agieren. Zusätzlich befindet sich ein Östrogen Reaktives Element (ERE) in Konstrukt -1011. In den Deletionskonstrukten -247 und -290 lagen mögliche E2F- 
Bindungsstellen, die bei Interaktion mit E2F-1 als Repressoren und bei Interaktion mit E2F-6 als Aktivatoren des hTERT-Promotors in Tumorzellen beschrieben wurden (Crowe et al. 2001; Won et al. 2002). Das Wilms-Tumor-1-Protein (WT-1) wurde als ein Repressor der hTERT-Expression in Nierenkarzinomzellen beschrieben (Oh et al., 1999a) und befindet sich in Konstrukt -357 . Für die Region von Konstrukt -700 wurden Multiple-Zink-Finger-2 Motive (MZF-2) beschrieben, die als wichtige Silencer in Tumorzellen wirken können (Fujimoto et al. 2000). 5' war eine mögliche c-mybBindungsstelle im Konstrukt -905 und mögliche Nf- $\mathrm{KB}-$ und GKLF-Bindungsstellen im 1242 bp langen Promotor zu finden (Abbildung 1.4).

Tabelle 5.1

\begin{tabular}{lll}
\hline Name & Transkriptionsfaktor-Bindungsstellen & Referenz \\
\hline 1242 bp hTERT-Promotor & GKLF, NF-kB & \\
DC -1011 (s231Nhe1) & Östrogen sensitives Element (ERE) & (Kyo et al. 1999) \\
DC -905 (s337Nhe1) & c-myb & \\
DC -700 (s542Nhe1) & Silencer Region, & (Fujimoto et al. 2000) \\
DC -357 (s885Nhe1) & Sp1, Wilms-Tumor-1-Element (WT-1) & (Oh et al. 1999) \\
DC -290 (s952Nhe1) & E2F-1, E2F-6 & (Crowe et al. 2001; Won \\
DC -247 (s995Nhe1) & E2F-1, E2F-6 & et al. 2002) \\
DC -187 (s1055Nhe1) & c-myc (E-box) & (Kyo et al. 2000) \\
DC -161 (s1081Nhe1) & 2x Sp1 & \\
DC -101 (s1141Nhe1) & 2x Sp1 & (Kyo et al. 2000) \\
DC -48 (s1194Nhe1) & Sp1, EGF & \\
DC -16 (s1226Nhe1) & c-myc (E-box) &
\end{tabular}

Konstruierte Deletionskonstrukte des hTERT-Promotors mit einer Auswahl der in den Konstrukten vorhandenen wichtigen Transkriptionsfaktor-Bindungsstellen (Horikawa et al. 1999; Takakura et al. 1999; Poole et al. 2001; Ducrest et al. 2002; Kyo et al. 2002).

Um das jeweilige Deletionskonstrukt des hTERT-Promotors aus dem Plasmid mittels PCR zu amplifizieren, wurden die benötigten Primer mit dem Computerprogramm Vector NT erstellt. Die Konstrukte wurden dann in das Plasmid pGL3 subkloniert und transient in die fünf verschiedenen Zelltypen transfiziert. Die Etablierung der auf Lipofectamin basierenden Transfektions-Methode, zur transienten Transfektion der einzelnen Deletionskonstrukte in primäre Ösophagusepithelzellen, ist in dieser Arbeit erstmals gelungen. Damit war es möglich, die transkriptionelle Regulation der funktionellen Untereinheit der humanen Telomerase, hTERT, in primären und nicht transformierten Keratinozyten zu untersuchen. 


\subsection{Differenzielle transkriptionelle Regulation der Telomerase}

Die transkriptionelle Regulation der humanen Telomerase in Tumorzellen wurde von zahlreichen Arbeitsgruppen beschrieben. Neben der Regulation durch verschiedene Transkriptionsfaktoren konnte gezeigt werden, dass die Telomeraseaktivität in Tumoren mit malignen Eigenschaften korreliert und vermutlich Einfluss auf die Progression der Tumorerkrankung haben kann. Die meisten Arbeiten zur Promotorregulation wurden jedoch ausschließlich an Tumorzellen durchgeführt. Da die Telomerase in normalen humanen Zellen Zellzyklus abhängig und nur in sehr geringem Maße aktiviert ist, in Tumorzellen aber meist stark exprimiert wird, erschien es uns von entscheidender Bedeutung, $\mathrm{zu}$ untersuchen, wie die Telomerase in dem Prozess der malignen Transformation, das heißt im Übergang von der normalen Zelle zur Tumorzelle, aktiviert und reguliert wird (Poole et al. 2001). Dazu wurden in dieser Arbeit die wichtigen genetischen Alterationen der ösophagealen Karzinogenese rekapituliert und neben normalen primären Ösophagusepithelzellen (EPC), EPC mit inaktivierten p53 (EPC- $\Delta$ p53), EPC mit überexprimiertem hTERT (EPC-hTERT) und EPC mit Cyclin D1 Überexpression (EPC-D1) verwendet. Zum Vergleich wurden Ösophaguskarzinomzellen (TE-12) untersucht. Der Einfluss dieser häufigsten genetischen Veränderungen des Ösophaguskarzinoms auf die transkriptionelle Regulation der humanen Telomerase konnte so erstmals direkt bestimmt werden. An diesem Modell der Karzinogenese des Plattenepithels des Ösophagus konnte gezeigt werden, dass die Telomerase durch diese verschiedenen genetischen Alterationen unterschiedlich transkriptionell reguliert und aktiviert wird.

Die GC-reiche Sequenz des hTERT-Promotors enthält im Bereich des Core-Promotors multiple Bindungsstellen für den ubiquitär exprimierten Zink-Finger Transkriptionsfaktor Sp1 (Cong et al. 1999; Horikawa et al. 1999; Takakura et al. 1999). Sp1 spielt in unserem Modell der transkriptionellen Regulation des hTERT Gens in normalen EPC und sterblichen EPC- $\Delta$ p53 eine wichtige Rolle. In den immortalen EPC-D1, EPC-hTERT und TE-12 war Sp1 im Verbund mit anderen Transkriptionsfaktoren an der Regulation von hTERT mit beteiligt. Als ubiquitärer Transkriptionsfaktor wird Sp1 natürlich in Tumorzellen und in normalen Zellen exprimiert. Deswegen hat Sp1 alleine vermutlich nur eine geringe Bedeutung bei der Regulation der Telomeraseaktivität im Prozess der malignen Transformation. In dieser Arbeit konnten wir zeigen, dass Sp1 hauptsächlich in den sterblichen Zellen EPC und 
EPC- $\Delta$ p53 für die basale transkriptionelle Aktivität des hTERT-Promotors verantwortlich ist. Die in diesem Modell untersuchten Zelltypen zeigten alle ähnliche Expressionslevel von Sp1, mit Ausnahme von EPC, in denen eine erhöhte Expression $\mathrm{zu}$ erkennen war. Sp1 scheint also für die basale Aktivität des hTERT-Promotors mitverantwortlich zu sein, im Prozess der malignen Transformation erscheint jedoch zumindest eine Kooperation mit anderen Transkriptionsfaktoren notwendig zu sein.

Weiterhin wurde Sp1 mit der Rekrutierung von basalen Transkriptionsfaktoren in Verbindung gebracht und spielt so eine wichtige Rolle in der Regulierung und Aktivierung von Promotoren ohne TATA-Box (Pugh et al. 1991). Der hTERTPromotor ist ein solcher TATA-Box loser Promotor. Über eine mögliche Interaktion mit anderen Proteinen könnte der Transkriptionsfaktor Sp1 jedoch auch bei der malignen Transformation eine Rolle zur Regulierung der Telomerase spielen. Die Interaktion mit c-myc oder mit Korepressoren wie Histon-Deacetylasen (HDAC) könnte in den beschriebenen Zellen für die unterschiedlichen Promotoraktivitäten mitverantwortlich sein. Unter anderem wurde beschrieben, dass Sp1 einen Komplex mit p53 bilden kann und in dieser Form die Transkription des hTERT-Promotors nicht aktiviert, sondern inhibiert (Kanaya et al. 2000; Xu et al. 2000). Es wurde vermutet, dass der Tumorsupressor p53 eine wichtige Funktion bei der Inaktivierung der humanen Telomerase spielen könnte (Poole et al. 2001). Somit wäre es denkbar, dass eine Inaktivierung von p53 als ein wichtiger Schritt der malignen Transformation ösophagealer Plattenepithelzellen $\mathrm{zu}$ einer Aktivierung der Telomerase durch Sp1 führen könnte. In EPC- $\Delta$ p53 war jedoch trotz leichter Verlängerung der Telomere, sowie der Lebenszeit, keine Telomeraseaktivität messbar, so dass die Zellen sterblich blieben. Eine sensitivere Methode zur Detektion der Telomeraseaktivität könnte wahrscheinlich eine geringe Aktivität aufzeigen, da auch die RT-PCR eine leichte hTERT Expression erbrachte. Ob die p53 Inaktivierung in der Karzinogenese einen direkten Einfluss auf die Aktivierung der Telomerase besitzt, ist, wie auch von anderen Autoren vermutet, somit weiter nicht eindeutig geklärt (Horikawa et al. 2003).

Die Regulation des hTERT-Promotors über c-myc wurde hauptsächlich in den Tumorzellen (TE-12) und $\mathrm{zu}$ einem gewissen Grad in EPC-D1 nachgewiesen und bestätigte z.T. andere Arbeiten, die die hTERT-Promotoraktivität an Tumorzellen untersucht haben. In TE-12 interagiert c-myc mit einer im Konstrukt -187 befindlichen bekannten E-box und aktiviert so die hTERT Transkription. Die transkriptionelle Regulation durch diese E-box in TE-12 und in EPC-D1 könnte durch eine 
Komplexbildung von entweder myc/max oder mad/max abhängen, die festlegt, ob der Core-Promotor aktiviert oder reprimiert wird. Das c-myc Onkoprotein bildet dabei einen Komplex mit dem Max Protein und bindet als Heterodimer an die Promotorregion der E-box oder eine ähnliche Bindungsstelle (Wu et al. 1999). Das Mad Protein gilt als Antagonist von c-myc und ein Switch von Myc/Max zu Mad/Max resultiert in einer Verminderung der hTERT-Promotoraktivität (Gunes et al. 2000; Oh et al. 2000; Xu et al. 2001; Kyo et al. 2002). Die vorhandene hohe Telomeraseaktivität und die Expression von c-myc spricht für eine Regulation über den aktivierenden myc/max Komplex in Tumorzellen. Die c-myc Expression war interessanterweise in allen Zelltypen, unabhängig von den Regulationsmechanismen des hTERT-Promotors, ähnlich stark ausgeprägt, so dass man davon ausgehen kann, dass nicht die Menge an c-myc, sondern die Möglichkeit an die E-box im hTERT-Promotor zu binden, ausschlaggebend für die Aktivierung der hTERT-Transkription ist. Andere Gruppen konnten auch zeigen, dass die Transkription des hTERT-Promotors und die davon abhängige Telomeraseaktivität nicht von der exprimierten Menge c-myc abhängt, sondern von der Art und Weise, in der c-myc Komplexe mit entweder aktivierenden oder reprimierenden Partnern eingeht (Gewin et al. 2001; Horikawa et al. 2002).

Neben den oben beschriebenen Komplexen von myc/max und $\operatorname{mad} / \max$ ist eine Kooperation von c-myc mit Sp1, mit Bindung an eine der beiden E-boxen beschrieben worden (Kyo et al. 2000). In den Tumorzellen war ein schrittweiser Verlust der Promotoraktivität mit dem Verlust der E-box und der beiden Sp1-Bindungsstellen zu beobachten, der für eine Kooperation von c-myc mit Sp1 sprechen könnte. In EPC-D1 ist ebenfalls eine Interaktion dieser beiden Proteine denkbar. Die zweite E-box im Konstrukt -16 wurde in dieser Arbeit nicht mit EMSA untersucht, da aus den Ergebnissen der Transfektionen keine funktionelle Bedeutung für die Regulation des hTERT-Promotors zu erkennen war.

Aufgrund unserer Ergebnisse spielt c-myc bei der Transkription des hTERT-Promotors in normalen humanen Zellen keine größere Rolle, gewinnt aber mit zunehmendem Grad der malignen Transformation an Bedeutung. In maligne transformierten Zellen sind möglicherweise „myc-aktivierende“ genetische Alterationen vorhanden. Die aktive Überexpression von Telomerase scheint aber in Tumorzellen nicht ausschließlich von der transkriptionellen Aktivierung durch c-myc abzuhängen. Ob in diesem Kontext Cyclin D1 c-myc aktivieren kann, wurde in dieser Arbeit nicht untersucht, kann aber nicht ausgeschlossen werden. 
Die Proteine der E2F Familie sind normalerweise an der Transaktivierung von Genen beteiligt, die den Zellzyklus regulieren. Gleichwohl gelten sie als mögliche Regulatoren der Telomerase Expression, da mögliche Transkriptionsfaktor-Bindungsstellen auf dem hTERT-Promotor identifiziert werden konnten (Poole et al. 2001). Zusätzlich wurde E2F-1 eine $\mathrm{pRb}$ vermittelte Repression des hTERT-Promotors und der Telomeraseaktivität bei jedoch nur einer untersuchten Tumorzelllinie zugeschrieben (Crowe et al. 2001). Wir konnten an vier verschiedenen E2F-Bindungsstellen im hTERT-Promotor sowohl positive als auch negative Funktionen nachweisen. Für zwei negative cis-regulatorische Elemente, E2FWT(-266) und E2FWT(-281), konnten wir eine E2F-1 aber keine E2F-6 Interaktion demonstrieren. Somit konnten wir die Rolle von E2F-1 als funktionellen Repressor des hTERT-Promotors in den immortalen EPCD1 und EPC-hTERT bestätigen. In normalen sterblichen Zellen wie auch in Tumorzellen spielte E2F-1 keine wesentliche Rolle. E2F-1 wirkt also im Prozess der malignen Transformation von Ösophagusepithelzellen nicht in seiner typischen Form als Aktivator der Transkription, sondern scheint speziell am hTERT-Promotor als Repressor $\mathrm{zu}$ fungieren. Die durch den Cyclin D1/cdk Komplex vermittelte Hyperphosphorylierung von $\mathrm{pRb}$ führt generell zur Freisetzung von E2F und damit zur Progression des Zellzyklus in die S-Phase (Hinds et al. 1992). Trotz der in EPC-D1 vorhandenen Hyperphosphorylierung von pRb wirkt E2F-1 hier genauso als Repressor wie in den nicht pRb hyperphosphorylierten EPC-hTERT, so dass man annehmen muss, dass die Repression des hTERT-Promotors nicht nur über die Phosphorylierung von $\mathrm{pRb}$ vermittelt wird, sondern dass eine Interaktion von E2F-1 mit anderen Transkriptionsfaktoren $\mathrm{zu}$ verminderter Telomeraseaktivität führt. Interessanterweise scheint E2F in den Tumorzellen (TE-12) keine Rolle zu spielen, da trotz erhöhter E2F-1 Expression und der damit zusammenhängenden Hyperphosphorylierung von $\mathrm{pRb}$ keine E2F vermittelte hTERT Regulation zu beobachten war.

Eine kürzlich veröffentlichte Arbeit beschreibt E2F-1 als Aktivator in normalen Zellen und als Repressor in Tumorzellen. Dies konnten wir nur bedingt bestätigen, da nur eine gering aktivierende Funktion von E2F-1 in EPC und keine reprimierende Funktion in den Tumorzellen festgestellt werden konnte. Die immortalen, prämalignen Zellen zeigten allerdings die für die Tumorzellen postulierte Funktion von E2F als Repressor der hTERT Expression (Won et al. 2002).

Im 5' gelegenen Teil des Promotors waren die Unterschiede in der Promotoraktivität zwischen den fünf verschiedenen Zelltypen nicht eindeutig. Eine bereits beschriebene 
funktionelle Silencer Region im Bereich des Konstruktes -700 mit multiplen ZinkFinger-Protein-2 (MZF-2) Elementen, auf die später nochnäher eingegangen wird, war in allen Zellen von Bedeutung (Horikawa et al. 1999; Takakura et al. 1999). Weitere Transkriptionsfaktoren, wie NF- $\mathrm{BB}$, AP1 und ERE in strangaufwärts gelegenen Regionen des hTERT-Promotors, zeigten kein spezifisches Bindungsverhalten am hTERT-Promotor und spielen daher wahrscheinlich eine untergeordnete Rolle (Kyo et al. 2002). Als Repressor der hTERT-Promotoraktivität wurde zuvor das Wilms Tumor1 Protein identifiziert (Oh et al. 1999). Als Transkriptionsfaktor, der Telomerase nur in Niere, Milz und Gonaden reprimiert, konnten wir in dieser Arbeit eine Rolle von WT-1 als spezifischem Repressor am hTERT-Promotor nicht nachweisen.

\subsection{Telomerase Regulation durch Promotormethylierung}

Ein weiterer Regulationsmechanismus, der möglicherweise eine Rolle bei der Inaktivierung der katalytischen Untereinheit der Telomerase spielt, ist die Methylierung des hTERT-Promotors. Bereits vorausgegangene Promotor Analysen haben eine Reihe von CpG-Inseln im hTERT-Promotor nachgewiesen. Auch in dem in dieser Arbeit verwendeten 1242 bp langen hTERT-Promotor konnten wir drei CpG-Inseln lokalisieren. Da wir zeigen konnten, dass der Core-Promotor hauptsächlich durch unterschiedliche Transkriptionsfaktoren reguliert wird, haben wir uns auf CpG-Inseln 5' des Core-Promotors konzentriert. Eine 5' gelegene Region, die funktionell einer Silencer Region entsprach, zeigte eine Methylierung in allen immortalen Zellen, EPCD1, EPC-hTERT und den Tumorzellen TE-12 sowie in den sterblichen Zellen EPC$\Delta$ p53. Bei vorhandener Telomeraseaktivität scheint die Telomerase trotz der Methylierung des hTERT-Promotors aktivierbar zu bleiben. Im Gegensatz dazu blieben die normalen Zellen (EPC) in dieser Region des hTERT-Promotors unmethyliert. Man kann daraus schließen, dass die Telomeraseaktivität in normalen Ösophagusepithelzellen nicht durch Methylierung des hTERT-Promotors unterdrückt wird. Die Ergebnisse stimmen insofern mit anderen Studien überein, in denen die meisten hTERT negativen, normalen Zellen sowie ein Drittel der hTERT exprimierenden Zellen einen unmethylierten bzw. hypomethylierten hTERT-Promotor besitzen. Dagegen ist in zwei Drittel der hTERT-exprimierenden Zellen der hTERTPromotor teilweise oder vollständig methyliert (Devereux et al. 1999). Weitere Studien an Telomerase-positiven und -negativen Tumoren zeigten, dass immortale Zelltypen, die ihre Telomere durch ALT erhalten und Telomerase negativ sind, einen methylierten 
hTERT-Promotor aufweisen können und, dass eine Demethylierung des Promotors zu einer Telomerase-Reaktivierung führt (Dessain et al. 2000). Die Autoren schlossen aus ihren Experimenten, dass es verschiedene Methylierungszustände der CpG-Inseln des hTERT-Promotors gibt, welche die hTERT-Expression über Methylierungen und Demethylierungen regulieren können.

Interessanterweise korrelierte die methylierte Region in den genetisch veränderten Zellen EPC- $\Delta$ p53, EPC-hTERT und EPC-D1 mit einer Silencer Region. Die funktionellen Ergebnisse der Transfektionen dieser Bereiche zeigten negative cisregulatorische Elemente, so dass der Methylierungsstatus des hTERT-Promotors mit der funktionellen Promotoranalyse korrelierte. Natürlich ist es nicht möglich, die Ergebnisse der transienten Transfektion direkt mit dem Methylierungsstatus zu vergleichen, da man bei der transienten Transfektion nur die Regulation des Promotors in einem Zeitraum von $24 \mathrm{~h}$ in einem Plasmid und mit der Methylierungs spezifischen PCR die genomische DNA der Zellen untersucht. Trotzdem lassen unsere Daten den Schluss zu, dass die Methylierung möglicherweise eine noch genauer zu definierende Rolle in der Regulation der humanen Telomerase im Prozess der malignen Transformation spielen kann. Die Methylierung scheint zwar kein genereller Mechanismus für die Regulation der hTERT Expression zu sein, könnte aber eine Rolle in bestimmten Zelltypen, in bestimmten Entwicklungsstadien oder zu bestimmten Zeitpunkten der Karzinogenese spielen.

Zusammenfassend kann man sagen, dass die Methylierung des hTERT-Promotors in normalen Zellen keine Rolle bei der Suppression der Telomeraseaktivität spielt. In den genetisch veränderten Zellen muss es neben der Methylierung noch andere Mechanismen geben, die zusammen mit der Methylierung den Promotor reprimieren können. Andere Mechanismen erlauben es auch, dass in Tumorzellen die Telomerase trotz massiver Methylierung des Promotors exprimiert wird (Horikawa et al. 2003). Die Methylierung könnte jedoch in Telomerase-negativen, aber schon genetisch veränderten Zellen, wie EPC- $\Delta$ p53, unter anderem dazu beitragen, dass die Telomeraseaktivität noch unterdrückt wird.

\subsection{Schlussfolgerungen}

Molekulargenetische Forschungen haben hTERT als ein wichtiges Gen in der Entstehung von Tumoren definiert, das durch verschiedene positive und negative Faktoren reguliert werden kann. Bisher wurde die Regulation des hTERT Gens 
besonders in Telomerase-positiven Tumorzellen untersucht. In dieser Arbeit wird erstmals ein Modell der humanen Karzinogenese vorgestellt und die Regulation der humanen Telomerase in dem Prozess der malignen Transformation von der normalen ösophagealen Plattenepithelzelle zur Tumorzelle untersucht. Unser Zellkultur-Modell beinhaltet neben den normalen Ösophagusepithelzellen (EPC) und der Ösophaguskarzinom-Zelllinie (TE-12) Zellen, die drei wichtige genetische Veränderungen des ösophagealen Plattenepithelkarzinoms aufweisen, nämlich eine Inaktivierung des Tumorsuppressors p53 (EPC- $\Delta$ p53) sowie eine Überexpression des hTERT Gens (EPC-hTERT) und des Zellzyklus regulierenden Gens Cyclin D1 (EPCD1). EPC und EPC- $\Delta \mathrm{p} 53$ wurden anhand ihrer Telomerbiologie und Proliferationseigenschaften als sterbliche Zellen mit kurzen Telomeren und fehlender Telomeraseaktivität charakterisiert. EPC-D1 und EPC-hTERT wurden als immortale Zellen mit langen Telomeren und hoher Telomeraseaktivität und TE-12 als maligne Zellen mit hoher Telomeraseaktivität, aber kurzen Telomeren charakterisiert.

So konnte die Regulation der humanen Telomerase in dieser Arbeit erstmals an genetisch veränderten sterblichen, immortalen und malignen Zellen untersucht werden. Die Untersuchungen identifizierten nicht nur wichtige Transkriptionsfaktoren im Prozess der malignen Transformation des ösophagealen Plattenepithelkarzinoms, sondern ergeben auch wichtige Erkenntnisse über den Prozess der Karzinogenese an sich. Die in dieser Arbeit für die Regulation des hTERT Gens wichtigen Transkriptionsfaktoren Sp1, E2F und c-myc erfüllen alle Kriterien eines transkriptionellen Regulators des hTERT Gens: (1) Sie sind in normalen Zellen als Transkriptionsfaktoren von Bedeutung. (2) Sie agieren am hTERT-Promotor. (3) Sie zeigen ein unterschiedliches Verhalten im Bezug auf die unterschiedlichen genetischen Veränderungen im Prozess der malignen Transformation (Horikawa et al. 2003). In EPC wie auch in den sterblichen EPC- $\Delta$ p53 wird die Telomerase hauptsächlich durch Sp1 reguliert. Die hTERT Regulation in den immortalen EPC-hTERT und EPC-D1 ist komplexer und wird durch eine transkriptionelle Aktivierung von c-myc und Sp1 bzw. eine Suppression mittels E2F-1 vermittelt. Die Telomerase der Tumorzellen wird hauptsächlich durch c-myc, eventuell in Kooperation mit Sp1, transkriptionell reguliert. Zusätzlich konnte in dieser Arbeit gezeigt werden, dass neben der differenziellen transkriptionellen Regulation der humanen Telomerase auch die Methylierung des hTERT-Promotors eine Rolle spielen könnte. 


\subsection{Perspektiven}

Erkenntnisse über die Regulation der humanen Telomerase im Prozess der Karzinogenese können in Zukunft möglicherweise zu therapeutischen Ansätzen führen. Ein solcher therapeutischer Ansatz wäre, die Telomerase in Tumorzellen zu hemmen und damit die Teilungsfähigkeit der Zellen zu reduzieren (Kyo et al. 2002). Ein Problem der Telomerase-Hemmung ist allerdings die Tatsache, dass auch normale Zellen zu einem gewissen Grad und zu einem bestimmten Zeitpunkt ihres Zellzyklus Telomerase exprimieren (Masutomi et al. 2003). Somit wäre die Hemmung nicht Tumorzellspezifisch. Die in dieser Arbeit gezeigte differenzielle Regulation der Telomerase durch unterschiedliche Transkriptionsfaktoren könnte Signaltransduktionswege aufzeigen, die wichtig für die Aktivierung der Telomerase einerseits und Tumorzell-spezifisch andererseits sind. So könnten hTERT-Promotor regulierende Transkriptionsfaktoren oder zumindest ihre Signaltransduktionswege mögliche therapeutische Ziele darstellen. Genauere Kenntnisse der Kontrollmechanismen des hTERT Gens könnten die Erfolgsaussichten der bereits unternommenen Versuche, den hTERT-Promotor als Vektor für die intrazelluläre Tumortherapie zu verwenden, verbessern. Mit dem Wissen, welche Transkriptionsfaktoren in bestimmten Tumoren überexprimiert sind und welche Transkriptionsfaktoren den hTERT-Promotor in diesen Tumoren aktivieren, könnte zu spezifischen Therapien mit Apoptose-induzierenden Genen, wie zum Beispiel Caspasen, führen (Gu et al. 2000; Komata et al. 2001).

Die Regulation der Telomerase in Tumorzellen wie auch in normalen Zellen ist jedoch noch nicht eindeutig geklärt. So sollten in weiterführenden Untersuchungen Zellen mit kombinierten genetischen Veränderungen untersucht werden, da in Tumorzellen in der Regel multiple genetische Veränderungen vorliegen. Methodisch könnte die spezifische Regulation der einzelnen Transkriptionsfaktoren nicht nur durch Mutationsanalysen, sondern auch durch Chromatin-Immunopräzipitations-Assays bestätigt und die Signaltransduktionswege der einzelnen Transkriptionsfaktoren auf ihre Tumorspezifität hin untersucht werden. Die weitere Untersuchung der Regulation der für die Tumorgenese wichtigen Telomerase an einem, wie hier vorgestellten, mehrstufigen Modell der Karzinogenese sollte in Zukunft die Untersuchungen an Tumorzellen komplementieren und zu einem besseren Verständnis der Telomerase Regulation in der Tumorentstehung führen können. 


\section{Zusammenfassung}

Normale humane Zellen haben eine limitierte replikative Lebenszeit bevor sie in Seneszenz gehen. Die Verkürzung der Telomere ist ein wichtiger Faktor in diesem Prozess. Die Mehrzahl humaner Tumorzellen, unter anderem die des Plattenepithelkarzinoms des Ösophagus, erhalten ihre Telomere durch die Aktivierung des Enzyms Telomerase (hTERT). Bisher ist relativ wenig über die Regulation der Telomerase während des Prozesses der malignen Transformation bekannt. Aus diesem Grund haben wir die transkriptionelle Regulation der Telomerase im Proze $\beta$ der malignen Transformation von normalen ösophagealer Plattenepithelzellen zu Ösophaguskarzinomzellen untersucht.

Normale humane Ösophagusepithelzellen (EPC), in denen jeweils Cyclin D1 (EPC-D1), dominant negatives p53 (EPC- $\Delta$ p53) oder hTERT (EPC-hTERT) retroviral überexprimiert war sowie die Tumorzelllinie TE-12 wurden als fünfstufiges Modell der malignen Transformation verwendet. Die hTERT Genexpression (RT-PCR, qRT-PCR), die Proliferation der Zellen, die Telomeraseaktivität (TRAP) und Telomerlänge (TRF) in diesen Zelltypen wurden bestimmt. Der komplette (1242 bp) hTERT-Promotor und elf, mittels PCR hergestellte Deletionskonstrukte wurden transient in die Zellen transfiziert. Die Transfektionsergebnisse wurden mit TRAP, TRF und dem Methylierungsstatus (MSP) des hTERT-Promotors korreliert. Zusätzlich wurde die Bindung von verschiedenen Transkriptionsfaktoren (EMSA) an den hTERT-Promotor untersucht und mit der Protein-Expression korreliert.

In dem hier vorgestellen Modell der ösophagealen Karzinogenese konnten wir zeigen, dass die Transkription und Aktivität der humanen Telomerase in den genetisch alterierten Zellen unterschiedlich reguliert wurde. Die Regulation ist dabei jeweils von den eingefügten genetischen Veränderungen ( $\Delta$ p53, Cyclin D1, hTERT) abhängig. In EPC, wie auch in den sterblichen EPC- $\Delta$ p53, war die Telomerase hauptsächlich durch Sp1 reguliert. Die hTERT-Expression und -Aktivität in den immortalen EPC-hTERT und EPC-D1 war durch c-myc und Sp1 sowie E2F-1 reguliert. Die Telomerase der Tumorzellen TE-12 war durch c-myc, eventuell in Kooperation mit Sp1, reguliert. Zusätzlich spielte der Methylierungsstatus des hTERT-Promotors vor allem in den immortalen Zellen eine Rolle bei der Regulation der humanen Telomerase. 


\section{Literaturverzeichnis}

Aisner, D. L., W. E. Wright, et al. (2002). Telomerase regulation: not just flipping the switch. Curr Opin Genet Dev 12(1): 80-5.

Armbruster, B. N., K. T. Etheridge, et al. (2003). Putative telomere-recruiting domain in the catalytic subunit of human telomerase. Mol Cell Biol 23(9): 3237-46.

Bartkova, J., J. Lukas, et al. (1995). Abnormal patterns of D-type cyclin expression and G1 regulation in human head and neck cancer. Cancer Res 55(4): 949-56.

Bartsch, H., H. Ohshima, et al. (1984). In-vivo nitrosation, precancerous lesions and cancers of the gastrointestinal tract. On-going studies and preliminary results. IARC Sci Publ(57): 955-62.

Blackburn, E. H. (1991). Telomeres. Trends Biochem Sci 16(10): 378-81.

Blasco, M. A. and W. C. Hahn (2003). Evolving views of telomerase and cancer. Trends Cell Biol 13(6): 289-94.

Bodnar, A. G., M. Ouellette, et al. (1998). Extension of life-span by introduction of telomerase into normal human cells. Science 279(5349): 349-52.

Broccoli, D., J. W. Young, et al. (1995). Telomerase activity in normal and malignant hematopoietic cells. Proc Natl Acad Sci U S A 92(20): 9082-6.

Bryan, T. M., A. Englezou, et al. (1997). Evidence for an alternative mechanism for maintaining telomere length in human tumors and tumor-derived cell lines. Nat Med 3(11): 1271-4.

Cairns, P., T. J. Polascik, et al. (1995). Frequency of homozygous deletion at p16/CDKN2 in primary human tumours. Nat Genet 11(2): 210-2.

Cerezo, A., H. Kalthoff, et al. (2002). Dual regulation of telomerase activity through cMyc-dependent inhibition and alternative splicing of hTERT. J Cell Sci 115(Pt 6): 1305-12.

Cong, Y. S., J. Wen, et al. (1999). The human telomerase catalytic subunit hTERT: organization of the gene and characterization of the promoter. Hum Mol Genet 8(1): $137-42$.

Counter, C. M., A. A. Avilion, et al. (1992). Telomere shortening associated with chromosome instability is arrested in immortal cells which express telomerase activity. Embo J 11(5): 1921-9.

Counter, C. M., W. C. Hahn, et al. (1998). Dissociation among in vitro telomerase activity, telomere maintenance, and cellular immortalization. Proc Natl Acad Sci U S A 95(25): 14723-8.

Crowe, D. L., D. C. Nguyen, et al. (2001). E2F-1 represses transcription of the human telomerase reverse transcriptase gene. Nucleic Acids Res 29(13): 2789-94.

Dahse, R., W. Fiedler, et al. (1997). Telomeres and telomerase: biological and clinical importance. Clin Chem 43(5): 708-14.

Dang, C. V. (1999). c-Myc target genes involved in cell growth, apoptosis, and metabolism. Mol Cell Biol 19(1): 1-11.

Dessain, S. K., H. Yu, et al. (2000). Methylation of the human telomerase gene CpG island. Cancer Res 60(3): 537-41.

Devereux, T. R., I. Horikawa, et al. (1999). DNA methylation analysis of the promoter region of the human telomerase reverse transcriptase (hTERT) gene. $\underline{\text { Cancer Res }}$ 59(24): 6087-90.

Ducrest, A. L., H. Szutorisz, et al. (2002). Regulation of the human telomerase reverse transcriptase gene. Oncogene 21(4): 541-52.

Enders, G. H., J. Koh, et al. (1996). p16 inhibition of transformed and primary squamous epithelial cells. Oncogene 12(6): 1239-45. 
Fujimoto, K., S. Kyo, et al. (2000). Identification and characterization of negative regulatory elements of the human telomerase catalytic subunit (hTERT) gene promoter: possible role of MZF-2 in transcriptional repression of hTERT. Nucleic Acids Res 28(13): 2557-62.

Fujimoto, R., N. Kamata, et al. (2003). Gene expression of telomerase related proteins in human normal oral and ectocervical epithelial cells. Oral Oncol 39(5): 44552.

Gewin, L. and D. A. Galloway (2001). E box-dependent activation of telomerase by human papillomavirus type 16 E6 does not require induction of c-myc. J Virol 75(15): 7198-201.

Greenberg, R. A., R. C. O'Hagan, et al. (1999). Telomerase reverse transcriptase gene is a direct target of c-Myc but is not functionally equivalent in cellular transformation. Oncogene 18(5): 1219-26.

Greider, C. W. (1991). Telomerase is processive. Mol Cell Biol 11(9): 4572-80.

Greider, C. W. (1996). Telomere length regulation. Annu Rev Biochem 65: 337-65.

Greider, C. W. (1998). Telomeres and senescence: the history, the experiment, the future. Curr Biol 8(5): R178-81.

Greider, C. W. and E. H. Blackburn (1987). The telomere terminal transferase of Tetrahymena is a ribonucleoprotein enzyme with two kinds of primer specificity. Cell 51(6): 887-98.

Greider, C. W. and E. H. Blackburn (1996). Telomeres, telomerase and cancer. Sci Am 274(2): 92-7.

Gu, J., S. Kagawa, et al. (2000). Tumor-specific transgene expression from the human telomerase reverse transcriptase promoter enables targeting of the therapeutic effects of the Bax gene to cancers. Cancer Res 60(19): 5359-64.

Gunes, C., S. Lichtsteiner, et al. (2000). Expression of the hTERT gene is regulated at the level of transcriptional initiation and repressed by Mad1. Cancer Res 60(8): 2116-21.

Hahn, W. C. (2002). Immortalization and transformation of human cells. Mol Cells 13(3): 351-61.

Hahn, W. C. (2003). Role of telomeres and telomerase in the pathogenesis of human cancer. J Clin Oncol 21(10): 2034-43.

Hahn, W. C. and M. Meyerson (2001). Telomerase activation, cellular immortalization and cancer. Ann Med 33(2): 123-9.

Hahn, W. C. and R. A. Weinberg (2002). Rules for making human tumor cells. N Engl J Med 347(20): 1593-603.

Hanahan, D. and R. A. Weinberg (2000). The hallmarks of cancer. Cell 100(1): 57-70.

Harada, H., H. Nakagawa, et al. (2003). Telomerase induces immortalization of human esophageal keratinocytes without p16INK4a inactivation. Mol Cancer Res 1(10): 729-38.

Harle-Bachor, C. and P. Boukamp (1996). Telomerase activity in the regenerative basal layer of the epidermis inhuman skin and in immortal and carcinoma-derived skin keratinocytes. Proc Natl Acad Sci U S A 93(13): 6476-81.

Harley, C. B. (1991). Telomere loss: mitotic clock or genetic time bomb? Mutat Res 256(2-6): 271-82.

Harley, C. B. (2002). Telomerase is not an oncogene. Oncogene 21(4): 494-502.

Harley, C. B., A. B. Futcher, et al. (1990). Telomeres shorten during ageing of human fibroblasts. Nature 345(6274): 458-60.

Harley, C. B., N. W. Kim, et al. (1994). Telomerase, cell immortality, and cancer. Cold Spring Harb Symp Quant Biol 59: 307-15. 
Harris, C. C. (1996). p53 tumor suppressor gene: from the basic research laboratory to the clinic--an abridged historical perspective. Carcinogenesis 17(6): 1187-98.

Hayflick, L. (1965). The Limited in Vitro Lifetime of Human Diploid Cell Strains. Exp Cell Res 37: 614-36.

Hayflick, L. (1997). Mortality and immortality at the cellular level. A review. Biochemistry (Mosc) 62(11): 1180-90.

Henson, J. D., A. A. Neumann, et al. (2002). Alternative lengthening of telomeres in mammalian cells. Oncogene 21(4): 598-610.

Hinds, P. W., S. Mittnacht, et al. (1992). Regulation of retinoblastoma protein functions by ectopic expression of human cyclins. Cell 70(6): 993-1006.

Hiyama, H., A. Iavarone, et al. (1997). Regulated ectopic expression of cyclin D1 induces transcriptional activation of the cdk inhibitor p21 gene without altering cell cycle progression. Oncogene 14(21): 2533-42.

Hollstein, M. C., R. A. Metcalf, et al. (1990). Frequent mutation of the p53 gene in human esophageal cancer. Proc Natl Acad Sci U S A 87(24): 9958-61.

Hollstein, M. C., L. Peri, et al. (1991). Genetic analysis of human esophageal tumors from two high incidence geographic areas: frequent p53 base substitutions and absence of ras mutations. Cancer Res 51(15): 4102-6.

Holt, S. E., D. L. Aisner, et al. (1997). Lack of cell cycle regulation of telomerase activity in human cells. Proc Natl Acad Sci U S A 94(20): 10687-92.

Horikawa, I. and J. C. Barrett (2003). Transcriptional regulation of the telomerase hTERT gene as a target for cellular and viral oncogenic mechanisms. Carcinogenesis 24(7): 1167-76.

Horikawa, I., P. L. Cable, et al. (1999). Cloning and characterization of the promoter region of human telomerase reverse transcriptase gene. Cancer Res 59(4): 82630 .

Horikawa, I., P. L. Cable, et al. (2002). Downstream E-box-mediated regulation of the human telomerase reverse transcriptase (hTERT) gene transcription: evidence for an endogenous mechanism of transcriptional repression. Mol Biol Cell 13(8): 2585-97.

Huang, Y., S. J. Meltzer, et al. (1993). Altered messenger RNA and unique mutational profiles of p53 and $\mathrm{Rb}$ in human esophageal carcinomas. Cancer Res 53(8): 1889-94.

Ishizuka, T., C. Tanabe, et al. (2002). Gene amplification profiling of esophageal squamous cell carcinomas by DNA array CGH. Biochem Biophys Res Commun 296(1): 152-5.

Jiang, W., Y. J. Zhang, et al. (1993). Altered expression of the cyclin D1 and retinoblastoma genes in human esophageal cancer. Proc Natl Acad Sci U S A 90(19): 9026-30.

Kanaya, T., S. Kyo, et al. (2000). Adenoviral expression of p53 represses telomerase activity through down-regulation of human telomerase reverse transcriptase transcription. Clin Cancer Res 6(4): 1239-47.

Kim, M. S., S. L. Li, et al. (1993). State of p53, Rb and DCC tumor suppressor genes in human oral cancer cell lines. Anticancer Res 13(5A): 1405-13.

Kim, N. W., M. A. Piatyszek, et al. (1994). Specific association of human telomerase activity with immortal cells and cancer. Science 266(5193): 2011-5.

Kipling, D. (1995). Telomerase: immortality enzyme or oncogene? Nat Genet 9(2): 104-6.

Kolquist, K. A., L. W. Ellisen, et al. (1998). Expression of TERT in early premalignant lesions and a subset of cells in normal tissues. Nat Genet 19(2): 182-6. 
Komata, T., Y. Kondo, et al. (2001). Treatment of malignant glioma cells with the transfer of constitutively active caspase- 6 using the human telomerase catalytic subunit (human telomerase reverse transcriptase) gene promoter. Cancer Res 61(15): 5796-802.

Kyo, S. and M. Inoue (2002). Complex regulatory mechanisms of telomerase activity in normal and cancer cells: how can we apply them for cancer therapy? Oncogene 21(4): 688-97.

Kyo, S., T. Kanaya, et al. (1999). Expression of human telomerase subunits in ovarian malignant, borderline and benign tumors. Int J Cancer 80(6): 804-9.

Kyo, S., M. Takakura, et al. (1999). Estrogen activates telomerase. Cancer Res 59(23): 5917-21.

Kyo, S., M. Takakura, et al. (2000). Sp1 cooperates with c-Myc to activate transcription of the human telomerase reverse transcriptase gene (hTERT). Nucleic Acids Res 28(3): 669-77.

Lam, A. K. (2000). Molecular biology of esophageal squamous cell carcinoma. $\underline{\text { Crit Rev }}$ Oncol Hematol 33(2): 71-90.

Lendvay, T. S., D. K. Morris, et al. (1996). Senescence mutants of Saccharomyces cerevisiae with a defect in telomere replication identify three additional EST genes. Genetics 144(4): 1399-412.

Levine, A. J. (1997). p53, the cellular gatekeeper for growth and division. Cell 88(3): 323-31.

Levy, M. Z., R. C. Allsopp, et al. (1992). Telomere end-replication problem and cell aging. J Mol Biol 225(4): 951-60.

Li, K. and P. Yu (2003). Food groups and risk of esophageal cancer in Chaoshan region of China: a high-risk area of esophageal cancer. Cancer Invest 21(2): 237-40.

Lingner, J., T. R. Hughes, et al. (1997). Reverse transcriptase motifs in the catalytic subunit of telomerase. Science 276(5312): 561-7.

Liu, K., R. J. Hodes, et al. (2001). Cutting edge: telomerase activation in human T lymphocytes does not require increase in telomerase reverse transcriptase (hTERT) protein but is associated with hTERT phosphorylation and nuclear translocation. J Immunol 166(8): 4826-30.

Mandard, A. M., P. Hainaut, et al. (2000). Genetic steps in the development of squamous cell carcinoma of the esophagus. Mutat Res 462(2-3): 335-42.

Mao, L., A. K. El-Naggar, et al. (1996). Telomerase activity in head and neck squamous cell carcinoma and adjacent tissues. Cancer Res 56(24): 5600-4.

Masutomi, K., E. Y. Yu, et al. (2003). Telomerase maintains telomere structure in normal human cells. Cell 114(2): 241-53.

McEachern, M. J. and E. H. Blackburn (1996). Cap-prevented recombination between terminal telomeric repeat arrays (telomere CPR) maintains telomeres in Kluyveromyces lactis lacking telomerase. Genes Dev 10(14): 1822-34.

Messmann, H. (2001). Squamous cell cancer of the oesophagus. Best Pract Res Clin Gastroenterol 15(2): 249-65.

Meyerson, M., C. M. Counter, et al. (1997). hEST2, the putative human telomerase catalytic subunit gene, is up-regulated in tumor cells and during immortalization. Cell 90(4): 785-95.

Morin, G. B. (1997). Telomere control of replicative lifespan. Exp Gerontol 32(4-5): 375-82.

Nakamura, T. M. and T. R. Cech (1998). Reversing time: origin of telomerase. $\underline{\text { Cell }}$ 92(5): 587-90. 
Nakamura, T. M., G. B. Morin, et al. (1997). Telomerase catalytic subunit homologs from fission yeast and human. Science 277(5328): 955-9.

Nicholl, D. S. T. (1995). Gentechnische Methoden. Labor im Fokus.

Nobori, T., K. Miura, et al. (1994). Deletions of the cyclin-dependent kinase-4 inhibitor gene in multiple human cancers. Nature 368(6473): 753-6.

Ogawa, T. and T. Okazaki (1980). Discontinuous DNA replication. Annu Rev Biochem 49: 421-57.

Oh, S., Y. Song, et al. (1999). The Wilms' tumor 1 tumor suppressor gene represses transcription of the human telomerase reverse transcriptase gene. J Biol Chem 274(52): 37473-8.

Oh, S., Y. H. Song, et al. (1999). In vivo and in vitro analyses of Myc for differential promoter activities of the human telomerase (hTERT) gene in normal and tumor cells. Biochem Biophys Res Commun 263(2): 361-5.

Oh, S., Y. H. Song, et al. (2000). Identification of Mad as a repressor of the human telomerase (hTERT) gene. Oncogene 19(11): 1485-90.

Okazaki, T. (2002). [Okazaki furaguments and discontinuous replication]. Seikagaku 74(2): 103-17.

Okazaki, T. (2003). [Days devoted to elucidating the mechanism of discontinuous DNA replication]. Tanpakushitsu Kakusan Koso 48(6): 718-26.

Opitz, O. G. and A. K. Rustgi (2000). Interaction between Sp1 and cell cycle regulatory proteins is important in transactivation of a differentiation-related gene. Cancer Res 60(11): 2825-30.

Opitz, O. G., Y. Suliman, et al. (2001). Cyclin D1 overexpression and p53 inactivation immortalize primary oral keratinocytes by a telomerase-independent mechanism. J Clin Invest 108(5): 725-32.

Pelengaris, S., M. Khan, et al. (2002). c-MYC: more than just a matter of life and death. Nat Rev Cancer 2(10): 764-76.

Poole, J. C., L. G. Andrews, et al. (2001). Activity, function, and gene regulation of the catalytic subunit of telomerase (hTERT). Gene 269(1-2): 1-12.

Pugh, B. F. and R. Tjian (1991). Transcription from a TATA-less promoter requires a multisubunit TFIID complex. Genes Dev 5(11): 1935-45.

Reddel, R. R., T. M. Bryan, et al. (2001). Alternative lengthening of telomeres in human cells. Radiat Res 155(1 Pt 2): 194-200.

Reed, A. L., J. Califano, et al. (1996). High frequency of p16 (CDKN2/MTS-1/INK4A) inactivation in head and neck squamous cell carcinoma. Cancer Res 56(16): 3630-3.

Rhyu, M. S. (1995). Telomeres, telomerase, and immortality. J Natl Cancer Inst 87(12): 884-94.

Romero, D. P. and E. H. Blackburn (1991). A conserved secondary structure for telomerase RNA. Cell 67(2): 343-53.

Rustgi, A. K. (1997). Biomarkers for malignancy in the columnar-lined esophagus. Gastroenterol Clin North Am 26(3): 599-606.

Schreiber, E., P. Matthias, et al. (1989). Rapid detection of octamer binding proteins with 'mini-extracts', prepared from a small number of cells. Nucleic Acids Res 17(15): 6419.

Serrano, M., G. J. Hannon, et al. (1993). A new regulatory motif in cell-cycle control causing specific inhibition of cyclin D/CDK4. Nature 366(6456): 704-7.

Sharpless, N. E. and R. A. DePinho (1999). The INK4A/ARF locus and its two gene products. Curr Opin Genet Dev 9(1): 22-30. 
Shay, J. W. (1997). Telomerase in human development and cancer. J Cell Physiol 173(2): 266-70.

Sherr, C. J. and R. A. DePinho (2000). Cellular senescence: mitotic clock or culture shock? Cell 102(4): 407-10.

Shillitoe, E. J., S. P. Schantz, et al. (1993). Environmental carcinogenesis and its prevention: the head and neck cancer model. Cancer Res 53(9): 2189-91.

Shippen-Lentz, D. and E. H. Blackburn (1990). Functional evidence for an RNA template in telomerase. Science 247(4942): 546-52.

Sidransky, D. (1995). Molecular genetics of head and neck cancer. Curr Opin Oncol 7(3): 229-33.

Sons, H. U. (1987). Etiologic and epidemiologic factors of carcinoma of the esophagus. Surg Gynecol Obstet 165(2): 183-90.

Soussi, T., K. Dehouche, et al. (2000). p53 website and analysis of p53 gene mutations in human cancer: forging a link between epidemiology and carcinogenesis. Hum Mutat 15(1): 105-13.

Stewart, S. A. and R. A. Weinberg (2000). Telomerase and human tumorigenesis. Semin Cancer Biol 10(6): 399-406.

Stoner, G. D., D. T. Morrissey, et al. (1991). Inhibitory effects of phenethyl isothiocyanate on $\mathrm{N}$-nitrosobenzylmethylamine carcinogenesis in the rat esophagus. Cancer Res 51(8): 2063-8.

Tahara, H., H. Kuniyasu, et al. (1995). Telomerase activity in preneoplastic and neoplastic gastric and colorectal lesions. Clin Cancer Res 1(11): 1245-51.

Takakura, M., S. Kyo, et al. (1999). Cloning of human telomerase catalytic subunit (hTERT) gene promoter and identification of proximal core promoter sequences essential for transcriptional activation in immortalized and cancer cells. $\underline{\text { Cancer }}$ Res 59(3): 551-7.

Takakura, M., S. Kyo, et al. (1998). Expression of human telomerase subunits and correlation with telomerase activity in cervical cancer. Cancer Res 58(7): 155861.

Tanaka, M., S. Kyo, et al. (1998). Expression of telomerase activity in human endometrium is localized to epithelial glandular cells and regulated in a menstrual phase-dependent manner correlated with cell proliferation. Am J Pathol 153(6): 1985-91.

Thompson, D. A., G. Belinsky, et al. (1997). The human papillomavirus-16 E6 oncoprotein decreases the vigilance of mitotic checkpoints. Oncogene 15(25): 3025-35.

Todd, R., P. W. Hinds, et al. (2002). Cell cycle dysregulation in oral cancer. $\underline{\text { Crit Rev }}$ Oral Biol Med 13(1): 51-61.

Ulaner, G. A., J. F. Hu, et al. (1998). Telomerase activity in human development is regulated by human telomerase reverse transcriptase (hTERT) transcription and by alternate splicing of hTERT transcripts. Cancer Res 58(18): 4168-72.

Ulaner, G. A., J. F. Hu, et al. (2001). Tissue-specific alternate splicing of human telomerase reverse transcriptase (hTERT) influences telomere lengths during human development. Int J Cancer 91(5): 644-9.

Ulaner, G. A., J. F. Hu, et al. (2000). Regulation of telomerase by alternate splicing of human telomerase reverse transcriptase (hTERT) in normal and neoplastic ovary, endometrium and myometrium. Int J Cancer 85(3): 330-5.

Wang, J., L. Y. Xie, et al. (1998). Myc activates telomerase. Genes Dev 12(12): 176974. 
Weinberg, R. A. (1989). Oncogenes, antioncogenes, and the molecular bases of multistep carcinogenesis. Cancer Res 49(14): 3713-21.

Weinberg, R. A. (1998). Telomeres. Bumps on the road to immortality. Nature 396(6706): 23-4.

Won, J., J. Yim, et al. (2002). Opposing regulatory roles of E2F in human telomerase reverse transcriptase (hTERT) gene expression in human tumor and normal somatic cells. Faseb J 16(14): 1943-5.

Wright, W. E., M. A. Piatyszek, et al. (1996). Telomerase activity in human germline and embryonic tissues and cells. Dev Genet 18(2): 173-9.

Wright, W. E. and J. W. Shay (1992). The two-stage mechanism controlling cellular senescence and immortalization. Exp Gerontol 27(4): 383-9.

Wu, K. J., C. Grandori, et al. (1999). Direct activation of TERT transcription by cMYC. Nat Genet 21(2): 220-4.

Xu, D., N. Popov, et al. (2001). Switch from Myc/Max to Mad1/Max binding and decrease in histone acetylation at the telomerase reverse transcriptase promoter during differentiation of HL60 cells. Proc Natl Acad Sci U S A 98(7): 3826-31.

$\mathrm{Xu}, \mathrm{D} ., \mathrm{Q}$. Wang, et al. (2000). Downregulation of telomerase reverse transcriptase mRNA expression by wild type p53 in human tumor cells. Oncogene 19(45): 5123-33.

Yamasaki, L., R. Bronson, et al. (1998). Loss of E2F-1 reduces tumorigenesis and extends the lifespan of Rb1(+/-)mice. Nat Genet 18(4): 360-4.

Yang, J., E. Chang, et al. (1999). Human endothelial cell life extension by telomerase expression. J Biol Chem 274(37): 26141-8.

Yoo, G. H., H. J. Xu, et al. (1994). Infrequent inactivation of the retinoblastoma gene despite frequent loss of chromosome $13 \mathrm{q}$ in head and neck squamous cell carcinoma. Cancer Res 54(17): 4603-6. 


\section{Abkürzungen}

\begin{tabular}{|c|c|}
\hline $\mathrm{Ab}$ & Antibody \\
\hline Amp & Ampicillin \\
\hline AS & Aminosäure \\
\hline $\mathrm{bp}$ & Basenpaar \\
\hline BSA & Bovine Serum Albumin (Rinderserumalbumin) \\
\hline cDNA & komplementäre Desoxyribonukleinsäure \\
\hline $\mathrm{d}$ & Tag \\
\hline$d \mathrm{ATP}$ & Desoxy-Adenosintriphosphat \\
\hline$d \mathrm{CTP}$ & Desoxy-Cytosintriphosphat \\
\hline$d \mathrm{GTP}$ & Desoxy-Guanosintriphosphat \\
\hline $\mathrm{dH}_{2} \mathrm{O}$ & deionisiertes $\mathrm{H}_{2} \mathrm{O}$ \\
\hline DMEM & Dulbecco's Modifiziertes Eagle Medium \\
\hline DMSO & Dimethylsulfoxid \\
\hline DNA & Desoxyribonukleinsäure \\
\hline$d \mathrm{NTP}$ & 2'-Desoxynukleosid-5'-triphosphat \\
\hline$d \mathrm{TTP}$ & Desoxy-Thymidintriphosphat \\
\hline E. coli & Escherichia coli \\
\hline EDTA & Ethylendiamin-N,N,N',N'-tetraessigsäure \\
\hline FBS & Fötales Rinderserum \\
\hline IPTG & Isopropyl-b-D-thiogalaktosid \\
\hline $\mathrm{kbp}$ & Kilobasenpaare \\
\hline LB & Luria-Broth \\
\hline $\mathrm{nt}$ & Nukleotid \\
\hline PAGE & Polyacrylamid-Gelelektrophorese \\
\hline PBS & Phosphatgepufferte Salzlösung \\
\hline PCR & Polymerase-Kettenreaktion \\
\hline PMSF & Phenyl-Methyl-Sulfonyl-Flourid \\
\hline PVDF & Poly-Venylene-Diflourid \\
\hline RNA & Ribonukleinsäure \\
\hline $\mathrm{rpm}$ & Umdrehungen pro Minute \\
\hline $\mathrm{RT}$ & Raumtemperatur \\
\hline SDS & Natriumdodecylsulfat \\
\hline
\end{tabular}


sec

TAE

TBE

TBST

TE

TEMED

Tris

U

UV

Vol.

$\mathrm{Wt}$
Sekunde(n)

Tris-Acetat-EDTA-Puffer

Tris-Borat-EDTA-Puffer

Tris bufferd saline + Tween ${ }^{\circledR} 20$

Tris-EDTA-Puffer

N,N,N',N'-Tetramethyl-ethylendiamin

a,a,a,-Tris-(hydroxymethyl)-methylamin

Unit, Einheit

Ultraviolett

Volumen

Wildtyp

Die chemischen Elemente wurden mit den üblichen Symbolen abgekürzt. Verwendete Vorsilben für Potenzen der Zahl 10: $\mathrm{p}=$ Pico $\left(1 \times 10^{-12}\right), \mathrm{n}=$ Nano $\left(1 \times 10^{-9}\right), \mu=$ Mikro $\left(1 \times 10^{-6}\right), \mathrm{m}=$ Milli $\left(1 \times 10^{-3}\right), \mathrm{k}=$ Kilo $\left(1 \times 10^{3}\right), \mathrm{M}=$ Mega $\left(1 \times 10^{6}\right)$. Zeitbegriffe: $\mathrm{d}=$ Tag, $\min =$ Minute, $\sec =$ Sekunde. 


\section{Danksagung}

Herrn Dr. O. G. Opitz möchte ich für die Anregung und Überlassung des Themas und die hervorragende Betreuung meiner Dissertation sowie für die exzellente wissenschaftliche Anleitung und Lehre, die ausgezeichneten Arbeitsbedingungen und die Möglichkeit zum Besuch von Kongressen ganz besonders herzlich danken.

Ein herzlicher Dank geht an Prof. Dr. Drs. h. c. H. E. Blum für die großzügige Betreuung und die Korrektur meiner Dissertation.

Gitta Gössel gilt ein besonderer Dank für die bereitwillige und kompetente methodische Anleitung, konstruktive Kritik, die hervorragende Unterstützung bei der täglichen Arbeit im Labor und die Korrektur dieser Arbeit.

Christine Fulda möchte ich für die Unterstützung bei zahlreichen Experimenten, ständige Hilfsbereitschaft und kollegiale Zusammenarbeit danken.

Alexander von Werder gilt nicht nur ein besonderer Dank für Hilfe, Kritik, Diskussion und Unterstützung im Labor, sondern auch für die abwechslungsreiche Zeit neben und nach der Labortätigkeit.

Dr. H. Usadel, Dr. Ch. Arnold und Dr. M. Follow möchte ich für konstruktive Diskussionen und die bereitwillige Anleitung in einzelnen molekularbiologischen Methoden danken.

Allen Mitarbeitern der B-Labore danke ich für die freundliche und harmonische Arbeitsatmosphäre, großzügige Hilfe und konstruktive Kritik, die das tägliche Laborleben immer begleitet haben.

Mein besonderer Dank geht an Anne, die mich während der ganzen Zeit unterstützt und davon überzeugt hat, eine molekularbiologische Dissertation zu beginnen.

Ganz besonders danke ich auch meinen Eltern für die großzügige finanzielle und persönliche Unterstützung und interessierte Fragen. 


\section{Veröffentlichungen}

\section{ORIGINALARBEITEN}

Quante M, Heeg S, von Werder A, Goessel G, Fulda C, Doebele M, Nakagawa H, Beijersbergen R, Blum HE, Opitz OG; Differential transcriptional regulation of human telomerase in a cellular model representing important alterations in esophageal squamous carcinogenesis

Carcinogenesis. 2005 Nov;26(11):1879-1889

Gitta Goessel, Michael Quante, William C. Hahn, Hideki Harada, Steffen Heeg, Yasir Suliman, Alexander von Werder, Christine Fulda, Hiroshi Nakagawa, Anil K. Rustgi, Hubert E. Blum and Oliver G. Opitz; Creating oral squamous cancer cells a cellular model of oral-esophageal carcinogenesis

Proc Natl Acad Sci US A. 2005 Oct 20;

Opitz OG, Quante M, von Werder A, Heeg S, Blum HE; A mouse model of oralesophageal carcinogenesis

Onkologie. 2005 Jan;28(1):44-8.

\section{ABSTRACTA}

M Quante, G Gössel, B Jacobmeier, H Harada, H Nakagawa, Y Suliman, HE Blum, AK Rustgi, OG Opitz; Immortalization and transformation of primary human oral keratinocytes recapitulating human oral and esophageal squamous carcinogenesis

$A A C R$, Special conference- the role of telomere and telomerase, 2002, San Francisco, CA, USA

M Quante, A v Werder, G Gössel, H Harada, H Nakagawa, Y Suliman, HE Blum, AK Rustgi, OG Opitz; Malignant transformation of primary human oral squamous epithelial cells without ectopic activation of telomerase

9. Winterkurs der AGO, 2003, Ludwigshafen

M Quante, H Harada, Y Suliman, R Beijersbergen, AK Rustgi, HE Blum, OG Opitz; Differential transcriptional regulation of human telomerase in a cellular modell of esophageal squamous carcinogenesis.

DDW, 2003, Orlando, FL, USA

M Quante, H Harada, Y Suliman, R Beijersbergen, AK Rustgi, HE Blum, OG Opitz; Differenzielle transkriptionelle Regulation der humanen Telomerase in einem 
zellulären Karzinogenese-Modell am Beispiel des Plattenepithelkarzinoms des Ösophagus

DGVS 2003, Nürnberg

M Quante, A v Werder, G Goessel, C Fulda, H Nakagawa, Y Suliman, R Beijersbergen, AK Rustgi, HE Blum, OG Opitz; The hTERT-Promotor is regulated by different transcriptional mechanisms during malignant transformation of esophageal squamous epithelial cells

DDW, 2004, New Orleans, LO, USA

M Quante, C Fulda, A v Werder, G Goessel, S Heeg, A Walch, H Nakagawa, Y Suliman, HE Blum, OG Opitz; Expression profiling in a genetically defined mouse model of oral-esophageal dysplasia and cancer

DDW, 2005, Chicago, Il, USA; DGVS 2005, Köln 


\section{Lebenslauf}

\section{Persönliche Daten:}

Name: $\quad$ Michael Quante

Geburtsdatum: $\quad 02.02 .1978$

Geburtsort: $\quad$ Münster

Staatsangehörigkeit: deutsch

Familienstand: $\quad$ verheiratet mit Dr. med. Anne Siobhain Quante, geb. Jürgens

Adresse: $\quad$ Christophstrasse 21; 40225 Düsseldorf

\section{Ausbildung}

1984-1988 Grundschule, Münster

1988-1997 Gymnasium Paulinum, Münster

1997

Abitur: 14.06.1997

1997-1998 Wehrdienst: Gebirgsjägerbatallion 232, Berchtesgaden

1998-1999 MTA-Schule, Münster

1999-2001 Studium der Humanmedizin an der Westfälischen Wilhelms Universität, Münster

$2001 \quad$ Physikum: 19.03.2001

Seit 2001 Studium der Humanmedizin an der Albert-Ludwigs-Universität, Freiburg

2002

1. Staatsexamen: 21.03.2002

Seit 2002 Dissertation in der Abteilung Gastroenterologie, Hepatologie,

Endokrinologie und Infektiologie der Medizinischen Universitätsklinik Freiburg

2003 Erster Abschnitt des US-Amerikanischen Medizinischen Staatsexamens

2004 2. Staatsexamen: 02.09.2004

2004-2005 Praktisches Jahr an der Heinrich Heine Universität Düsseldorf Wahlfach: Pädiatrie

2005: $\quad 3$. Staatexamen: 24.11.2005

ab 01.01.2006 Assitenzarzt an der Klinik für Allgemeine Innere Medizin mit den Schwerpunkten Gastroenterologie-Hepatologie, Hämatologie-Onkologie und Nephrologie des Universitätsklinikum Bonn

\section{Sonstige Tätigkeiten}

Medizinisches Pflegepraktikum, Royal Victoria Hospital, Newcastle, England (1997) Aushilfe im Pflegedienst im Clemenshospital Münster (1999-2001) 
Wissenschaftliche Hilfskraft, Anatomischen Institut der Universität Münster (2001)

Famulatur der Inneren Medizin; Allgemeines Krankenhaus Wien, Österreich (2001)

Lehrtätigkeit an der Schwesternschule Waldkirch (2001/02)

POL-Tutor an der Medizinischen Universitätsklinik Freiburg (2001-2004)

Wissenschaftliche Hilfskraft im medizinischen Dekanat Freiburg (2002-2004)

Famulatur der Notfallmedizin; St. Vincent Hospital, Indianapolis, IN, USA (2002)

Famulatur der Pädiatrie; Universitätsklinikum Münster, Deutschland (2003)

Ultraschall-Grundkurs der DEGUM (2004)

Famulatur der Anästhesie; St. Joseph Klinikum Freiburg, Deutschland (2004)

\section{Preise und Stipendien}

Ludwig-Heilmeyer-Preis 2005 der Albert-Ludwigs-Universität Freiburg für eine hervorragende experimentelle Dissertation

Reisestipendium der GlaxoSmithKline Stiftung für eine Kongressreise zur Digestive Disease Week 2004, New Orleans, USA

Posterpreis Grundlagenforschung beim 9. Winterkurs der Arbeitsgemeinschaft Gastroenterologische Onkologie 2003 in Ludwigshafen

Präsidentenposter auf der Jahrestagung der Deutsche Gesellschaft für Verdauungsund Stoffwechselkrankheiten 2003 in Nürnberg 
